\title{
Utilização da Transformada Karhunen-Loève em Síntese de Tons Musicais
}

\author{
João Fernando Marar
}

Orientador:

Prof. Dr. Edson dos Santos Moreira

Dissertação apresentada ao Instituto de Ciências Matemáticas de São Carlos - USP, como parte dos requisitos para a abtenção do Título de Mestre em Ciências - ánea : "Ciências de Computação e Matemática Computacional".

USP - São Carlos

1992 
$A$ meus Pais

Issa Marar (em memória) e Najla Marar 
Aos meus amores

Lais e

Nandinho 


\section{Agradecimentos}

Ao Prof. Edson dos Santos Moreira, pela amizade, pelo estímulo, pelo apoio, pela humildade, pela disposição e confiança creditada em mim durante todas as horas agradáveis e difíceis enfrentadas neste trabalho.

À Minha esposa Lais e a meu filho Fernandinho, por tanto carinho dedicado e compreensão à minha ausência constante.

A meu irmão, Prof. Washington Luiz Marar, pelo carinho, companheirismo e estímulo dedicado desde o início de minha graduação.

A meu irmão, Dr. Antonio Carlos Marar, por manter suas portas abertas no início de minha carreira e que ainda hoje continuam.

A meu irmão, Charles Marar, por ter comprado a placa Sound Blaster, a qual será muito útil para a demostração dos resultados deste trabalho e ao Charlinho por trazê-la.

Aos meus outros irmãos, porém, não menos importantes Marly, Sonia, Walter, Norma e Ricardinho e a todos os agregados, por todo o carinho e confiança dedicados a mim.

Ao Gutinho, pelas figuras e a revisão do texto nas horas de insônia que passamos juntos trabalhando.

Ao Sr. Laerte, Dona Odila e Dona Malvina por aturarem as travessuras do Fernandinho, enquanto eu estudava.

Ao amigo Prof. José Remo, pela amizade, pelas sugestões e pelas inúmeras ajudas não triviais a mim dedicadas.

Ao Prof. Arnaldo Mandel, pelo grande apoio e compreensão durante os meus estudos realizados no IME-USP.

Ao Prof. Oziride Manzoli, pela orientação em iniciação científica e a leitura desta dissertação.

Ao Prof. Carlos Biasi, pelo apoio e divulgação deste trabalho.

Aos amigos Prof. Sementile, Prof. Valdeni e Prof. Renato Táboas pelo carinho, amizade demonstradas nos momentos difíceis.

As quintas-feiras felizes vividas em São Carlos com os amigos Alka-seltser, Edson, Muna, Akemi, Totó, Onofre, Poti, Wagner, Graça, Neide, Stein, Lígia, Rui, Josué, Luciano, Elien, Carmem, Lene, Cibele, Renatas, Ana, Roberta, Robertinho, Roseli, Bob, Carioca, Martin, Sergião, Gracinha, Karen, Pastel, Raimundo, Véio.

Este trabalho contou com o apoio financeiro parcial da CAPES- PICD. 


\title{
Resumo
}

Sinais podem ser amostrados, armazenados e reproduzidos por computadores digitais. Adicionalmente, sinais podem ser analisados de modo que formas comportadas de sua representação possam ser extraídas, economizando o espaço de memória necessário para o armazenamento. A transformada de Fourier tem sido tradicionalmente utilizada para este fim. Este trabalho trata da utilização da transformada Karhunen-Loève como método alternativo de representação de tons musicais, possibilitando grande economia de recursos computacionais comparada com a transformada de Fourier.

\begin{abstract}
Signals can be sampled, stored and played back by digital computers. Furthermore, signals can be analized in such a way that compressed forms of their representation can be extracted, reducing the amount of memory needed to store them. The Fourier transform have been traditionally used in this way. This dissertation deals with the use of the Karhunen-Loève transform as an alternative method of representing a particular and dynamic signal, the musical tones, allowing bigger savings of computing resources, as compared to the Fourier transform.
\end{abstract}




\section{Conteúdo}

1 Introdução 1

1.1 Tons Musicais por Computador ................... 3

1.2 Porque é Interessante Utilizar o Computador para a Síntese . . . . . . . 5

1.3 A Problemática da Síntese de Tons Musicais por Computador . . . . . . 6

2 Processamento de Sinais $\quad 8$

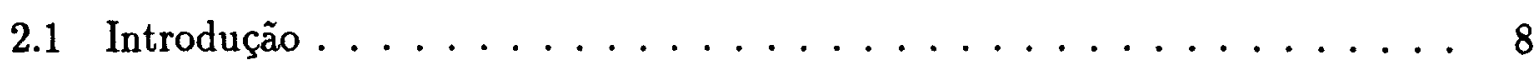

2.1.1 Processamento Analógico ...................... 9

2.1 .2 Processamento Digital . . . . . . . . . . . . 9

2.2 Conversão do Sinal . . . . . . . . . . . . . . . . . 10

2.3 O Teorema de Nyquist . . . . . . . . . . . . . . . . 12

2.4 Aplicações de Processamento Digital de Sinais . . . . . . . . . . . . 13

3 Características Físicas do Som 14

3.1 Introdução . . . . . . . . . . . . . . . . . . 14

3.2 Características de Tons Musicais . . . . . . . . . . . . . . . 15

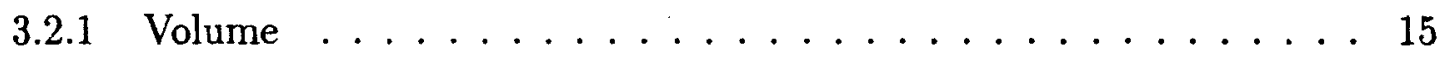

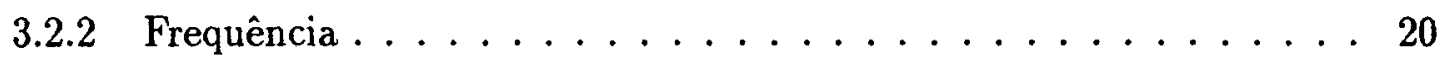

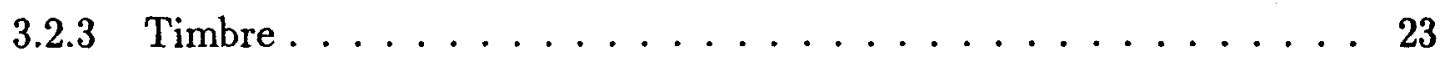

3.3 Características de Instrumentos Musicais . . . . . . . . . . . 23

3.3.1 Instrumentos de cordas . . . . . . . . . . . . 23 
3.3.2 Instrumentos de sopro $\ldots \ldots \ldots \ldots \ldots \ldots \ldots \ldots$

3.3.3 Instrumentos de percussão $\ldots \ldots \ldots \ldots \ldots \ldots \ldots \ldots$

3.4 Efeitos Impostos Sobre o Som Durante a Execução em Instrumentos Musicais 26

3.5 Análise Espectral de Tons Musicais . . . . . . . . . . . . 27

3.5.1 Representação de Sinais utilizando Transformadas Ortogonais . . 27

3.5.2 Representação de Sinais utilizando Série de Fourier . . . . . . 29

3.5.3 Método de Extração Harmônica, baseada em Filtragens Heteródinas 32

3.5.4 A Transformada de Fourier . . . . . . . . . . . . 34

3.5.5 Transformada de Fourier de Curta Duração (STFT) . . . . . . 36

4 Métodos Tradicionais de Síntese $\quad 39$

4.1 Introdução . . . . . . . . . . . . . . . . 39

4.1 .1 Osciladores $\ldots \ldots \ldots \ldots \ldots \ldots \ldots \ldots \ldots$

4.1 .2 Filtros $\ldots \ldots \ldots \ldots \ldots \ldots \ldots \ldots \ldots \ldots$

4.1 .3 Amplificadores $\ldots \ldots \ldots \ldots \ldots \ldots \ldots \ldots$

4.1.4 Geradores de Envelopes . . . . . . . . . . . . . 46

4.2 Classes de Sintese $\ldots \ldots \ldots \ldots \ldots \ldots \ldots \ldots \ldots \ldots$

4.3 Visão Geral sobre Síntese de Tons Musicais $\ldots \ldots \ldots \ldots$. . . . 48

4.4 Métodos de Síntese $\ldots \ldots \ldots \ldots \ldots \ldots \ldots \ldots \ldots$

4.4 .1 Síntese Aditiva $\ldots \ldots \ldots \ldots \ldots \ldots \ldots \ldots \ldots$

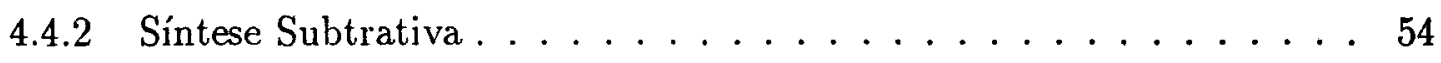

4.4 .3 Síntese por Frequência Modulada $\ldots \ldots \ldots \ldots \ldots$

4.4.4 Síntese por Distorção de Fase . . . . . . . . . . . 60

4.4.5 Síntese Digital por Amostragem (Sampling) $\ldots \ldots \ldots \ldots$

5 A Transformada Karhunen-Loève $\quad 69$

5.1 Introdução . . . . . . . . . . . . . . . 69

5.2 Representação de Sinais Utilizando Transformadas Karhunen-Loève . . . 70 
5.3 Aplicação de Transformada Karhunen-Loève em Tons Musicais . . . . . . . 73

6 Algoritmos para Utilização da Transformada K-L em Síntese Aditiva 76

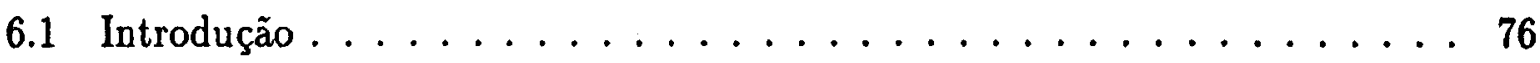

6.2 Normalização e Filtragem das Funções-arnostras . . . . . . . . . . . . . 77

6.3 Alinhamento de Fase ..................... . 80

6.4 Classificação das Funções-amostras . . . . . . . . . . . . . 82

6.5 Determinação das Funções Básicas Karhunen-Loève . . . . . . . . . . 83

6.6 Determinação das funções Amplitude e Frequência . . . . . . . . . . 84

7 Conclusões e Trabalhos Futuros $\quad 90$

$\begin{array}{lc}\text { Bibliografia } & 93\end{array}$ 


\section{Capítulo 1}

\section{Introdução}

Os matemáticos do século XIX, herdaram de seus colegas do século anterior, problemas difíceis associados a fenômenos físicos, para os quais tiveram que desenvolver muitas ferramentas matemáticas hoje existentes. Destacamos aqui, o problema de vibração de cordas [BOA 66].

O matemático e físico francês Jean Baptiste Fourier, baseado nas pesquisas realizadas por Taylor [KRE 69], Bernoulli [FIG 87] e Laplace [BOY 79], acreditava que a solução do problema de vibração de cordas poderia ser colocada na forma de séries trigonométricas. Em 1822, Fourier publicou um trabalho intitulado de Thèorie mathématique de la chaleur [FIG 87], onde expressou formalmente os coeficientes e escreveu as séries de senos e cossenos de várias funções. $\mathrm{O}$ autor afirmava que qualquer função podia ser representada pela referida série, que hoje leva seu nome. No entanto, tal afirmação não é verdadeira, pois é necessário que a função satisfaça algumas condições (discutidas no capítulo 3, seção 3.6). Porém, deve-se a Fourier o mérito por ter explicitado claramente a forma da série.

Em 1.863, o médico e físico H.L.F. Helmholtz [KOE 65] tornou-se o primeiro cientista a aplicar a teoria proposta por Fourier em síntese de tons musicais. Helmholtz realizou vários experimentos com uma série de diapasões comandados eletricamente, sendo que para cada diapasão existia acoplado um cilindro ressonador para uma determinada frequência. Desta maneira, ele conseguiu analisar e reproduzir tons musicais. Os ressonadores utilizados por Helmholtz, eram equipamentos extremamente rudimentares, os quais identificavam apenas um estado transiente do tom musical, a sustentação, de maneira que, ao sintetizar as informações obtidas pela análise, Helmholtz percebia grandes diferenças entre o tom original e seu sintético.

Desde então, várias pesquisas foram realizadas com a intenção de compreender e modelar os fenônenos físicos que ocorrem com os sinais sonoros musicais. Com o advento dos computadores eletrônicos, os cientistas passaram a buscar nestes equipamentos meios de geração de sinais musicais. 
Em 1969, Max Mathews, publicou o livro intitulado The Technology of computer music [MAT 69], considerado a primeira obra de aplicação computacional em música, onde descreveu os princípios fundamentais desta nova área de pesquisa e ainda apresentou um sistema computacional, o MUSIC V, que possibilitou a geração de tons musicais. A repercusão da obra foi imediata, chamando a atenção de muitos pesquisadores de música para esta recente conquista. Tal foi o caso de Vercoe, Risset, Chowning, Moore, entre outros. Vercoe, baseado no sistema Music V, construiu outros sistemas, o Music 11 e o Music 360. Tais sistemas possibilitavam ao compositor escrever um programa para a geração de tons musicais.

Em busca de novos recursos para o compositor e uma melhor qualidade na geração dos sinais, Mathews e Risset, iniciaram pesquisas em síntese de tons, baseados em uma análise matemática prévia do sinal proveniente de instrumentos musicais. Neste segmento de pesquisa, muitos cientistas passaram a desenvolver algoritmos para a síntese baseada em análise. Desde então, muitas técnicas surgiram, das quais a mais popular é a síntese aditiva baseada na análise, devido à alta fidelidade dos tons gerados, principalmente quando este é gerado por um conjunto de funções básicas de Fourier (senóides). A figura 1.1 ilustra um exemplo deste procedimento.

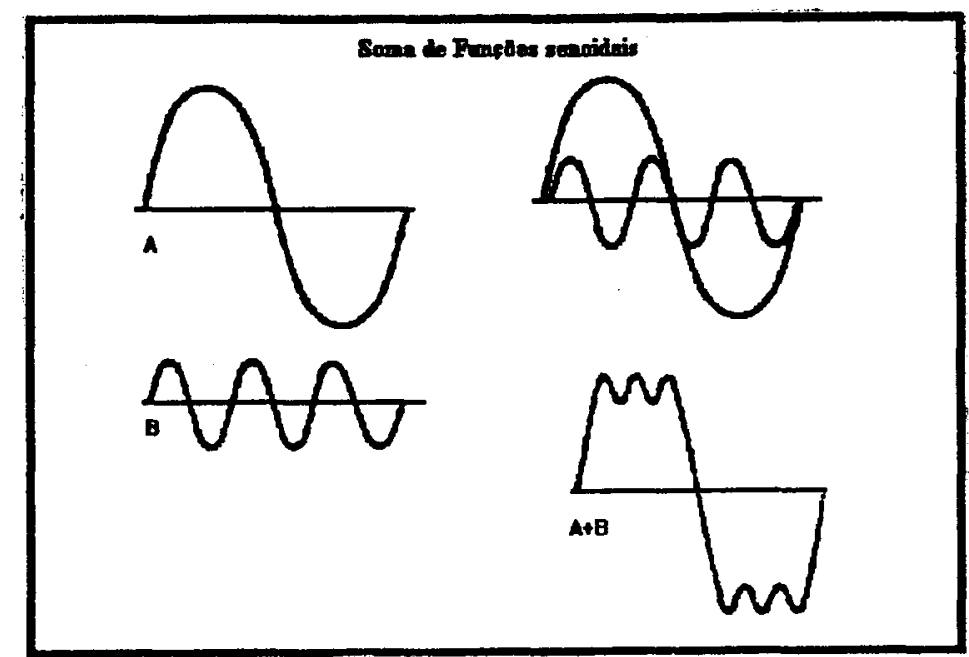

Figura 1.1: Representa a construção de um sinal baseado em somas de senóides

Este trabalho aborda algumas técnicas, bem como salientar alguns conceitos básicos, fundamentais para a aplicação de computadores em síntese de tons musicais e, finalmente, descrever um método de síntese aditiva baseada em análise, utilizando um conjunto de funções básicas não senoidais [STA 88]. Vários métodos existem : funções Rademacher [PAL 32], funções Haar [NAG 65] e Walsh [WAL 23], nestes casos, o conjunto de funções básicas são ondas quadradas ou pulsos. Mostraremos neste trabalho a transformada Karhunen-Loève (K-L).

$\mathrm{O}$ método K-L, também conhecido por análise das principais componentes do sinal [CHE 91] é baseado na criação da matriz de covariância dos dados de entrada (sinais). Os auto-vetores, principais componentes, são extraídos desta matriz, e ordenados de acordo com a magnitude dos auto-valores. O primeiro auto-vetor está associado com o maior 
auto-valor, e assim sucessivamente. Resultados práticos demonstram os ganhos computacionais através de comparação com outros métodos [CAM 71],[STA 88], [CHE 91], possibilitando sua aplicação em tempo real.

\subsection{Tons Musicais por Computador}

Um instrumento musical nada mais é que uma fonte geradora de estímulos sonoros, agindo dentro de uma faixa bem determinada de frequências. Para cada instrumento existe um limitante inferior, o qual depende da sua construção [JOS 69], sua forma geométrica, seu material, seu comprimento, entre outros e um limitante superior que dependerá tanto da virtuosidade do instrumentista como também dos outros itens citados acima. A figura 1.2 ilustra alguns instrumentos de orquestra e suas respectivas faixas de frequências.

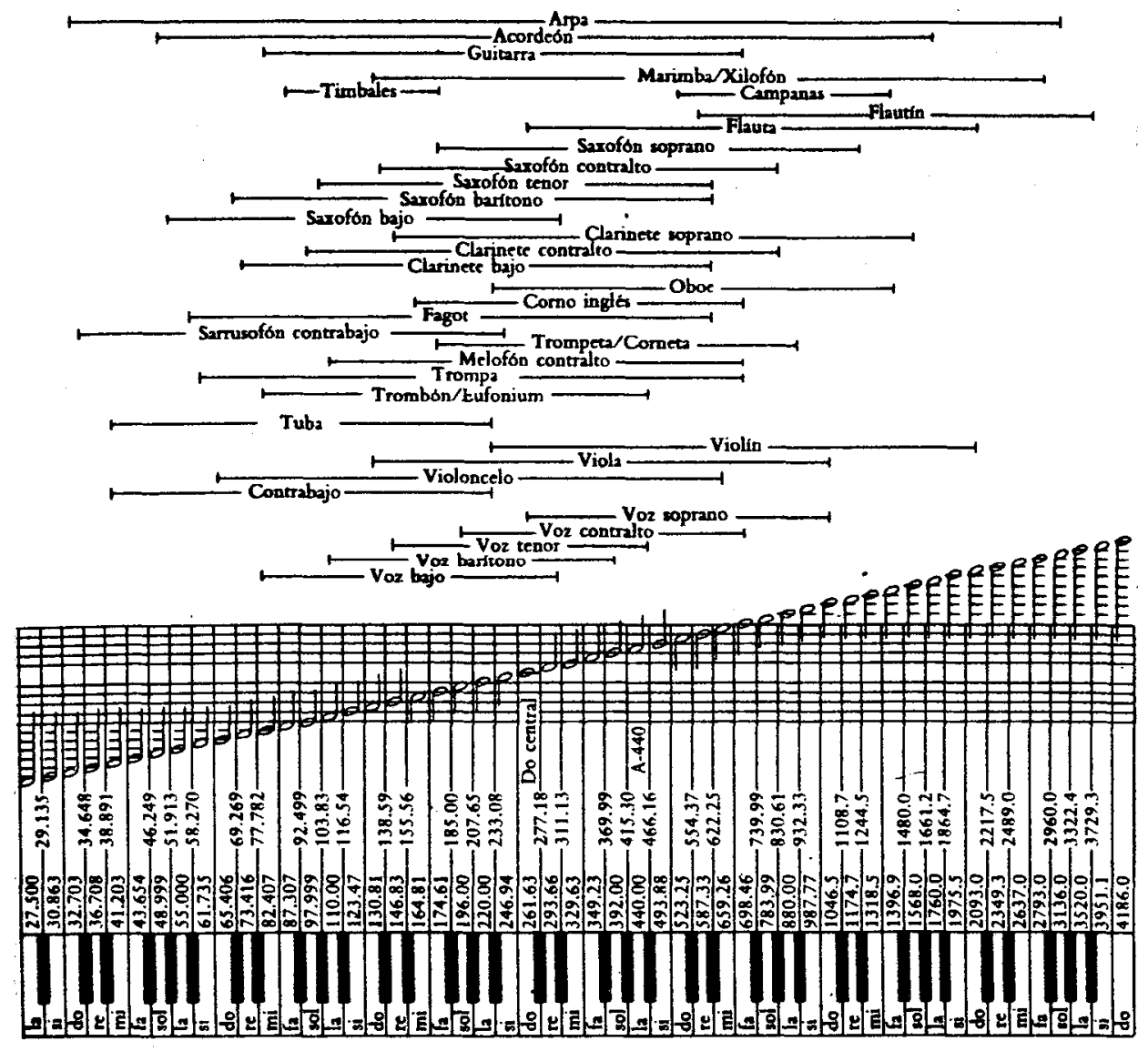

Figura 1.2 : Representa o teclado de um piano e o alcance de alguns instrumentos 
De maneira geral, instrumentos musicais geram sinais complexos, analógicos e contínuos no tempo. Por sua vez, os computadores digitais somente estão preparados a processar informações discretas e digitais. A figura 1.3 ilustra a conversão de um sinal contínuo para sua representação discreta.
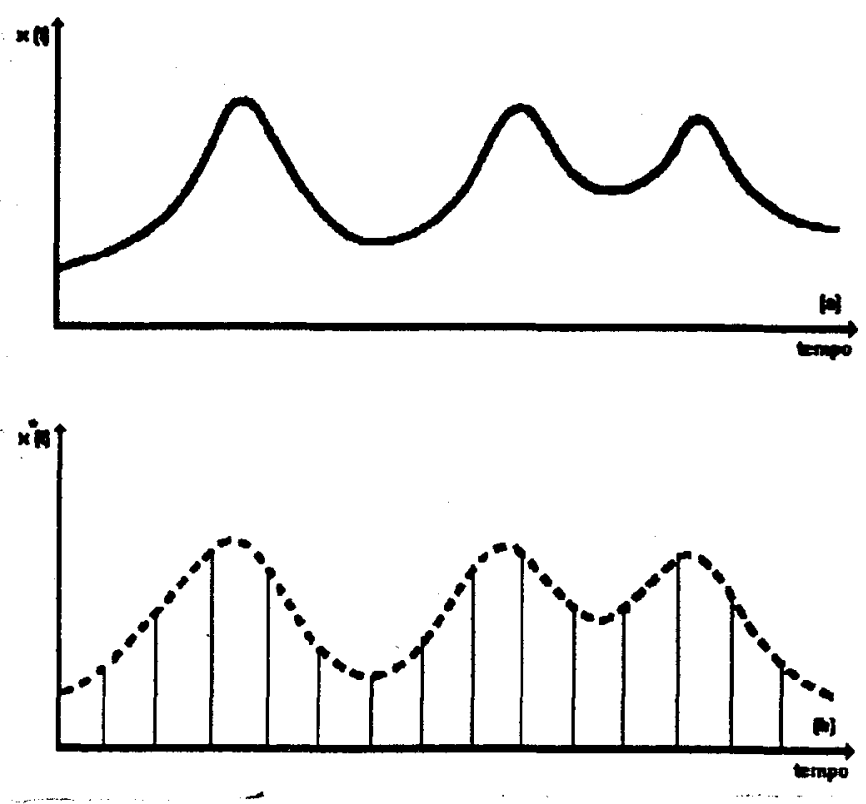

Figura 1.3: Representa a conversão de um sinal contínuo (a) e sua representação discreta (b)

Seja $x(t)$ um sinal analógico, que é uma função contínua no tempo, transportando uma certa informação, podendo ser um tom musical. Se $x(t)$ for submetido a uma amostragem ideal [OTN 72], isto é, de $x(t)$ será obtido um conjunto de valores discretos, os quais possibilitam a reconstrução fiel do sinal original, a uma taxa específica de $N$ amostras por segundo, descrita por :

$$
x^{*}(t) \cong \Delta t \sum_{m=0}^{N-1} x(m \Delta t) \delta(t-m \Delta t)
$$

onde $\Delta t$ é o intervalo entre duas amostras consecutivas e $\delta(\bullet)$ corresponde à função impulso, conhecida por função delta de Dirac [OPP 75]. O resultado desta amostragem é uma sequência de dados $\{X(m)\}, m=0,1, \ldots, N-1$, onde $X(m)=x(m \delta t)$. O termo sequência digital implica que cada elemento de $\{X(m)\}$, foi quantificado e codificado na forma digital. Por consequência direta, o termo sinal digital $x^{*}(t)$ implica que cada valor amostrado $x(m \Delta t)$, na equação 1.1 , tenha sido quantizado e codificado na forma digital [HEL 73]. No capítulo 2 discutiremos melhor esta conversão, tecnicamente denominada por A/D (analógico-digital).

Consequentemente, todos os sinais contínuos podem ser representados por meio de uma sequência de valores discretos. Desta forma, o computador pode processar,calcular e gerar 
uma sequência de valores numéricos e enviá-la a um conversor D/A (digital-analógico), o qual converterá esta sequência em pulsos de tensão, ou corrente com amplitudes, proporcionais às magnitudes destes valores numéricos enviados pelo computador.

\subsection{Porque é Interessante Utilizar o Computador para a Síntese}

Em [TOF 80], Toffler descreve a progressão da sociedade em três ondas. A primeira onda representa o período agrícola, em que as pessoas estavam presas à terra e tinham familias maiores para prover o trabalho necessário. A segunda onda é representada pela revolução industrial, a qual exigiu que as pessoas deixassem suas casas para trabalhar, sendo encorajada a uniformização de maneira consistente, tanto na escola como no trabalho, para fins de produção em massa.

Toffler acredita que a sociedade encontra-se no limiar da terceira onda, onde se espera uma grande mudança na produção industrial de massa, caracterizada pelas indústrias pesadas e grandes fábricas. Nesta nova sociedade haverá maior ênfase no indivíduo e em pequenos grupos.

O computador na sociedade da segunda onda é usado para fins de controle, isto é, as pessoas são vistas como números num computador, o qual controla as ações, podendo privar os individuos de sua liberdade e privacidade. Já, na terceira onda, o computador é usado para moldar o meio conforme as necessidades das pessoas. Toffler vê na versatilidade do computador um meio de se libertar dos controles e da rigidez da produção em massa. Numa fábrica de roupas operada por computador, todas as medidas necessárias do cliente são armazenadas em memórias, bem como o modelo da roupa, o tecido e a cor da peça. O computador dirige a seleção dos materiais assim como o corte e a costura para produzir uma única peça para o indivíduo. Muitas projeções de Toffler já chegaram a acontecer. Parece provável que a sociedade tenha entrado em sua terceira onda.

Nos últimos anos temos acompanhado uma rápida evolução na tecnologia de construção de computadores. Como consequência, deste desenvolvimento tecnológico, associado à competitividade, o custo de produção e comercialização dos equipamentos vem barateando dia após dia (característica da segunda onda), forçando a indústria, periódicamente, a substituir seus equipamentos disponiveis no mercado, anexando melhorias ou simplesmente desenvolvendo novos projetos (característica da terceira onda), que atraiam usuários (consumidores). Neste contexto inserem-se os sintetizadores, os quais aparecem como parte da evolução do movimento musical, que passa a buscar novos recursos, para produzir formas diferentes de sons, das que já são geradas pelos instrumentos musicais tradicionais.

No entanto, alguns problemas são encontrados em síntese de tons musicais. Estes resi- 
dem principalmente, na quantidade absurda de processamento aritmético exigido pelos algoritmos mais simples existentes. Em música, como em muitas outras áreas, reconhece-se que o computador tem muito para oferecer como mecanismo destinado a poupar trabalho.

A utilização de técnicas de sintese digital e o total controle dos parâmetros para geração de sons, fazem com que apareçam hoje em nosso meio os compositores que criam sons abstratos, através de 'enxertos' sonoros, conseguindo os resultados mais variados, tais como o de um piano com som de guitarra.

Desta maneira, acreditamos que a evolução da área de processamento de sinais digitais e, especificamente, da parte que tange à síntese de tons musicais possa ser extremamente aceleradas, através do desenvolvimento de algoritmos e do projeto de máquinas dedicadas para este fim. Isto possibilitará que uma grande quantidade de indivíduos possuam equipamentos eletrônicos, que produzam sons de mesma qualidade dos encontradas em instrumentos musicais.

\subsection{A Problemática da Síntese de Tons Musicais por Computador}

Através da amostragem de um sinal sonoro, obtém-se sua representação discreta no domínio do tempo. A análise destes sinais discretos, tem por objetivo extrair características para posterior reprodução. Uma transformação para o domínio da frequência, auxilia a análise do sinal.

A transformação de sinais entre os domínios do tempo e frequência, geralmente, não se configura como um problema de grandes proporções e várias ferramentas estão disponíveis. Para isto utilizamos a Transformada de Fourier, Transformada de Laplace, Transformada Z, entre outras [DeF 88],[PRO 88], [WIN 78]. Entretanto, para uma determinada classe de sinais, algumas particularidades existem, o que dificulta a reconstrução precisa do sinal através das informações espectrais. Tal é o caso de sinais que apresentam um quadro de componentes, que varia com o tempo de duração do sinal. Estas variações podem envolver as componentes de frequência, suas amplitudes e fases. A reconstrução do sinal a partir das suas características espectrais exige o emprego de um tratamento dinâmico, resultando em grande demanda de potência aritmética do processador e/ou na quantidade de memória requerida [MOO 77]. É o que se verifica na síntese de tons musicais.

A reprodução fiel de um instrumento musical implica em se levar em consideração todas as variações em amplitude, quantidade e fase dos harmônicos que ocorrem durante o tempo de duração de um tom. Para isso várias técnicas existem e hoje são utilizadas, dentre as quais, destacam-se a Distorção de Fase - utilizada nos equipamentos Casio, Frequência Modulada - utilizada nos equipamentos Yamaha, Métodos Subtrativos, Aditivos , Métodos de Amostragem, etc [MAS 87]. 
O esforço computacional exigido por métodos de síntese de tons musicais, podem tornálos proibitivos para execução em tempo real, utilizando-se computadores convencionais. Por exemplo em [DOL 89], verifica-se que 1 segundo de síntese de som, requereu cerca de 2 minutos da CPU de um computador VAX 11/780. Trabalhos têm sido desenvolvidos na tentativa de simplificar a geração de tons musicajs, através da utilização de funções não senoidais [STA 88],[HUT 75]. Estes métodos exigem uma cuidadosa análise, para que se evite a degradação na qualidade do som produzido, bem como para manter a simplicidade para o controle das funções parâmetros, amplitude e frequência, para construção de novos tons [MOO 77].

O presente trabalho se enquadra neste contexto. 


\section{Capítulo 2}

\section{Processamento de Sinais}

\subsection{Introdução}

Sinais representam as variações do comportamento ou da natureza física de um fenômeno. Estas variações podem ocorrer em função do tempo, espaço ou a partir de outras variáveis independentes. A tensão e corrente variando com o tempo, em um circuito eletrônico, são típicos exemplos de sinal.

Chamamos de transdutores aos sistemas capazes de transformar um tipo de sinal em outro. Este é o caso de um microfone que, através de pressão proveniente das ondas sonoras da fala ou de outras fontes sonoras, faz com que este sistema apresente em sua saída um sinal elétrico. Seu oposto seria um alto-falante que, através de um sinal elétrico, gera ondas sonoras.

Processamento de sinais é um conjunto de operações (algoritmos) que, aplicado a um sinal o modifica, produzindo uma modificação deste na saída do sistema.

Muito antes de se ter esgotado as melhorias a nível de integração de componentes eletrônicos e uma maior velocidade nos dispositivos de hardware, pesquisas em computação já buscavam alternativas para um melhoramento na performance dos equipamentos existentes. $\mathrm{O}$ desenvolvimento de poderosos algoritmos impulsionou a ciência de computação muitos anos à frente do hardware existente.

A alocação de uma quantidade de processadores trabalhando em paralelo em diferentes partes de um mesmo problema, poderia, aparentemente garantir melhorias na performance. Muitos estudos foram e vem sendo realizados para máquinas paralelas, mas pouco sucesso foi obtido pois os desafios de se gerenciar (e bem) dados, processadores e processos de maneira a viabilizar estas construções, ainda permanecem em estudo. Quando se trata de aplicações de propósitos gerais, a complexidade destes sistemas se torna extremamente 
grande, no que diz respeito à alocação de processadores e a organização da memória [MOR 89].

Entretanto, se impusermos certas restrições sobre o tipo de processamento que o sistema irá realizar, o projeto de uma arquitetura específica, paralela, poderá ser grandemente simplificado. É o caso de problemas associados a processamento de sinais digitais (DSP Digital Signal Processing), onde a maioria dos algoritmos são altamente estruturados, tornando-os seletos candidatos a serem executados em computadores especialmente projetados para esta finalidade. Os algoritmos existentes para o cálculo de transformadas rápidas de Fourier (FFT) [COO 65], [THE 69], [KAH 70], [BLA 87], se enquadram nesta categoria.

Os sistemas para processamento de sinal se dividem em duas classes : processamento analógico e processamento digital

\subsubsection{Processamento Analógico}

Um sinal analógico varia de maneira contínua no tempo. Tais sinais são definidos para todos os valores das variáveis independentes e assumem valores em um intervalo contínuo.

Antes do advento dos computadores, o processamento de sinais era feito exclusivamente de forma analógica, isto é, atuando sobre o sinal diretamente. Até próximo dos anos 60 , os sistemas analógicos eram somente processados em tempo real. Não existiam meios de se armazenar os sinais.

Atualmente, técnicas digitais tem substituido as analógicas. Existem ainda algumas aplicações onde complexos circuitos analógicos são utilizados para atender com velocidade as respostas requeridas do sistema. Para estes casos, sistemas com respostas muito rápidas são utilizados para processar o sinal. Este é o típico caso de certas aplicações onde o processamento da luz é envolvido e existe a restrição do tempo de resposta.

\subsubsection{Processamento Digital}

Todo sinal digital pode ser entendido como a representação de um sinal analógico discretizado no tempo, tornando-o uma sequência de valores numéricos discretos. Normalmente esta sequência é obtida por meio de amostragem de um sinal analógico, em uma taxa específica.

Os sistemas digitais possuem inúmeras vantagens em relação aos sistemas analógicos. Uma delas é sua versatilidade, pois se considerarmos o controle e a precisão sobre o sinal 
que as técnicas digitais possibilitam,veremos que com o auxílio do computador poderemos realizar "micro-cirurgias" nas formas de onda, com o custo reduzido em relação ao sistema analógico. Este é um fator bastante atraente quando se trata de optar por um dos dois métodos.

Um fato bastante interessante, uma vez o sinal tenha sido convertido para a forma digital, este pode ser armazenado e utilizado mais tarde, possibilitando implementaçóes de algoritmos complexos em computadores digitais.

\subsection{Conversão do Sinal}

No mundo real, todos os sinais aparecem naturalmente de maneira analógica. Para adequarmos estes sinais, a fim de que sejam processados digitalmente, é necessário primeiramente convertê-los em uma forma digital. Esta transformação é obtida por meio de um conversor analógico-digital (A/D). A figura 2.1 ilustra este processo.

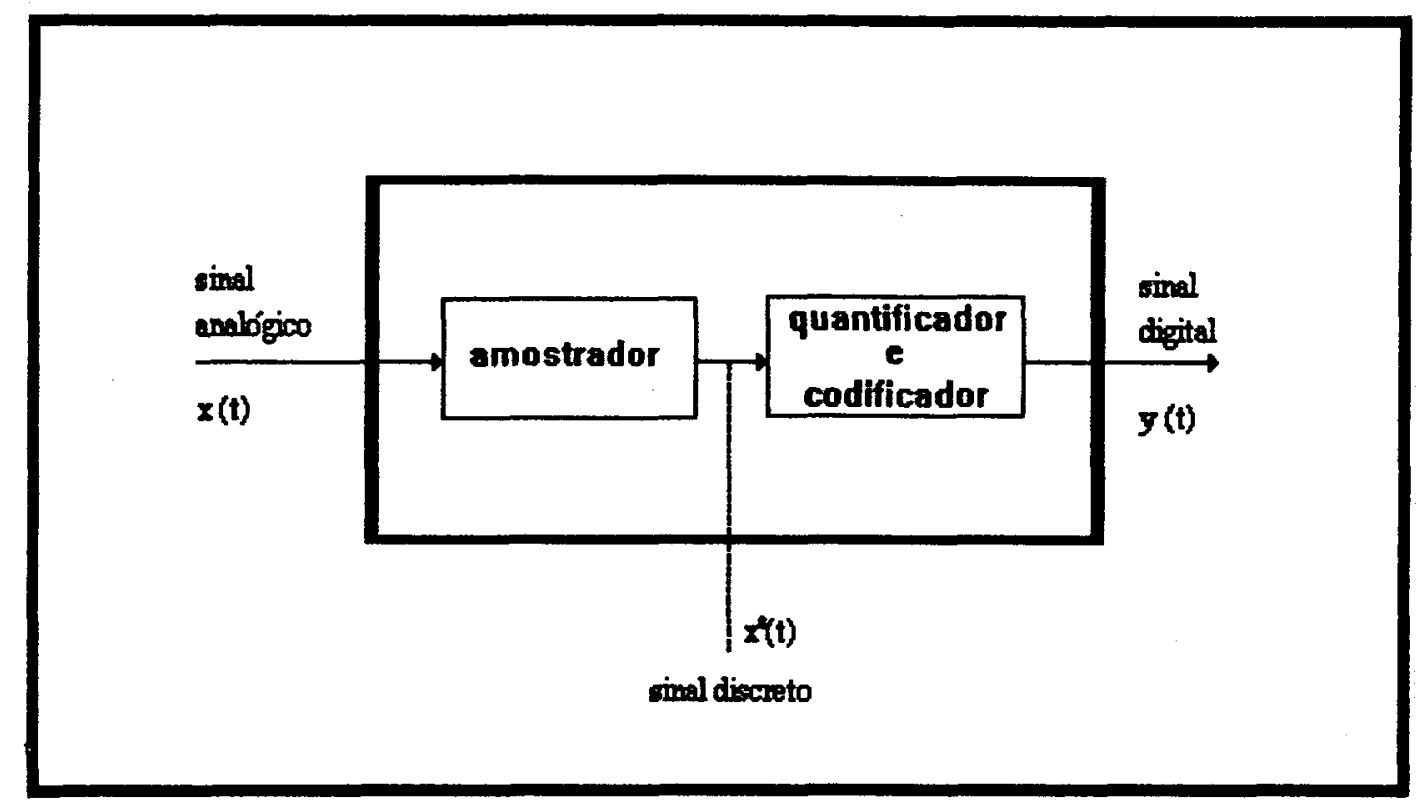

Figura 2.1: Representa o processo de conversão de um sinal analógico para a forma digital 
O processo de conversão pode ser visto em dois passos, constituido por :

- Amostragem

O sinal de entrada é amostrado em intervalos de tempo discreto, possibilitando uma representação discreta para o sinal.

- Quantização

O sinal discreto é então convertido para a forma digital, onde cada valor discreto receberá sua representação digital. A diferença entre o sinal original e o quantizado é chamada erro de quantização [PAP 66].

As amostras obtidas de uma função contínua no tempo, $x(t)$, compõem uma série regularmente espaçada no tempo. Se o intervalo de amostragem for constante, $\Delta$,então o valor discreto da função contínua no tempo $t=r \Delta$, é escrito como $x_{r}$ e a sequência $\left\{x_{r}\right\}$, para $r=0,1,2, \ldots, N$, é chamada série temporal finita, dado que a condição de ser finita é muito importante quando se deseja utilizar o computador.

Um dos objetivos da análise de séries temporais é a determinação de características estatísticas da função original, da qual a série discreta foi obtida. Para a obtenção de estimativas espectrais de dados mensuráveis, o melhor método é estimar uma função de correlação apropriada e então realizar a transformada de Fourier, para a obtenção do espectro.

Antes de 1965, não existiam algoritmos eficientes para o cálculo da transformada de Fourier, os algoritmos da época resultavam num esforço computacional da ordem de $N^{2}$ multiplicações complexas, onde $N$ é o tamanho da sequência. Em 1965, Cooley e Tukey [COO 65] demonstram um algoritmo para o cálculo da transformada de modo bastante eficiente, resultando num esforço computacional da ordem de $2 \mathrm{Nlog}_{2} \mathrm{~N}$, quando tomadas amostras de comprimento $N=2^{n}$. O algoritmo descoberto por Cooley e Tukey é popularmente conhecido por tansformada rápida de Fourier (FFT). Por exemplo, se desejarmos obter a transformada de Fourier para uma sequência de 1.024 pontos, teriamos que realizar 1.048.576 multiplicações complexas através de uma computação direta. Para o algoritmo de DFT, se utilizarmos o algoritmo de FFT, o número de multiplicaçóes complexas será de 5.120 .

A precisão do conversor analógico-digital é determinada pela sua capacidade de manipulação binária. Se um conversor A/D manipular informações de apenas um bit, este apenas poderia informar se existe ou não nível do sinal em sua entrada, representado por 1 a existência e 0 a falta do nível do sinal. Em geral, conversores de 16 a 24 bits são 
utilizados em síntese de tons musicais, dado a necessidade de obtermos alta fidelidade nos sons gerados. A figura 2.2 ilustra um sinal amostrado.

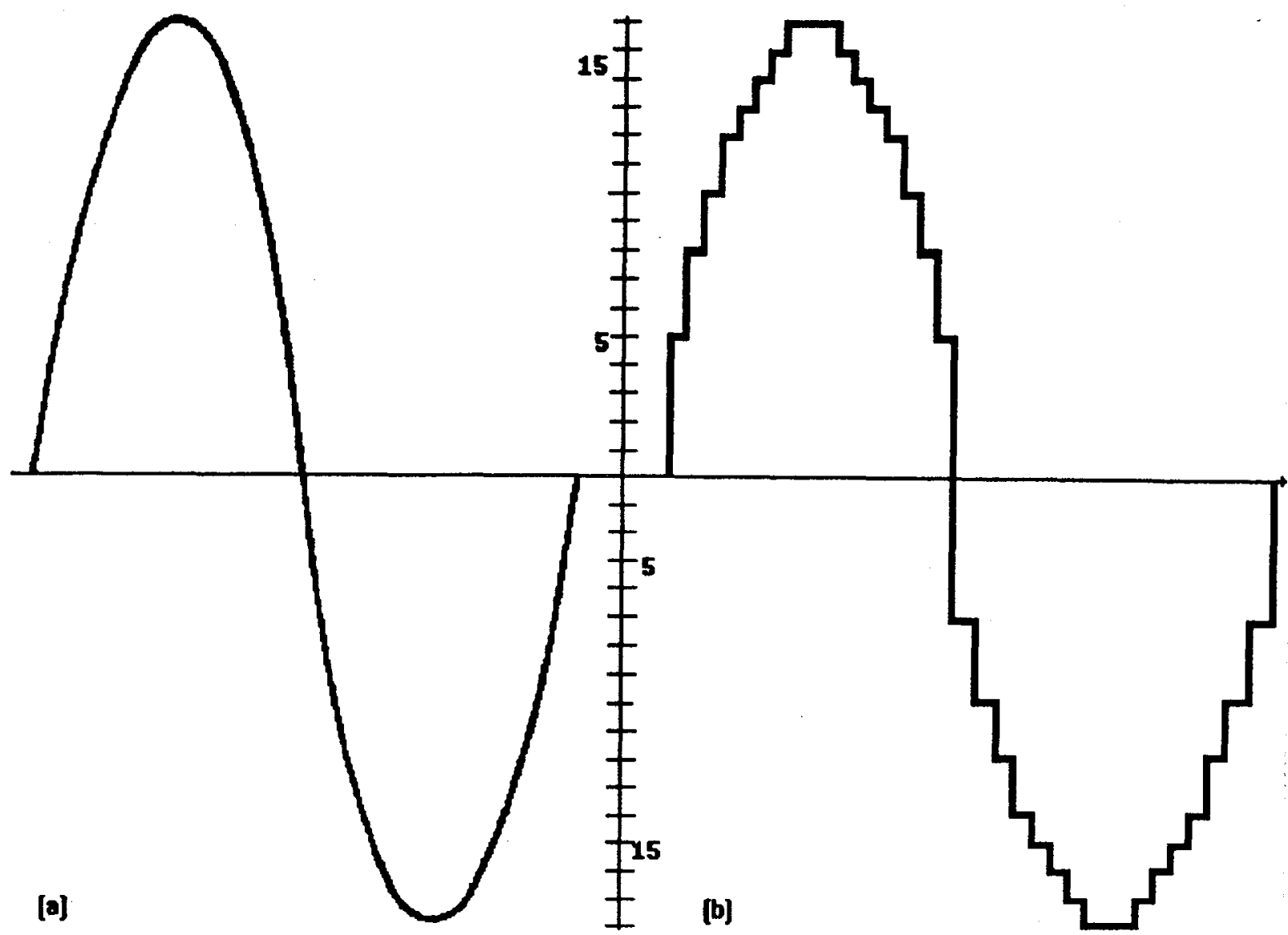

Figura 2.2 : Representação de um sinal analógico (a) e seu equivalente digital (b)

\subsection{O Teorema de Nyquist}

Como já vimos anteriormente, é possível a conversão do sinal para a forma digital. Nossa preocupação, neste instante, é garantir que a representação do sinal digital preserve todas as caracteríscas importantes para a reconstrução do sinal original.

Todo sinal complexo composto de frequências variando entre 0 e $\mathrm{N} \mathrm{Hz}$ é propriamente descrito por uma sequência de no mínimo $2 N$ amostras por segundo, a representação discreta de sinais complexos está apoiada na amostragem do sinal pelo conhecido teorema de Nyquist, que estabelece que um sinal de banda limitada (faixa de frequências) pode 
ser representado por amostras tomadas periodicamente no tempo, desde que a taxa de amostragem seja superior ou igual ao dobro da frequência máxima do sinal [OTN 72].

Desta forma, garantimos a não existência dos efeitos indesejáveis de superposição, conhecidos por aliasing, que é a superposição das frequências mais altas sobre as mais baixas.

\subsection{Aplicações de Processamento Digital de Sinais}

As aplicações de Processamento Digital de Sinais são empregadas em muitas áreas diferentes, dentre as quais destacamos :

- Processamento digital de tons Musicais

- Manipulação de gráficos e desenhos

- Processamento de imagens

- Espectroscopia

- Reconhecimento e Síntese de voz

- Compactação da dados para sistemas de comunicação

Os sistemas digitais são hoje extremamente confiáveis e compactos. A tecnologia atual possibilita a implementação de sistemas digitais extremamente complexos, em uma única pastilha (chip) de dimensões muitas vezes inferiores à área de uma tecla de computador, e sua velocidade de processamento é alta o suficiente para suportar implementações de funções complexas. Tal é o caso das funções utilizadas em processamento digital de tons musicais em tempo real. 


\section{Capítulo 3}

\section{Características Físicas do Som}

\subsection{Introdução}

O movimento vibratório de uma massa em contato com o ar produz som. Isto corresponde a variações na densidade e na pressão do ar ao redor da massa. Se desenharmos o gráfico da pressão do ar versus o tempo, esta representação corresponderá a respectiva forma de onda gerada.

A forma de onda pode ser representada através de uma coleção de componentes de frequência, a qual chamamos de espectro. A relação deste com a forma de onda é obtida através da transformada de Fourier, a qual discutiremos no final deste capítulo. Assim, todo som possui duas representações :

- A Forma de Onda

Corresponde à representação do som no domínio do tempo.

- O Espectro

Corresponde à representação do som no domínio da frequência.

Alguns movimentos possuirão vibrações constantes, outros transitórias, mas nem todos os movimentos produzirão sons, pois dependerão do meio para transmitir a energia criada até os nossos ouvidos, onde o som será percebido.

A origem destas vibrações poderá ocorrer pela natureza ou pela própria mão do homem. O som existe mesmo que não exista ouvido humano para captá-lo. Existem sons que os humanos não percebem, mas isto não significa que ninguém os ouça. A sensibilidade de alguns animais para sons é muito maior que a dos humanos. 
Admitindo em nosso trabalho que o meio para transmissão seja o ar, podemos então definir que a sensação sonora é para nós a deteç̧ão das vibrações de ar pelos ouvidos, os quais as converterão em pulsos elétricos que serão transmitidos via nervos ao cérebro.

\subsection{Características de Tons Musicais}

Em termos de tons musicais, os movimentos vibratórios podem ser causados por instrumentos acústicos ou por meio de ondas eletricamente excitadas através de um alto falante. Todo som possui três propriedades características; vejamos quais são, através de um exemplo retirado do cotidiano.

Ao caminharmos por uma avenida movimentada, ouvimos muitos sons ao mesmo tempo, automóveis, motos, ônibus, rádios tocando em diversos volumes, pessoas caminhando e falando, que produzem simultaneamente sons mais altos e mais baixos, mais fortes e mais fracos. Com nossos ouvidos, distinguimos automaticamente, por exemplo, a voz aguda de uma criança e o tom mais grave da voz de um homem e o barulho do trânsito; também sabemos que o instrumento musical, que provêm de um rádio, é um violino.

Quando identificamos, dentro da complexa onda sonora que chega aos nossos ouvidos, o som de um violino, estamos analisando inconscientemente aquele fenômeno sonoro baseados em três características fundamentais que são :

- Volume

- Frequência

- Timbre

\subsubsection{Volume}

$\mathrm{O}$ volume é descrito pela amplitude do som. Um fato bastante interessante, analisando tons musicais, é que a amplitude, bem como os outros dois parâmetros, varia com o tempo. A maneira pela qual a amplitude varia é descrita pelo envelope do tom musical. Usualmente, o envelope pode ser dividido em três fases distintas :

- Ataque

- Sustentação 


\section{- Decaimento}

Cada uma destas partes possuem um comportamento próprio e bem definido,como podemos observar na figura 3.1 .

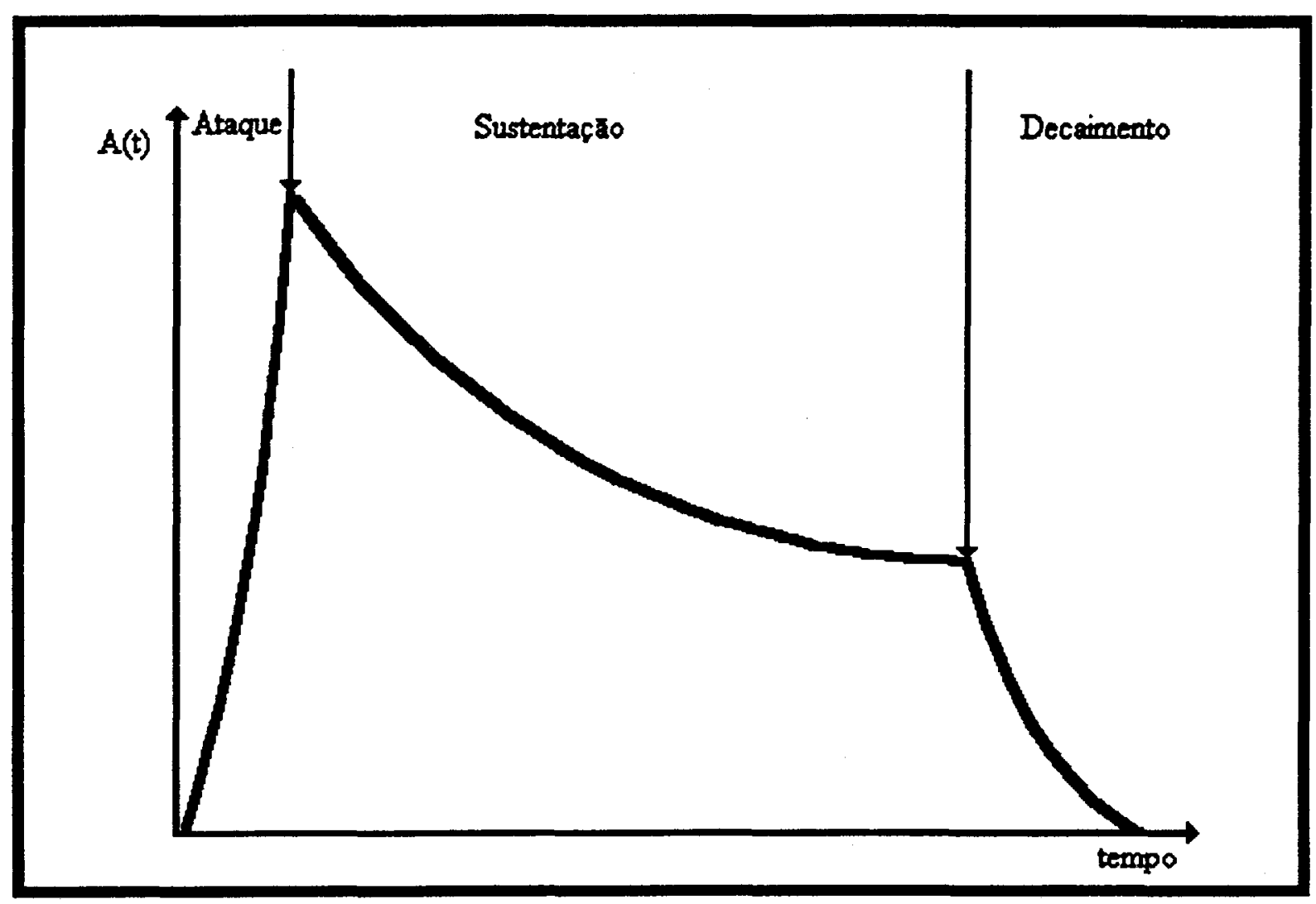

Fig 3.1 : característica de um envelope com as fases de ataque, sustentação e decaimento

\section{Ataque}

$\mathrm{O}$ ataque pode ser medido como um trecho do sinal a partir do momento em que o instrumentista toca a nota, até o instante em que o sinal se estabiliza próximo à uma frequência bem definida, a frequência fundamental. Este intervalo de tempo é bem pe- 
queno e contém uma grande quantidade de ruído [GRE 77]. A figura 3.2 ilustra o comportamento da forma de onda durante o estado de ataque.
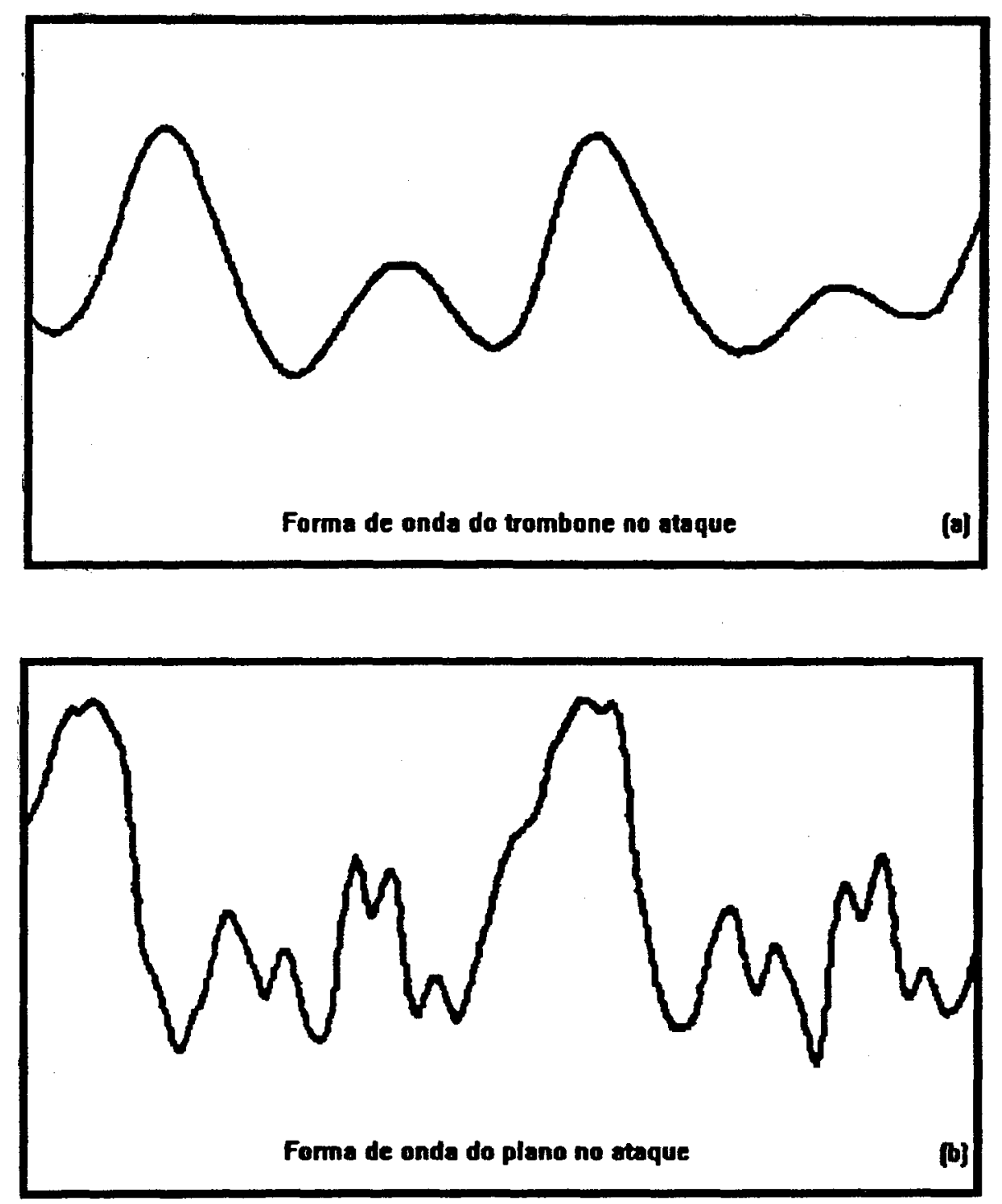

Figura 3.2: Representa o comportamento da forma de onda de um trombone (a) e de um piano (b) no estado de ataque

\section{Sustentação}

A sustentação, também conhecida por estado permanente, tem a propriedade de ser quasi-periódica [STR 66], e mais duradoura que os outros dois estados. Nesta condição, 
podemos estimar a frequência fundamental do tom musical. A figura 3.3 ilustra o comportamento da forma de onda durante o estado de sustentação.
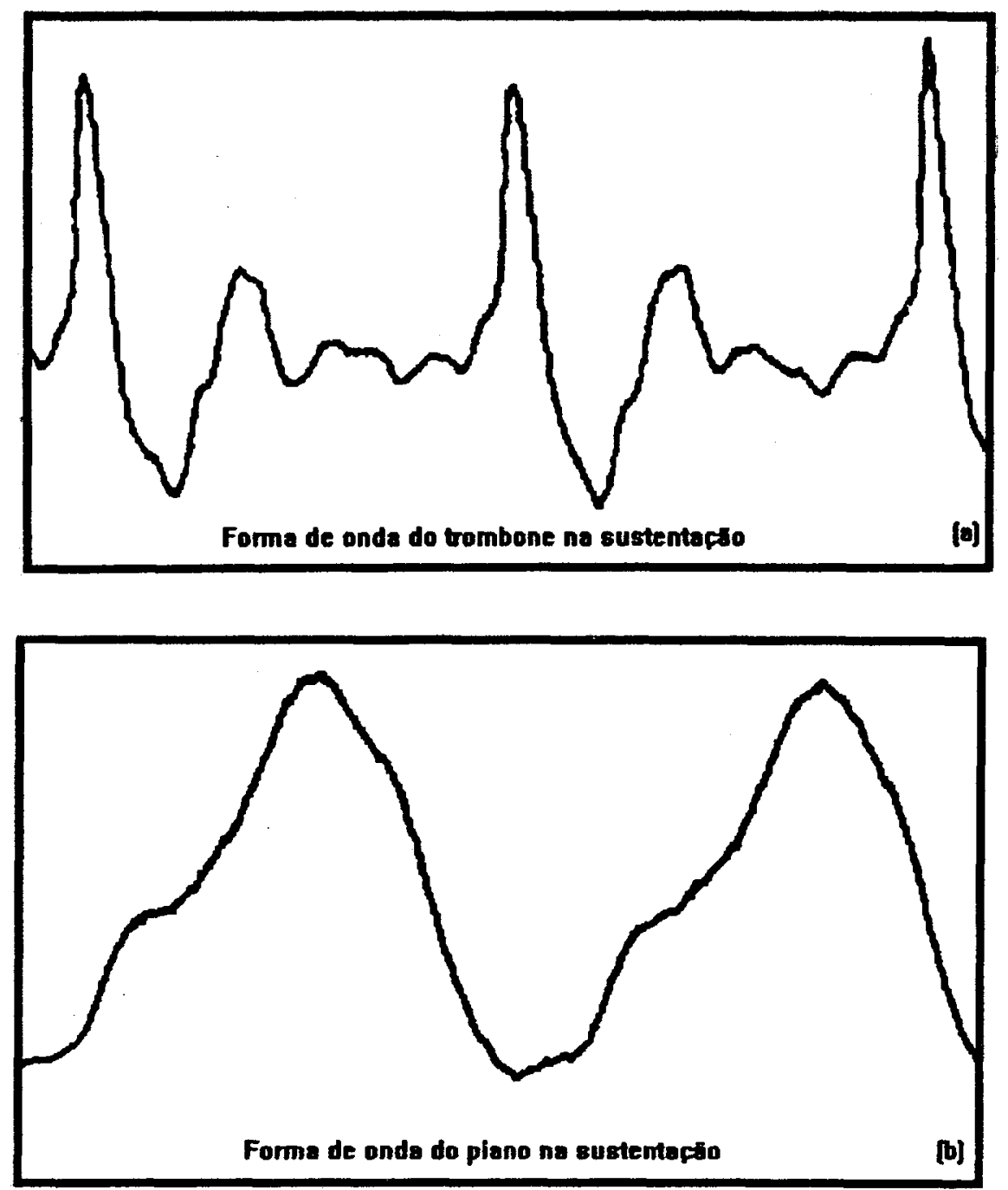

Figura 3.3: Representação do comportamento da forma de onda de um trombone (a) e de um piano (b) no estado de sustentação

\section{Decaimento}

O decaimento conserva a quasi-periodicidade do estado anterior, porém, como existirá a dissipação de energia, a característica deste estado transiente é desaparecer com um amortecimento exponencial.

Na figura 3.4, podemos observar também que nem todos os instrumentos musicais pos- 
suem estas 3 fases. Por exemplo, os instrumentos de percussão geram tons totalmente não periódicos, de modo a não possibilitarem uma estimativa de sua frequência fundamental. Mas podemos observar pela figura 3.5 o comportamento de uma clarinete que apresenta nítidamente seu envelope.
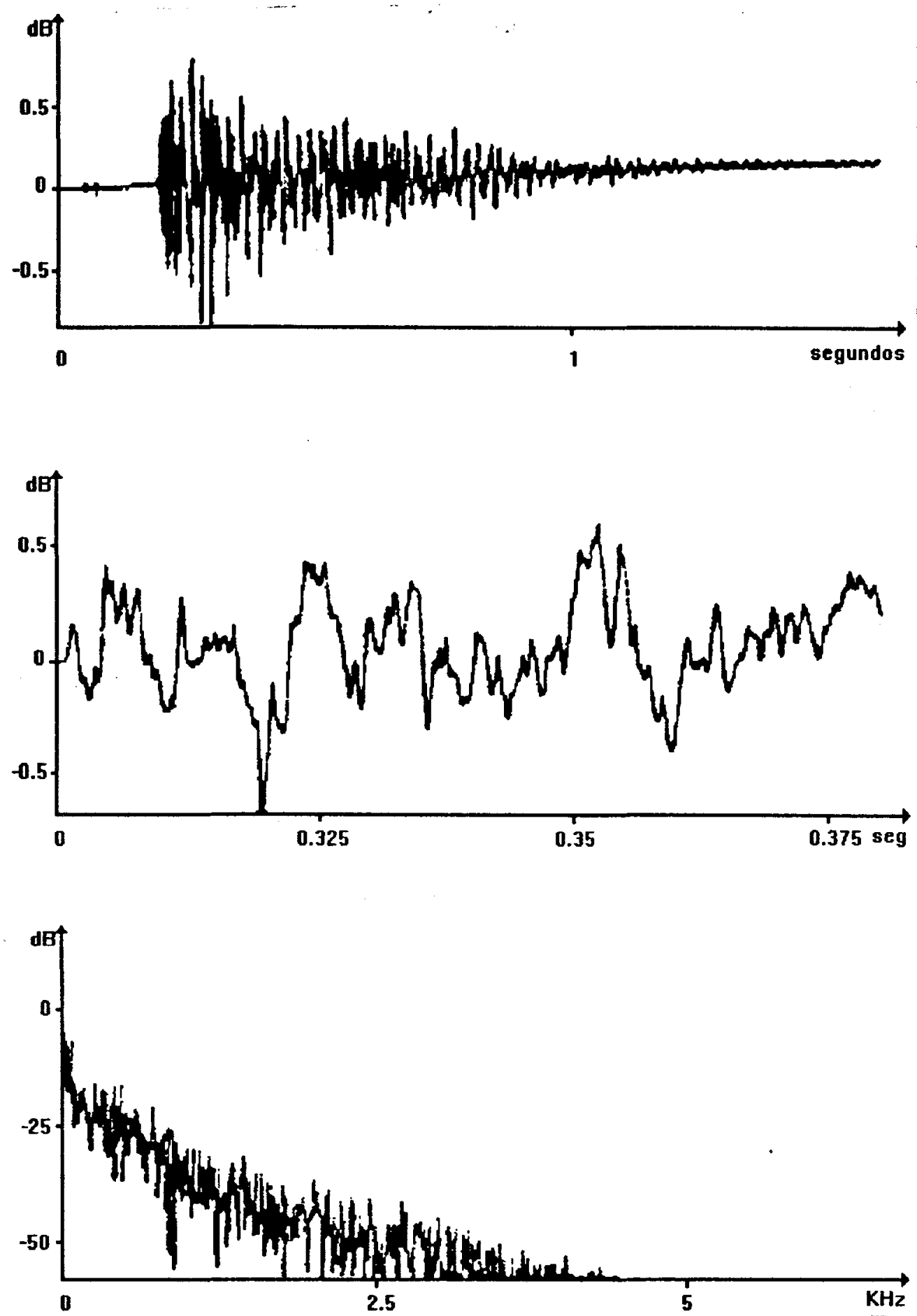

Fig 3.4: Características de um bumbo de bateria, onde a figura (a) representa a amostragem do sinal inteiro, (b) representa um pequeno seguimento do sinal ampliado na escala de tempo, (c) representa o espectro do sinal [MOO 77] 

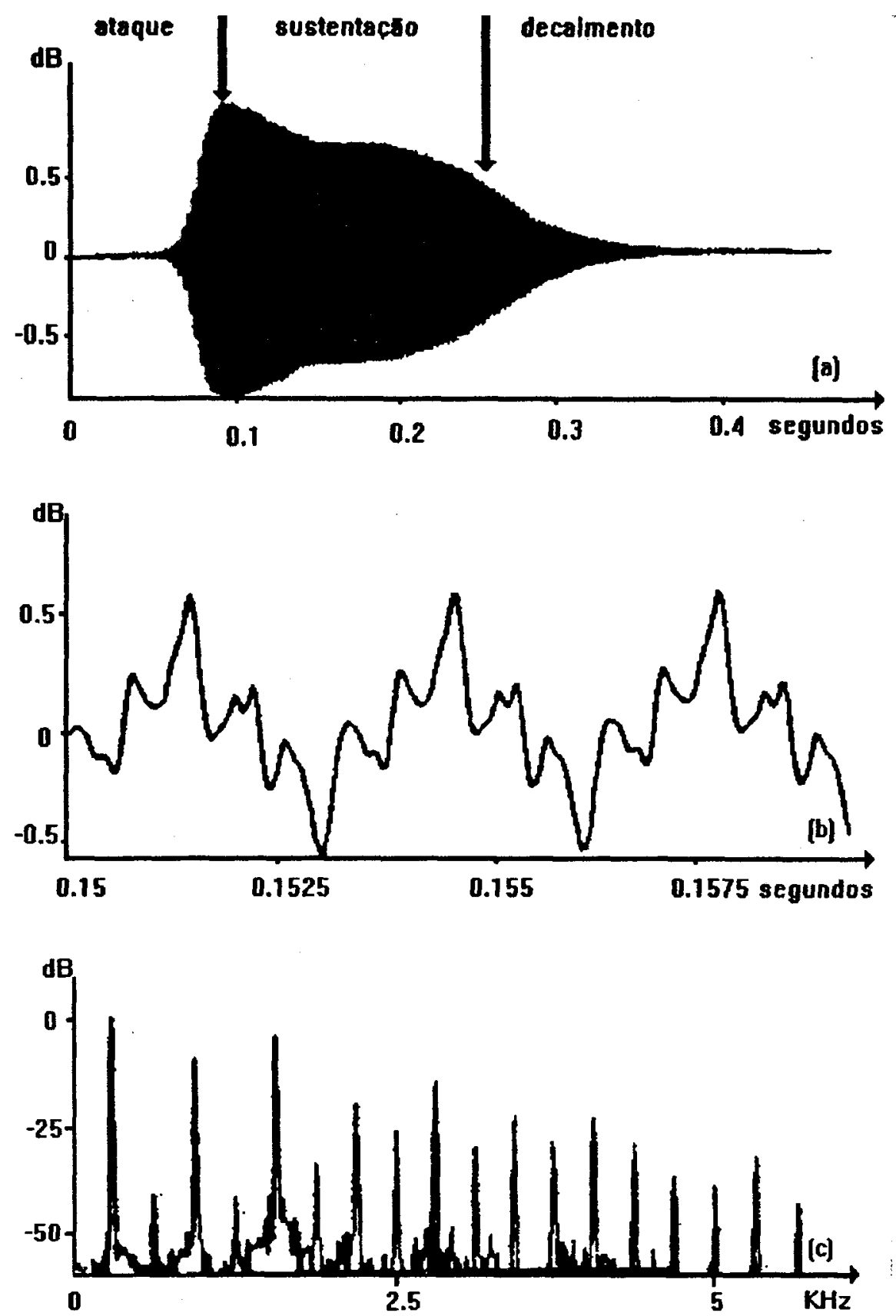

Fig 3.5 : Características de uma clarinete, onde a figura (a) representa a amostragem do sinal inteiro, onde podemos ver seu envelope, (b) representa um pequeno seguimento do sinal ampliado na escala de tempo, (c) representa o espectro do sinal [MOO 77]

\subsubsection{Frequência}

A maioria das pessoas, ao menos um dia, já ouviu os sons de dó, ré, mi, fá, sol, lá e si, produzidos por algum instrumento musical. Este fato é bastante curioso, pois a 
trivialidade de ouvir tais sons pode ser aprofundada para estudarmos os mecanismos da percepção sonora de um tom musical pelo ser humano. Como vimos anteriormente, a sensibilização do ser humano para sons e, mais específicamente para tons musicais, está relacionada com a compilação destes estímulos auditivos pelo cérebro. $\mathrm{Na}$ realidade, o som é formado por uma mistura de frequências, sendo que a menor delas é chamada de fundamental e uma combinação de outras frequências maiores chamadas de harmônicos, sobretons ou parciais.

O cérebro por sua vez, na percepção de frequências, faz uma audição seletiva que permite o reconhecimento de uma variedade de harmônicos justapostos associados a uma frequência preponderante (fundamental).

Uma propriedade da música ocidental que, de tão fundamental passa despercebida, é o fato de que, a cada oito tons tocados, a primeira e a última são consideradas análogas, ou seja a partir da oitava nota o ciclo se repete. A este intervalo de notas denominamos oitava, a qual é o intervalo básico musical. Por exemplo, o intervalo de de dó a dó ou ré a ré , são oitavas. Estes oito tons são representados pelas notas brancas de um piano. Isto não descarta a possibilidade de existirem outros intervalos, por exemplo um intervalo de cinco tons é chamado de quinta, o de quatro uma quarta, e assim por diante.

Teoricamente, a proporção entre as frequências de dois dós consecutivos sempre tenderá a ser igual a 1:2, isto é, se a frequência do dó escolhido é de $260 \mathrm{~Hz}$, a frequência do dó uma oitava acima, será $520 \mathrm{~Hz}$, e o dó uma oitava abaixo será $130 \mathrm{~Hz}$, como podemos observar na figura 1.2. Note que este exemplo é teórico pois na prática ocorrem pequenas variações nestes valores.

Uma escala é simplesmente uma série de tons musicais constituidas em progressão ascendente ou descendente a partir de um tom em sua oitava.

Em música ocidental a escala básica é a diatônica [KAR 90] que consiste de tons inteiros e semitons dentro de uma oitava, onde a oitava é dividida em 12 intervalos. Se subdividirmos oitava em 12 intervalos, as seguintes relações serão estabelecidas :

- (1) $\frac{d o^{*}}{d o^{1}}=\frac{r e}{d o^{\#}}=\frac{r \epsilon^{\#}}{r \epsilon}=\cdots=\frac{d o^{2}}{s i}$

- (2) A proporção entre a frequência de dois dós consecutivos será 1:2

- (3) As frequências estão distribuidas conforme a tabela 3.1 : 


\begin{tabular}{||l|c||}
\hline Tom & Frequência \\
\hline dó & $f$ \\
\hline$d o^{\#}$ & $\alpha f$ \\
\hline$r e$ & $\alpha^{2} f$ \\
\hline$r e^{\#}$ & $\alpha^{3} f$ \\
\hline$m i$ & $\alpha^{4} f$ \\
\hline$f a$ & $\alpha^{5} f$ \\
\hline$f a^{\#}$ & $\alpha^{6} f$ \\
\hline$s o l$ & $\alpha^{7} f$ \\
\hline$s o l^{\#}$ & $\alpha^{8} f$ \\
\hline$l a$ & $\alpha^{9} f$ \\
\hline$l a^{\#}$ & $\alpha^{10} f$ \\
\hline$s i$ & $\alpha^{11} f$ \\
\hline$d o$ & $\alpha^{12} f$ \\
\hline \hline
\end{tabular}

Tabela 3.1 : frequências em escala temperada

Como vemos a taxa de variação da frequência é denotada por uma função de $\alpha$, onde teremos que $\alpha^{12}=2$, dado pela tabela 3.1, vista acima. Desta forma, obteremos o valor de $\alpha=1.0595$, permitindo-nos levantar a tabela 3.2, para um instrumento musical.

\begin{tabular}{||l|c|c||}
\hline \hline Tom & Frequência & Quarta Oitava \\
\hline$d o$ & 1.0000 & 261.6 \\
\hline$d o^{\#}$ & 1.0595 & 277.2 \\
\hline$r e$ & 1.225 & 293.7 \\
\hline$r e^{\#}$ & 1.1893 & 311.1 \\
\hline$m i$ & 1.2602 & 329.6 \\
\hline$f a$ & 1.3351 & 349.3 \\
\hline$f a^{\#}$ & 1.4145 & 370.0 \\
\hline$s o l$ & 1.4987 & 392.1 \\
\hline$s o l^{\#}$ & 1.5878 & 415.4 \\
\hline$l a$ & 1.6823 & 440.0 \\
\hline$l a^{\#}$ & 1.7824 & 466.3 \\
\hline$s i$ & 1.8885 & 494.0 \\
\hline$d o$ & 2.0008 & 523.4 \\
\hline \hline
\end{tabular}

Tabela 3.2 : ilustra frequências em escala temperada de um instrumento musical 


\subsubsection{Timbre}

Ao se produzir sons de mesma frequência e mesma intensidade por um violino, piano, oboé, fagote, diapasão, etc, o ouvido reconhece instantâneamente a diferença entre estes instrumentos.

A esta diferença denominamos qualidade tonal ou timbre, a qual está relacionada com a composição de sobretons (harmônicos) apresentada pelo tom. Quanto maior a quantidade de sobretons no som, tanto maior será seu brilho.

Um exemplo poderá ser útil. Suponhamos que gravemos um tom de dó, a $261.6 \mathrm{~Hz}$, produzido por um clarinete e um piano. Comparamos primeiramente a reprodução do som dos dois instrumentos, cuja sensação será claramente distinta. Agora, por algum processo eletrônico, filtramos todos os sobretons acima de $600 \mathrm{~Hz}$ e comparamos os resultados. Será muito difícil reconhecer os instrumentos, pois as informações relevantes para a percepção da diferença estão localizadas acima de $600 \mathrm{~Hz}$.

Vale ressaltar que ainda existirão diferenças entre os dois sons processados, pois seus envelopes são diferentes.

\subsection{Características de Instrumentos Musicais}

O tom característico produzido por instrumentos musicais está intimamente ligado a dois aspectos básicos, em primeiro lugar ao material de sua confecção e sua forma física,em segundo a maneira de se tocar o instrumento. Os instrumentos numa orquestra são classificados em três categorias principais :

- Instrumentos de cordas

- instrumentos de sopro

- instrumento de percussão

\subsubsection{Instrumentos de cordas}

Os instrumentos de cordas incluem todos os instrumentos em que o som é produzido pela vibração de cordas retesadas. Estão divididos em três grupos, segundo a maneira como a vibração é gerada, que são : 


\section{- Instrumentos de arco}

Nos quais a corda vibra em consequência da fricção do arco. Alguns representantes desta classe são :

- violinos

- violoncellos

- contrabaixos

\section{- Instrumentos de cordas picadas}

Nos quais a vibração é produzida beliscando-se a corda. Alguns representantes desta classe são :

- violões

- harpas

\section{- Instrumentos de teclado}

Nos quais tocam a corda através de um pequeno martelo acionado por uma tecla. Alguns representantes desta classe são:

- pianos

- cravos

\subsubsection{Instrumentos de sopro}

Os instrumentos de sopro são aqueles que produzem sons pela vibração do ar em um tubo, sendo que esta vibração é provocada direta ou indiretamente pelo instrumentista ou por foles,respectivamente. A frequência do tom dependerá do comprimento do tubo : quanto menor for o tubo, maior será a frequência do tom. Os instrumentos de sopro são usualmente divididos em duas classes principais:

\section{- Instrumentos de sopro de madeira}

Estes instrumentos possuem um orifício, através do qual o instrumentista sopra o ar para dentro do tubo. Os sons desejados são controlados tampando e destampando os furos no corpo do instrumento. Tal é o caso da flauta, que existe também em metal.

Temos também aqueles que utilizam um agente como gerador do som, conhecido comumente por palheta, que é uma pequena e delgada lâmina de cana. Esta é presa numa extremidade ao bocal do instrumento, enquanto a outra extremidade vibra livremente quando o ar penetra no tubo, fazendo vibrar uma coluna de ar dentro do mesmo. Alguns destes instrumentos possuem duas palhetas que vibram uma contra a outra.

Assim, distinguimos entre instrumentos de palheta simples, que são representados pela: 
- clarinete

- saxofone (apesar do sax ser de metal, sua característica é ser de palheta )

- palhetas duplas que são representados pelo:

* oboé

* fagote

\section{- Instrumentos de sopro de metal}

Estes instrumentos possuem a característica de serem construidos por um longo tubo enrolado que termina em um pavilhão em forma de sino. A peculiaridade técnica dos instrumetos de metal em geral, consiste no fato da produção do som ser controlada pelos lábios do instrumentista, que servirá como uma palheta dupla quando este os pressiona contra o bocal. Os instrumentos que representam esta classe são :

- trompetes

- trompas

- trombones

- tubas

\subsubsection{Instrumentos de percussão}

O termo percussão refere-se a todos os instrumentos que produzem som ao serem diretamente golpeados ou sacudidos pelo executante. Dessa família muito numerosa, os instrumentos mais conhecidos e comumente usados são :

- tímpanos

- bongô

- caixa clara

- pratos

- triângulo

- tamborim

Em geral, instrumentos de percussão não geram sons musicais, isto é, o som produzido é considerado ruído, devido ao fato de não se poder medir a frequência fundamental. 0 tímpano é o único instrumento de percussão que produz sons com frequência fundamental mensurável. 


\subsection{Efeitos Impostos Sobre o Som Durante a Exe- cução em Instrumentos Musicais}

Uma grande variedade de efeitos poderão ser aplicadas em um som produzido por instrumentos musicais. Tais efeitos proporcionarão modificações no som, os instrumentistas exploram tais efeitos para aumentar o brilho do som, isto é, aumentar a quantidade de sobretons. Dentre os efeitos, destacamos os mais usuais :

- Vibrato

Este efeito é alcançado principalmente em instumentos de corda por uma ligeira movimentação do dedo para frente e para trás da corda. Em termos de frequência, esta ação gera uma pequena variação na frequência fundamental, na ordem de $7 \mathrm{~Hz}$, para cima ou para baixo da frequência fundamental.

- Batimento

Este efeito ocorrerá quando duas notas forem tocadas simultâneamente, existirá uma superposição física de suas ondas, produzindo uma variação na amplitude e a frequência final será igual a diferença entre as duas frequências iniciais.

- Portamento

É um modo de execução, quer vocal, quer instrumental, que consiste em ligar dois sons separados por um intervalo grande, em geral ascendente, passando rápidamente por todas as notas intermediárias.

- Glissando

É um efeito muito parecido com o portamento. Por exemplo, no piano é a passagem rápida, ascendente ou descentente da ponta dos dedos sobre uma série de notas concecutivas. Em instrumentos de corda friccionáveis, o deslize de um dedo para cima e para baixo sobre as notas de uma corda, enquanto o arco permanece em movimento

- Estacato

Em notação musical isto significa um sinal de intensidade representada por um pontinho ou uma espécie de sinal agudo sobre ou sub as notas, e que indica que o som deve ser interrompido mediante a um toque seco e breve. 


\subsection{Análise Espectral de Tons Musicais}

Como vimos o aparelho auditivo consegue identificar o timbre de um som, a partir da percepção da amplitude de cada frequência que o compõem. 0 mecanismo da audição realiza este fenômeno, no ouvido interno [JOS 69], transformando vibrações mecânicas em impulsos nervosos correspondentes às frequências componentes do som.

O cérebro por sua vez, não interpreta o som como flutuações instantâneas da pressão do ar, mas como uma mistura de sons puros [JOS 69], que são quaisquer estímulos sonoros que não tenham harmônicos ressonando consigo, num espectro de frequências.

O processo de análise espectral baseia-se na representação do sinal musical no domínio da frequência, sendo esta obtida através da transformada de Fourier. A transformada Fourier coloca em evidência propriedades do sinal que seriam difíceis de encontrar em sua forma original,isto é, no domínio do tempo, tal é o caso do timbre de um instrumento musical.

Com o intuito de rever algumas definições e conceitos básicos, essenciais ao entendimento da técnica de síntese de tons musicais, baseada em transformadas Karhunen-Lòeve, objeto de nossa implementação, abordaremos alguns tópicos importantes relacionados à transformada de Fourier, os quais serão também úteis para o entendimento da transformada Karhunen-Lòeve, que será apresentada no capitulo 5. Os tópicos são:

- Representação de sinais utilizando transformadas ortogonais

- Representação de sinais utilizando série de Fourier.

\subsubsection{Representação de Sinais utilizando Transformadas Or- togonais}

Seja $\Psi=\left\{\psi_{0}(t), \psi_{1}(t), \ldots, \psi_{n}(t), \ldots\right\}$ um conjunto de funções reais e contínuas,(utilizamos funções reais por conveniência), será dito ortogonal no intervalo $\left(t_{0}, t_{0}+T\right)$ se:

$$
\int_{t_{0}}^{t_{0}+T} \psi_{m}(t) \psi_{n}(t) d t= \begin{cases}c_{n} & \text { se } m=n \\ 0 & \text { se } m \neq n\end{cases}
$$

Para o caso onde $c_{n}=1$, o conjunto $\Psi$ é chamado ortonormal. Seja $x(t)$ uma função de valores reais, podendo ser um tom musical, definida em um intervalo $\left(t_{0}, t_{0}+T\right)$, e suponha que $x(t)$ possa ser escrita na forma : 


$$
x(t)=\sum_{n=0}^{\infty} a_{n} \psi_{n}(t)
$$

então os coeficientes $a_{n}$ podem ser obtidos da seguinte forma : multiplicamos ambos os lados da equação 3.2 por $\psi_{m}$ e integramos o resultado no intervalo $\left(t_{0}, t_{0}+T\right)$, onde obteremos :

$$
\int_{t_{0}}^{t_{0}+T} x(t) \psi_{m}(t) d t=\int_{t_{0}}^{t_{0}+T} \sum_{n=0}^{\infty} a_{n} \psi_{n}(t) \psi_{m}(t) d t
$$

Como $\psi_{m}$ e $\psi_{n}$ são ortogonais, temos :

$$
a_{m}=\frac{1}{c_{n}} \int_{t_{0}}^{t_{0}+T} x(t) \psi_{m}(t) d t, m=0,1,2, \ldots
$$

Um conjunto de funçôes ortogonais é chamado fechado ou completo se for verificada a seguinte condição:

- Para qualquer parte contínua de $x(t) \mathrm{com}$ :

$$
\int_{t_{0}}^{t_{0}+T} x^{2}(t) d t<\infty
$$

Qualquer que seja $\epsilon>0$, existe $N$ tal que seja possível representar uma aproximação de $x(t)$ por uma expansão finita :

$$
\int_{t_{0}}^{t_{0}+T}|x(t)-\hat{x}(t)|^{2} d t<\epsilon
$$

onde :

$$
\hat{x}(t)=\sum_{n=0}^{N-1} a_{n} \psi_{n}(t)
$$


Pelo desenvolvimento acima, é visivel que por uma expansão em funções ortogonais, sempre será possivel representar $x(t)$ por um conjunto infinito,mas enumerável $\left\{a_{0}, a_{1}, a_{2}, \ldots\right\}$. Entretanto, quando $\Psi$ for completo torna-se possivel uma estimativa de $x(t)$ através de um conjunto finito $\left\{a_{0}, a_{1}, \ldots, a_{N-1}\right\}$.

Retomemos a equação 3.2. Elevando-se ambos os lados desta equação ao quadrado, temos:

$$
x^{2}(t)=\sum_{n=0}^{\infty} a_{n}^{2} \psi_{n}^{2}(t)+\sum_{p=0}^{\infty} \sum_{q=0}^{\infty} a_{p} a_{q} \psi_{p}(t) \psi_{q}(t) \text { sempreque } p \neq q
$$

Integrando ambos os lados e aplicando-se a propriedade de funções ortogonais na equação 3.5, temos:

$$
\frac{1}{T} \int_{t_{0}}^{t_{0}+T} x^{2}(t) d t=\frac{c}{T} \sum_{n=0}^{\infty} a_{n}^{2}
$$

A equação 3.6, é conhecida como Teorema de Parseval [BOA 66]. Este resultado é de grande importância para a compreensão do significado físico de funções ortogonais.

Se a função $x(t)$ utilizada nas equações anteriores representasse a excitação de um sistema, o lado esquerdo da equação 3.6, representaria a energia total aplicada ao sistema, equanto o lado direito desta equação, representaria a distribuição de energia em $x(t)$.

\subsubsection{Representação de Sinais utilizando Série de Fourier}

A principal característica desta representação é que o conjunto de funções ortogonais é composto por funções senoidais, dado pelo conjunto $\left\{1, \cos n w_{0} t, \operatorname{sen} n w_{0} t\right\}$. A representação de funções por expansão em série, através deste conjunto de funções é chamada de série de Fourier e é dada por:

$$
x(t)=a_{0}+\sum_{n=1}^{\infty} a_{n} \cos n w_{0} t+\sum_{n=1}^{\infty} b_{n} \operatorname{sen} n w_{0} t
$$

Onde $w_{0}$ corresponde a frequência angular fundamental, que está relacionada com o período $\mathrm{T}$, obtido pela fórmula abaixo.

$$
T=\frac{2 \pi}{w_{0}}
$$


A frequência angular fundamental é igual a $2 \pi$ vezes a frequência fundamental $f_{0}$. Todas as frequências múltiplas inteiras da fundamental $\left(f_{0}\right)$ são chamadas harmônicas.

A função $x(t)$ deve satisfazer a condição imposta pela representação em funções ortogonais, que é :

$$
\int_{t_{0}}^{t_{0}+T} x^{2}(t) d t<\infty
$$

E ainda deverá satisfazer também as seguintes condições abaixo:

- 1. Ter um número finito de máximos e mínimos em um período.

- 2. Ter um número finito de descontinuidades em um período.

Para funções $x(t)$ que satisfaçam as condições acimas expostas, pode-se mostrar que o conjunto de coeficientes $\left\{a_{n}\right\}$ e $\left\{b_{n}\right\}$ é uniformente limitado. Em outras palavras, pode-se dizer que as séries de Fourier convergem no intervalo $(0, T)$ e a integração termo a termo é possível. Nos pontos de descontinuidade de $x(t)$, existirá uma convergência para a média.

Os coeficientes $\left\{a_{0}, a_{n}, b_{n}\right\}$ podem ser calculados usando-se o fato de que o conjunto de funções $\left\{\cos n w_{0} t, \operatorname{senn} w_{0} t\right\}$ é ortogonal em um periodo $\mathrm{T}$, o qual é dado por definição. Através deste resultado, temos:

$$
\begin{aligned}
& \int_{t_{0}}^{t_{0}+T} \cos n w_{0} t \cos m w_{0} t d t= \begin{cases}\frac{T}{2} & \text { se } m=n \\
0 & \text { se } m \neq n\end{cases} \\
& \int_{t_{0}}^{t_{0}+T} \operatorname{sen} n w_{0} t \operatorname{sen} m w_{0} t d t= \begin{cases}\frac{T}{2} & \text { se } m=n \\
0 & \text { se } m \neq n\end{cases} \\
& \int_{t_{0}}^{t_{0}+T} \cos n w_{0} t \text { sen } m w_{0} t d t=0, \text { para todo } m \text { e } n
\end{aligned}
$$

Através das relações acima e a representação em séries de Fourier para uma função $x(t)$, pode-se mostrar:

$$
\begin{gathered}
a_{0}=\frac{1}{T} \int_{t_{0}}^{t_{0}+T} x(t) d t \\
a_{n}=\frac{2}{T} \int_{t_{0}}^{t_{0}+T} x(t) \cos n w_{0} t d t \\
b_{n}=\frac{2}{T} \int_{t_{0}}^{t_{0}+T} x(t) \operatorname{senn} n w_{0} t d t
\end{gathered}
$$


Desta forma, conclui-se que o sinal $x(t)$ pode ser representado por um conjunto de números reais $\left\{a_{0}, a_{n}, b_{n}\right\}$. Pode-se demostrar que o resultado do teorema de Parseval, a partir dos coefientes obtidos pela expansão em série de Fourier, é dado por:

$$
\frac{1}{T} \int_{t_{0}}^{t_{0}+T} x^{2}(t) d t=a_{0}^{2}+\frac{1}{2} \sum_{n=1}^{\infty}\left(a_{n}^{2}+b_{n}^{2}\right)
$$

Uma extensão natural, para o conjunto dos números complexos, é dada utilizando-se as relações trigonométricas:

$$
\begin{aligned}
& \cos n w_{0} t=\frac{1}{2}\left(e^{i n w_{0} t}+e^{-i n w_{0} t}\right) \\
& \operatorname{sen} n w_{0} t=\frac{1}{2 i}\left(e^{i n w_{0} t}-e^{-i n w_{0} t}\right)
\end{aligned}
$$

Das equações 3.15 e 3.16 , temos :

$$
e^{-i n w_{0} t}=\cos n w_{0} t-i \operatorname{sen} n w_{0} t
$$

podemos escrever a equação 3.7 , na seguinte forma :

$$
\begin{gathered}
x(t)=a_{0}+\frac{1}{2} \sum_{n=1}^{\infty} a_{n}\left(e^{i n w_{0} t}+e^{-i n w_{0} t}\right)-i b_{n}\left(e^{i n w_{0} t}-e^{-i n \omega_{0} t}\right) \\
x(t)=a_{0}+\frac{1}{2} \sum_{n=1}^{\infty}\left(a_{n}-i b_{n}\right) e^{i n \omega_{0} t}+\left(a_{n}+i b_{n}\right) e^{-i n \omega_{0} t}
\end{gathered}
$$

Por conveniência, definimos :

$$
c_{n}=\frac{1}{2}\left(a_{n}-i b_{n}\right)
$$

O conjugado complexo da equação 3.19 , é dado por:

$$
\overline{c_{n}}=\frac{1}{2}\left(a_{n}-i b_{n}\right)
$$

Substituindo-se as equações 3.19 e 3.20 em 3.18 obteremos a representação em série de Fourier complexa da função $x(t)$, que é dada por:

$$
x(t)=\sum_{n=-\infty}^{\infty} c_{n} e^{i n w_{0} t}
$$




\subsubsection{Método de Extração Harmônica, baseada em Filtragens Heteródinas}

Uma aplicação interessante da teoria vista acima, é a decomposição de sinal em termos de suas componentes senoidais. Esta decomposição deve refletir as características variantes no tempo para a amplitude e frequência, para todas as componentes do sinal. Um método de análise frequentemente utilizado é a filtragem heteródina, [GRE 77], [BEA 69], baseada no fenômeno físico chamado batimento, descrito na secão 3.4 deste capítulo. A figura 3.6, ilustra este método.

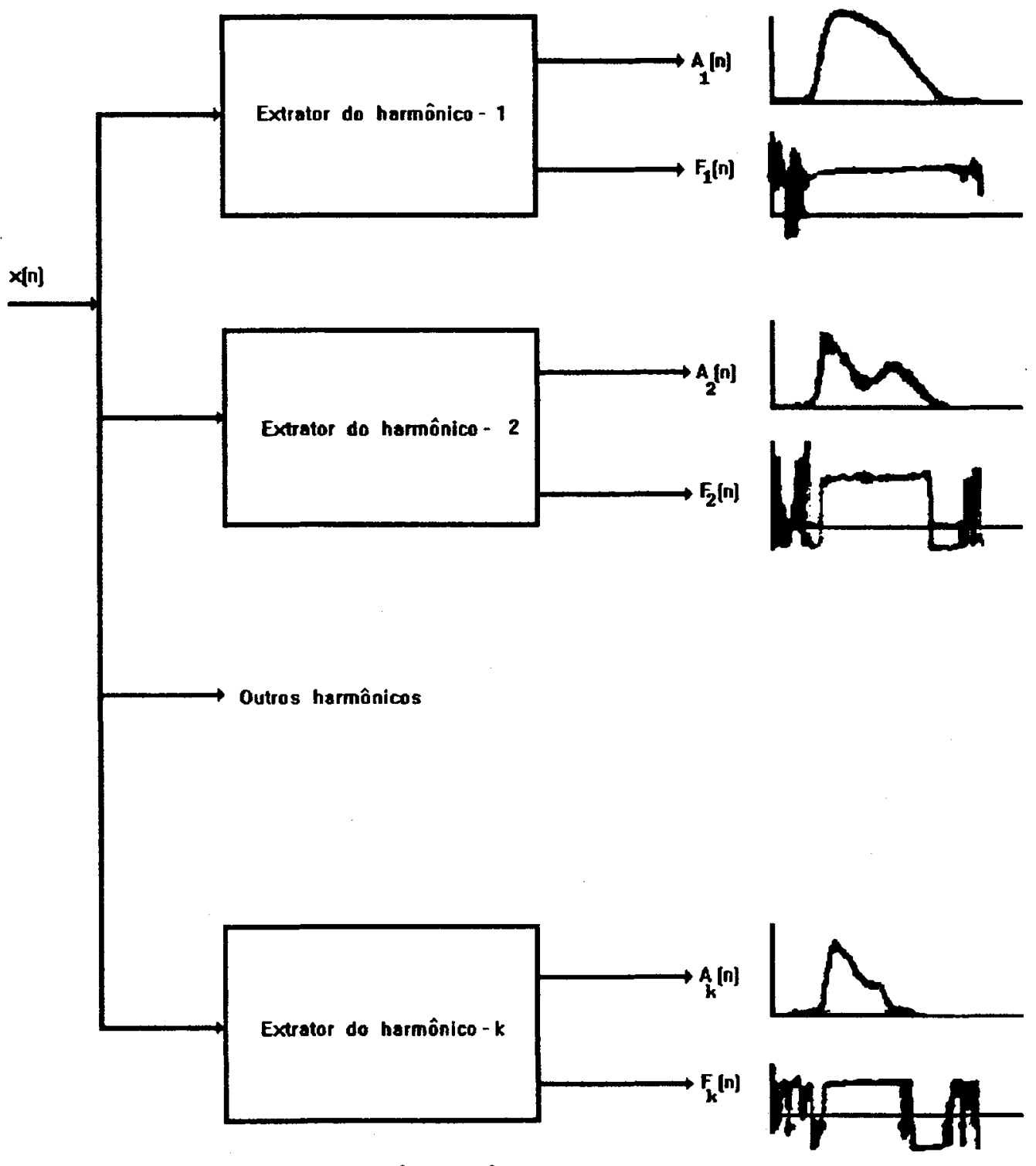

Figura 3.6 : Representa a forma geral de um estimador para as funçóes amplitude $e$ frequência de cada harmônico separadamente, como funções variantes no tempo, de uma forma de onda $x(t)$, proveniente de um tom, gerada por um instrumento musical 
O extrator de harmônico representado na figura 3.7, é definido matematicamente pelas equações abaixo:

$$
\begin{aligned}
& a_{k}(n)=\sum_{r=n}^{n+N-1} x(r) \cos \left(r k w_{0} T\right) \\
& b_{k}(n)=\sum_{r=n}^{n+N-1} x(r) \operatorname{sen}\left(r k w_{0} T\right)
\end{aligned}
$$

As equações 3.22 e 3.23 representam a filtragem heteródina para um harmônico específico, onde $\mathrm{k}$ é o harmônico em análise, $w_{0}$ é a frequência fundamental para a operação heteródina, $x(r)$ é o sinal amostrado, proveniente do instrumento musical, $N$ é um número inteiro mais próximo a quantidade de amostras por período do sinal de entrada. Vários métodos existem para a determinação valor de $N$ [NOL 67], [SON 68], [GOL 69].

A partir das equações 3.22 e 3.23 , obtém-se as estimativas para as funções amplitude e frequência, através das relações:

$$
\begin{gathered}
\hat{A}_{k}(n)=\sqrt{a_{k}^{2}(n)+b_{k}^{2}(n)} \\
\hat{\theta}_{k}(n)=\arctan \left(\frac{b_{k}(n)}{a_{k}(n)}\right) \\
\hat{F}_{k}(n)=\frac{1}{2 \pi} \frac{d \hat{\theta}_{k}(n)}{d t}
\end{gathered}
$$

Os chapéus (circunfléxicos) sobre as variáveis amplitude $(A)$, fase $(\theta)$ e frequência $(F)$, indicam que estes valores são estimativas para as funções. Em outras palavras, os valores 
encontrados não são exatamente iguais aos valores do sinal original. A figura 3.7 ilustra a representação interna para um extrator de harmônico.

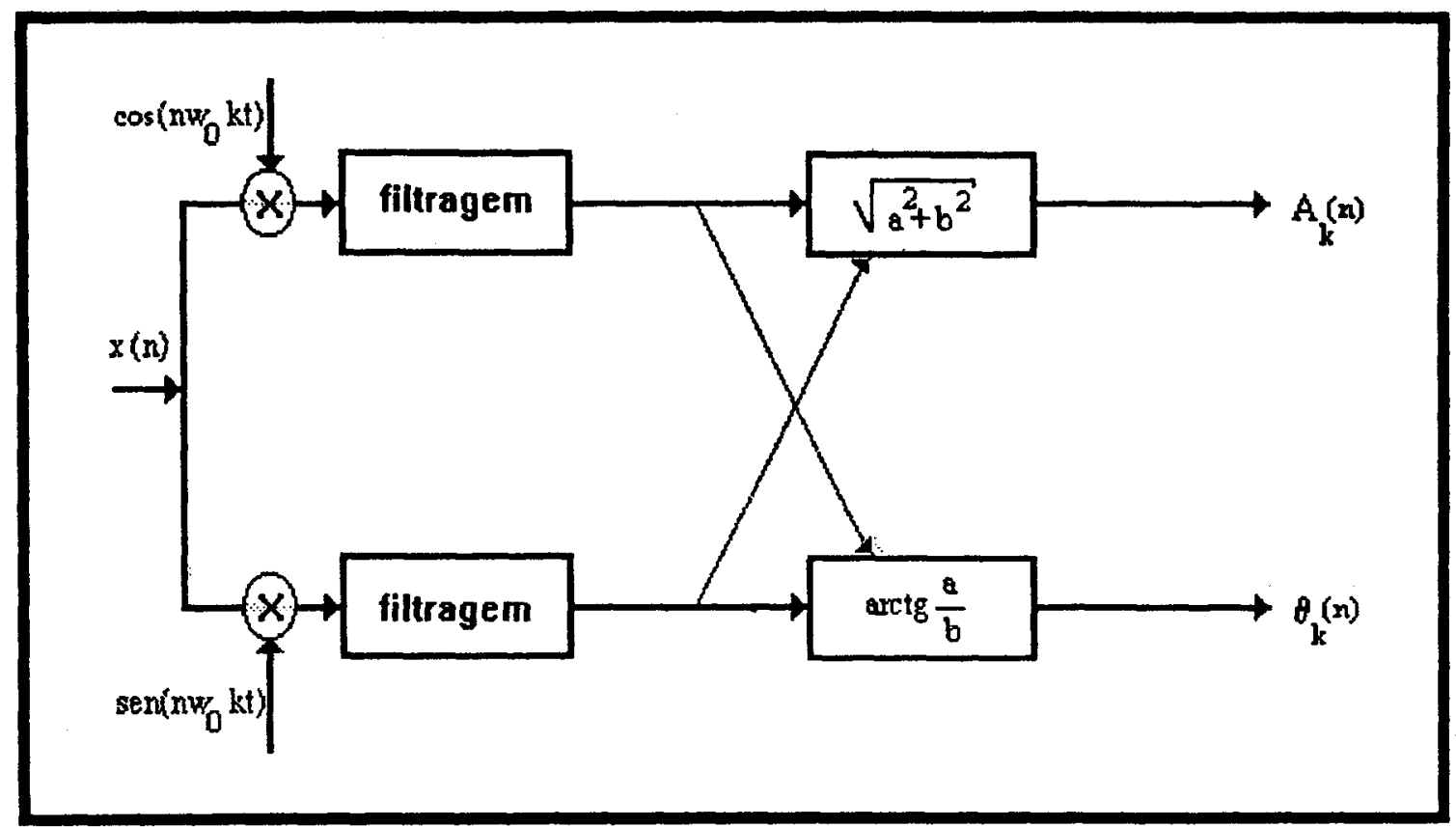

Figura 3.7 : Representação interna de um extrator de harmônico. O sinal $x(t)$ é primeiramente multiplicado pelas funções seno e cosseno com frequências do harmônico em análise, caracterizando a operação heteródina

\subsubsection{A Transformada de Fourier}

A transformada de Fourier [AND 79], [BRI 67], $F(w)$, de um sinal, $x(t)$, descrito no domínio do tempo é dada por :

$$
\begin{gathered}
F(w)=\int_{-\infty}^{\infty} x(t) e^{-i w t} d t \\
x(t)=\frac{1}{2 \pi} \int_{-\infty}^{\infty} F(w) e^{i w t} d w
\end{gathered}
$$

As equações 3.24 e 3.25 são a transformada de Fourier e a transformada inversa de Fourier respectivamente. 
Uma condição suficiente para a existência da transformada em 3.24 é que o sinal $\mathrm{x}(\mathrm{t})$ tenha energia finita, equação 3.26 , isto é :

$$
\lim _{t \rightarrow \infty} \int_{0}^{t}|x(t)|^{2} d t<\infty
$$

Em processamento digital de sinais, trabalhamos com sequências amostradas do sinal, espaçadas uniformemente no tempo. A representação da transformada de Fourier de uma sequência discreta $\mathrm{x}(\mathrm{n})$, onde $\mathrm{n}$ é uma variável inteira do tempo, é dada pelas equações :

$$
\begin{gathered}
F(w)=\sum_{-\infty}^{\infty} x(n) e^{-i w n} \\
x(n)=\frac{1}{2 \pi} \int_{-\pi}^{\pi} F(w) e^{i w n} d w
\end{gathered}
$$

A transformada de Fourier de uma sequência discreta pode ser interpretada como um caso particular da Transformada $\mathrm{Z}$ calculada somente sobre a circunferência unitária do plano Z, em que a variável Z foi substituida por $e^{i w}$. Para garantir a existência da equação 3.27 é suficiente que:

$$
\sum_{-\infty}^{\infty}|x(n)|^{2}<\infty
$$

No caso em que a sequência $\mathrm{x}(\mathrm{n})$ seja periódica, com período $N$, isto é, $x(n)=x(n+N)$, $\mathrm{x}(\mathrm{n})$ pode ser representada por uma soma discreta de senóides :

$$
\begin{gathered}
F(k)=\sum_{n=0}^{N-1} x(n) e^{-i 2 \pi k n / N} \\
x(n)=\frac{1}{N} \sum_{k=0}^{N-1} F(k) e^{i 2 \pi k n / N} \text { para }-\infty<n<\infty
\end{gathered}
$$

É importante observar que essa é uma representação exata de uma sequência periódica. A grande utilidade das equaçôes 3.30 e 3.31 está na transformação de sequências finitas. Para ilustrar isto, consideremos uma sequência finita $l(n)$ de valor zero fora do intervalo $0 . . N-1$. A transformada de Fourier é obtida a partir da equação 3.27, considerando apenas o intervalo $0 . . N-1$ temos :

$$
F(w)=\sum_{n=0}^{N-1} l(n) * e^{-i w n}, \text { para }-\pi<w<\pi
$$


Amostrando-se a transformada $F(w)$ em $\mathrm{N}$ intervalos uniformes de $w$, isto é, em $w_{k}=2 \pi k / N$, (considerando que $\left.e^{i w n}=e^{i w n+2 \pi}\right)$, obtém-se :

$$
F(2 \pi k / N)=\sum_{n, k=0}^{N-1} l(n) e^{-i 2 \pi n / N}
$$

Comparando-se as equações 3.30 e 3.33 verifica-se que os valores amostrados $F\left(w_{k}\right)$ do espectro de uma sequência finita, correspondem aos coeficientes da transformada de Fourier de uma sequência periódica de periodo igual ao comprimento da sequência finita de mesma quantidade de amostras. No caso, $x(n)=l(n)$, para, $n=0 . . N-1$ podemos associar um espectro discreto através da equação 3.30. Esse tipo de transformação corresponde a transformada discreta de Fourier (DFT), descrita por 3.30 , limitando $\mathbf{n}$ ao intervalo $0 . . N-1$.

Este resultado é bastante importante, pois pode ser aplicado em muitas áreas afins, tais como processamento de imagens, música, voz, entre outros, os quais possuem características marcantes de não periodicidade, nem necessariamente limitados no tempo. Podemos dividir a sequência ilimitada de amostras em sequências finitas de comprimento $\mathrm{N}$, calcular a DFT correspondente através da equação 3.30 e a transformada inversa através da equação 3.31 , recuperando exatamente o sinal original, trecho a trecho.

Esta interpretação da transformada de Fourier é conhecida como transformada de Fourier dependente do tempo ou de curta duração (STFT-Short Time Fourier Transform) [HAR 78],[POR 80], [MAH 90].

\subsubsection{Transformada de Fourier de Curta Duração (STFT)}

A definição de uma STFT é determinada pela necessidade de uma representação espectral que reflita as propriedades variantes com o tempo do sinal de um tom musical.

Uma definição prática para STFT de uma sequência é dada por :

$$
F(n, w)=\sum_{m=-\infty}^{\infty} p(n-m) x(m) e^{-i w m}
$$

Onde $p(n-m)$ é uma janela real do tempo discreto que particiona a sequência $\mathrm{x}(\mathrm{m})$ para dar ênfase a uma determinada porção do sinal. A transformada $F(n, w)$ é, então uma função de duas variáveis, uma variável discreta no tempo, n, e uma variável contínua de frequência, w. Uma interpretação para esta representação é que a cada intervalo de tempo 
n está associada uma janela $\mathrm{p}(\mathrm{n}-\mathrm{m})$ que define o trecho da sequência que será transformado gerando a função $F(n, w)$. A figura 3.8 ilustra esta interpretação. Observando que para um determinado valor de $\mathrm{n}, \mathrm{F}(\mathrm{n}, \mathrm{w})$ corresponde à transformada de Fourier da função $p(n-m) x(m)$ que pode ser recuperada exatamente pela expressão :

$$
\begin{gathered}
p(n-m) x(m)=\frac{1}{2 \pi} \int_{-\pi}^{\pi} F(n, w) e^{i w m} d w \\
x(n)=\frac{1}{2 \pi p(0)} \int_{-\pi}^{\pi} F(n, w) e^{i w m} d w
\end{gathered}
$$

As janelas mais comumente usadas são : a retangular e a Hamming [PRO 88], [HAR 78], definidas repectivamente por:

$$
\begin{gathered}
p(n)= \begin{cases}1 & \text { para } 0<n<N-1 \\
0 & \text { fora deste intervalo }\end{cases} \\
p(n)= \begin{cases}0.54-0.46 * \cos (2 \pi n /(N-1)) & \text { para } 0<n<N-1 \\
0 & \text { fora deste intervalo }\end{cases}
\end{gathered}
$$

Se a janela adotada for finita com duração $\mathrm{N}$, o valor de $F(n, w)$ para cada $\mathrm{n}$ nas frequências $w_{k}$ pode ser obtido pelo cálculo da DFT como no caso invariante com o tempo:

$$
\begin{gathered}
F\left(w_{k}, n\right)=\sum_{m=0}^{N-1} p(n-m) x(m) e^{-i 2 \pi k m / N} \\
p(n-m) x(m)=\frac{1}{N} \sum_{n, k=0}^{N-1} F\left(w_{k}, n\right) e^{-i 2 \pi k n / N} \\
x(n)=\frac{1}{N p(0)} \sum_{n, k=0}^{N-1} F\left(w_{k}, n\right) e^{-i 2 \pi k n / N)}
\end{gathered}
$$

Em vista dos resultados acima, pode-se dividir uma sequência ilimitada de amostras de um sinal em quadros consecutivos obtidos pela passagem de janelas que se deslocam no 
tempo, analisá-los através de qualquer dos algoritimos usados para cálculo de DFT, como por exemplo o algoritmo da FFT (Fast Fourier Transform), e recuperarmos exatamente o sinal.

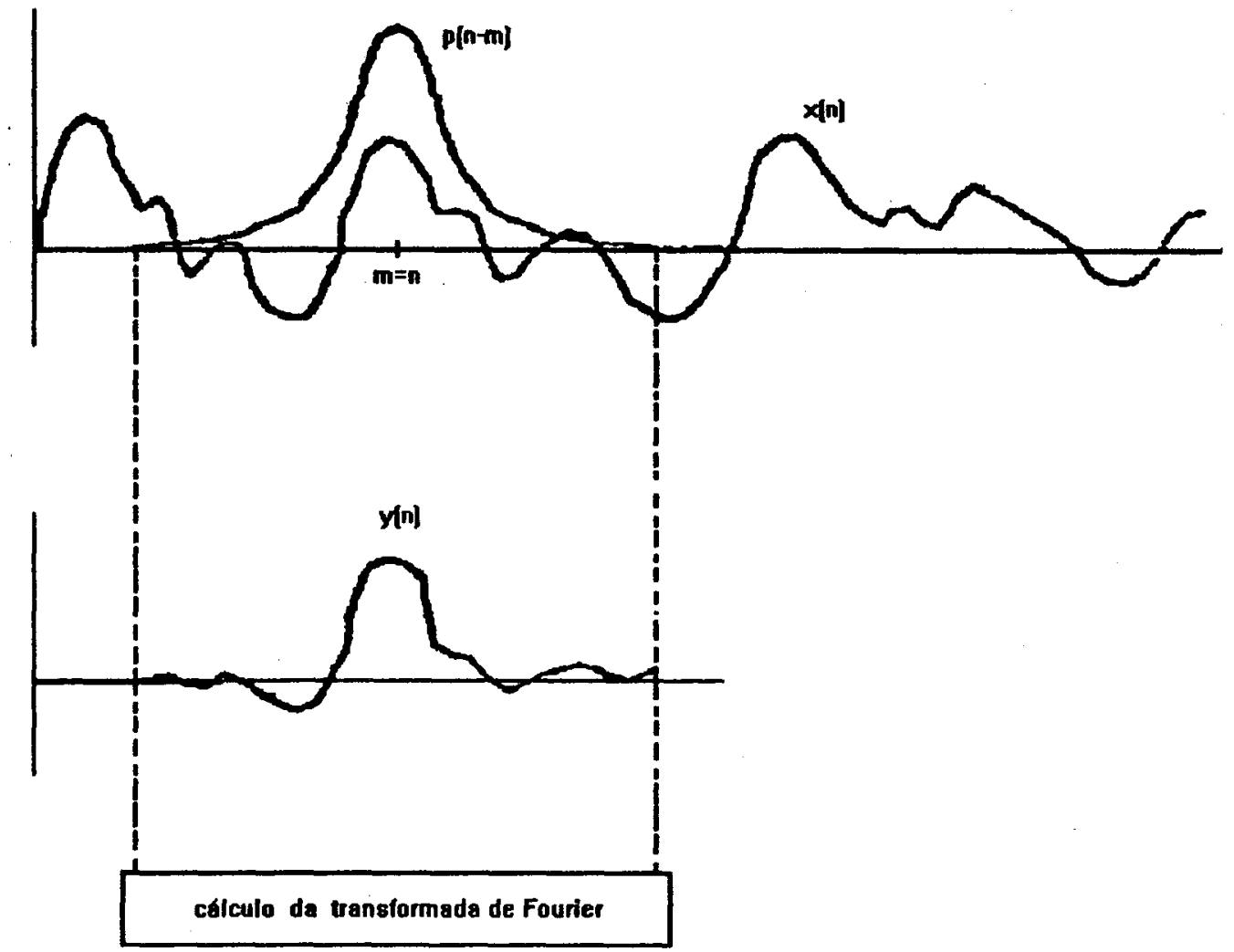

Figura 3.8 : Representa o deslocamento da janela de análise ao longo do tempo

A transformação pura e simples de sequências parciais de amostras para o domínio da frequência, não reduz a quantidade de dados necessária para a geração do sinal no domínio do tempo, mas auxiliará a identificação dos dados menos significativos ou redundantes que permitirá a redução de dados sem a ocorrência de degradação na qualidade do sinal sonoro. 


\section{Capítulo 4}

\section{Métodos Tradicionais de Síntese}

\subsection{Introdução}

Todo ambiente de sintese de música por computador requer três componentes básicos [GOR 85] : geração, conversão e controle, como podemos observar na figura 4.1.

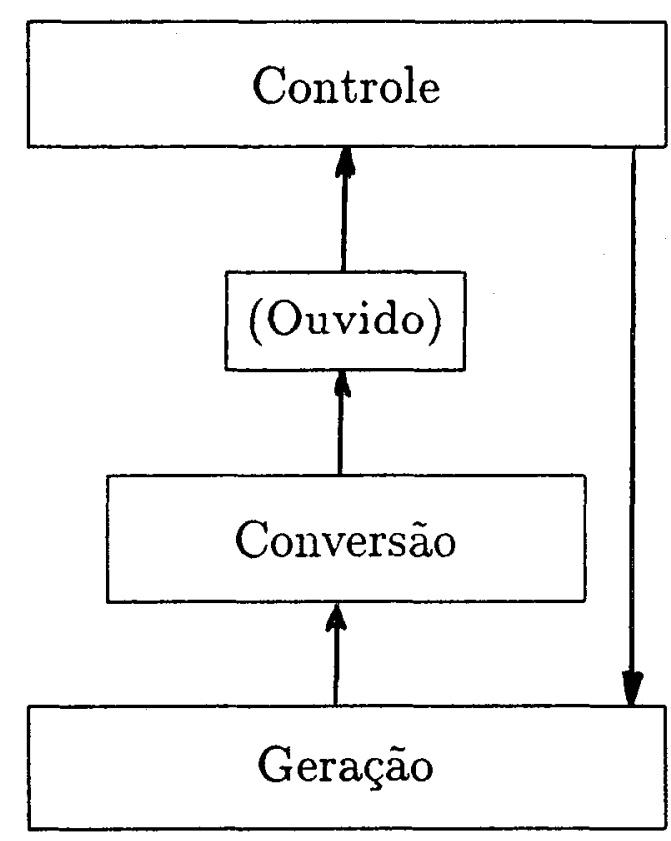

Figura 4.1: Componentes básicos para um sistema de música por computador [GOR 85] 
A síntese é acima representada pela geração do sinal digital. Este sinal digital é enviado ao conversor digital analógico, o qual converterá os valores numéricos em sinais analógicos, transformando-o em sinal sonoro. Este último sinal chega a nossos ouvidos para serem apreciados e, novamente, podem ser sintetizados através de controles provenientes da interação humana, alterando-se os parâmetros utilizados na síntese, que normalmente são a amplitude e frequência dos harmônicos.

É usual incluir, ao ambiente, itens opcionais tais como : capacidade de processar o sinal, conversor analógico digital e uma memória para armazenamento dos dados.

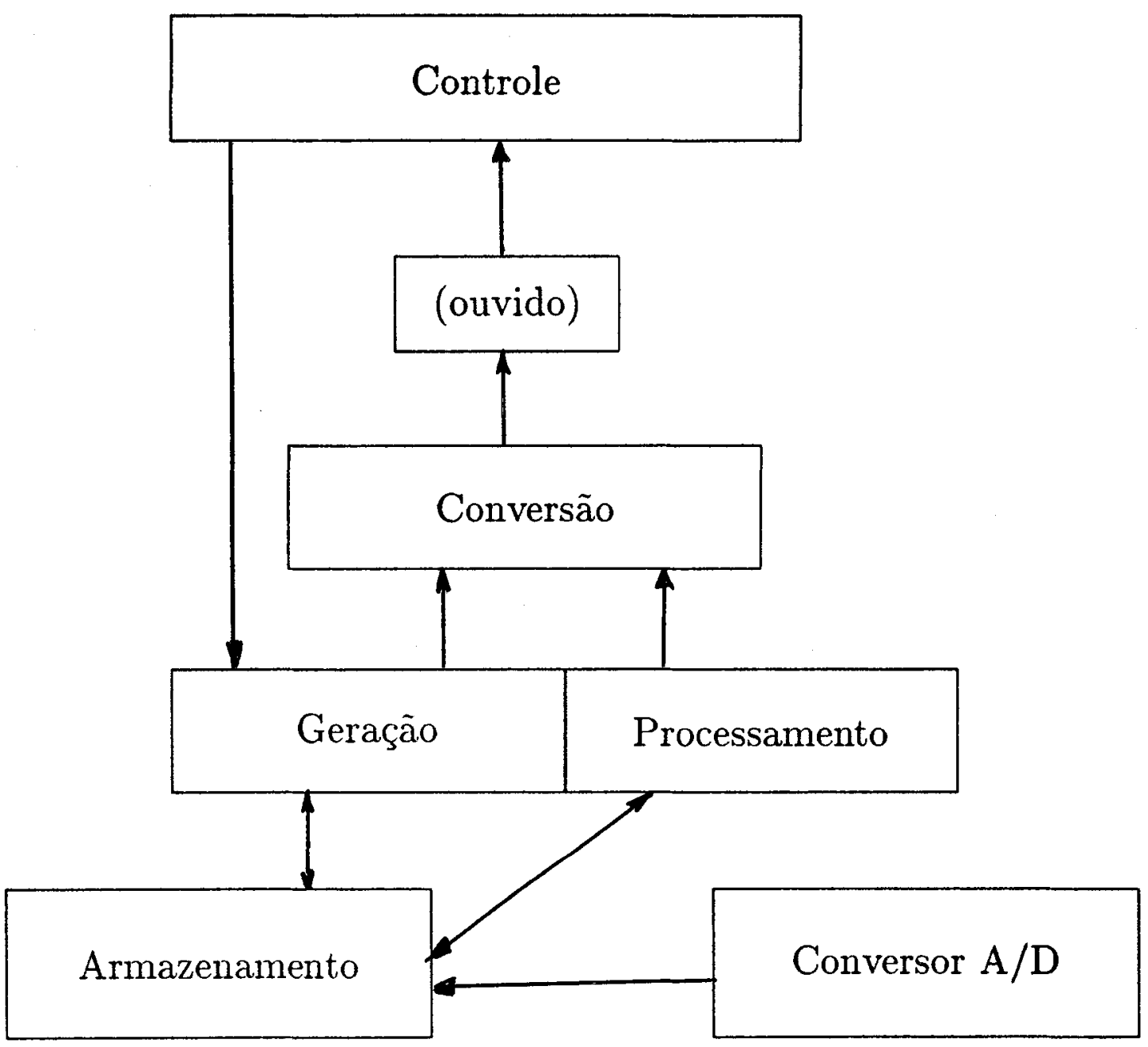

Figura 4.2 : Possiveis melhorias para um sistema da fig 4.1 [GOR 85]

A inclusão destes itens possibilitará amostragens de sinais a partir do conversor A/D. O sinal, devidamente processado, poderá ser reproduzido via conversão ou armazenado em memória de massa. 
O termo síntese, matematicamente falando, é a demonstração de proposições pela simples dedução das que já estão provadas [FER 86]. Em termos de música, isto assume diferentes conotações : em [CRO 86], síntese é fazer um elemento complexo a partir de um conjunto de elementos simples. A meta prioritária em música por computador é produzir uma sequência de valores, os quais devidamente convertidos em tensão analógica produzam sons de alta qualidade.

$\mathrm{Na}$ literatura chama-se de sintetizador ao aparelho eletrônico capaz de gerar tons musicais através de alguma técnica de síntese. Um sintetizador eletrônico e o computador digital são elementos extremamente versáteis, pois são capazes de realizar efeitos múltiplos, imitando ou mesmo criando novos sons. Existem dois tipos de sintetizadores : o analógico e o digital.

O sintetizador analógico cria sons através da manipulação direta dos sinais elétricos, enquanto o digital baseia-se essencialmente no uso em computadores que, através da manipulação numérica, gerará os sons. Na produção de sons por meio de um sintetizador, qualquer efeito pode ser produzido e controlado por meios eletrônicos, tanto para o digital como para o analógico. Entre os principais dispositivos utilizados para estes fins destacamos:

- osciladores

- filtros

- amplificadores

- geradores de envelopes

\subsubsection{Osciladores}

Em sintetizadores, as frequências podem variar de $0.03 \mathrm{~Hz}$ até frequências na ordem de $6 \mathrm{KHz}$ [RIG 85]. Os osciladores sâo os elementos responsáveis pela geração de sinais periódicos, que possibilitarão ao sintetizador manipular tais frequências. Em sistemas puramente analógicos, o oscilador é um dispositivo eletrônico capaz de gerar uma variação repetitiva no sinal elétrico de saída. Em sistemas digitais, os osciladores serão vistos como tabelas de valores numéricos, que serão armazenados em memória. $O$ controle sobre o dispositivo oscilador é tão rápido quanto desejarmos que ocorram as variações, o que determinará sua frequência.

Em geral, os sintetizadores utilizam vários tipos de osciladores (figura 4.3), sendo os mais importantes os seguintes :

- Forma de Onda Senoidal 
- Forma de Onda Triangular

- Forma de Onda Dente de Serra

- Forma de Onda Quadrada

- Forma de Onda Pulso ou Retangular

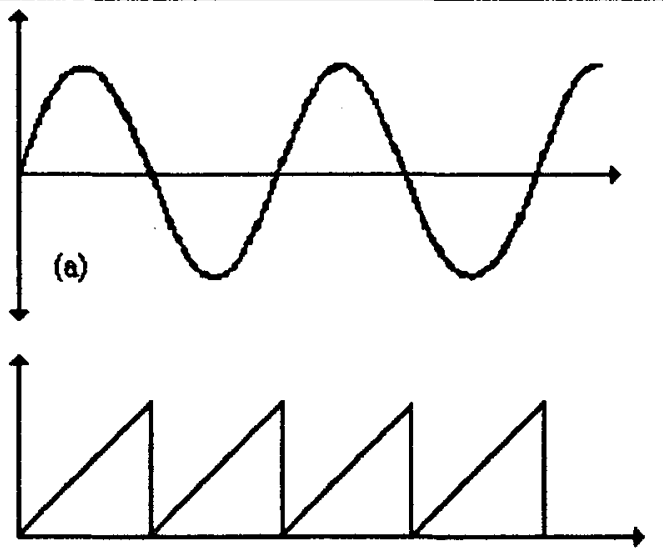

(c)
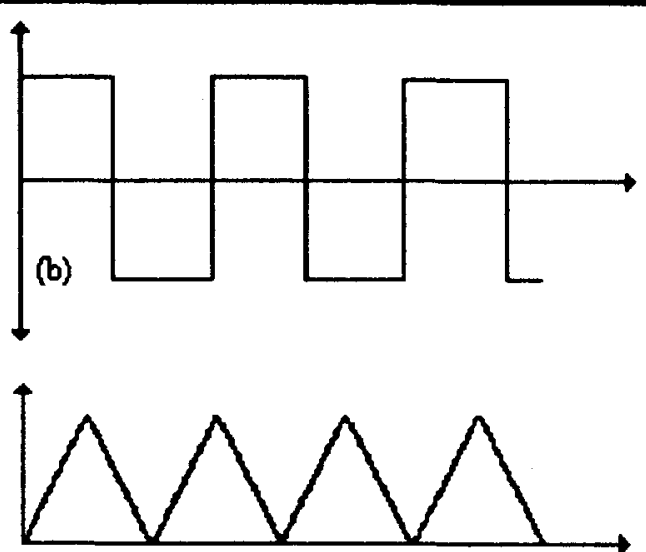

(d)

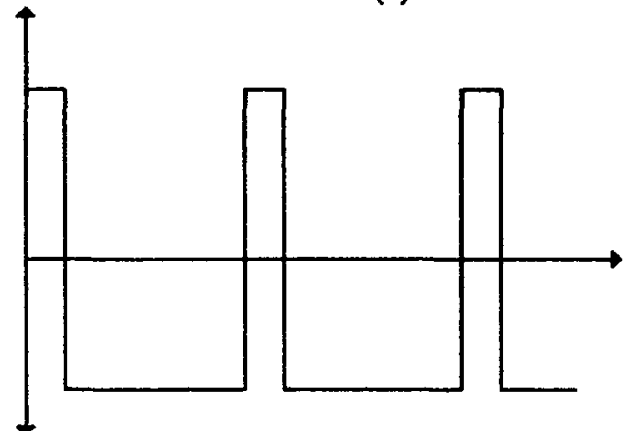

(e)

Figura 4.3: Gráfico de senoide(a), quadrada(b), dente de serra(c), triângular(d), pulso ou retangular $(e)$

As diferentes formas de onda causam uma ação direta no timbre de cada som. A classe mais simples de timbre é aquela representada pela senoide, a qual não contém nenhum sobretom (harmônico). Seu espectro de frequências (figura 4.4 a) é apenas composto de sua frequência fundamental e por esta razão produz um som uniforme e sem brilho.

A triangular possui muito poucos sobretons (figura 4.4 b), isto é, possui uma amplitude pequena no terceiro sobretom e uma minuscula no quinto. Como podemos esperar, o resultado sonoro será algo mais brilhante que o de um tom puro. $\mathrm{O}$ som produzido por 
este sinal é usualmente descrito como sendo algo parecido ao tom de uma flauta [MAS 87].

A dente de serra ou rampa é muito mais complexa (figura $4.4 \mathrm{~d}$ ) que as duas outras vistas, pois contém uma grande quantidade de sobretons, os quais decrescem proporcionalmente em amplitude. Isto é, seja $A$ é a amplitude da fundamental, $\frac{A}{2}$ será a amplitude do primeiro sobretom, e assim sucessivamente até que $\frac{A}{n}$ será a amplitude do n-ésimo+1 sobretom. Quanto major o número de sobretons, melhor será a representação dos 'cantos' na forma de onda gerada. Podemos esperar assim um resultado sonoro mais brilhante.

Já a onda quadrada é um caso particular de uma família que possui formas de onda conhecidas como pulso, onde metade do período ela será positiva e a outra negativa. Dada a existência de uma medida referencial, esta família pode gerar uma variedade muito grande de timbres, devido ao fato que podemos controlar a largura da parte positiva ou negativa. Podemos observar, na figura $4.4 \mathrm{c}$, o espectro de uma onda quadrada e a diferença para o espectro de uma possível onda pulso,figura $4.4 \mathrm{e}$.

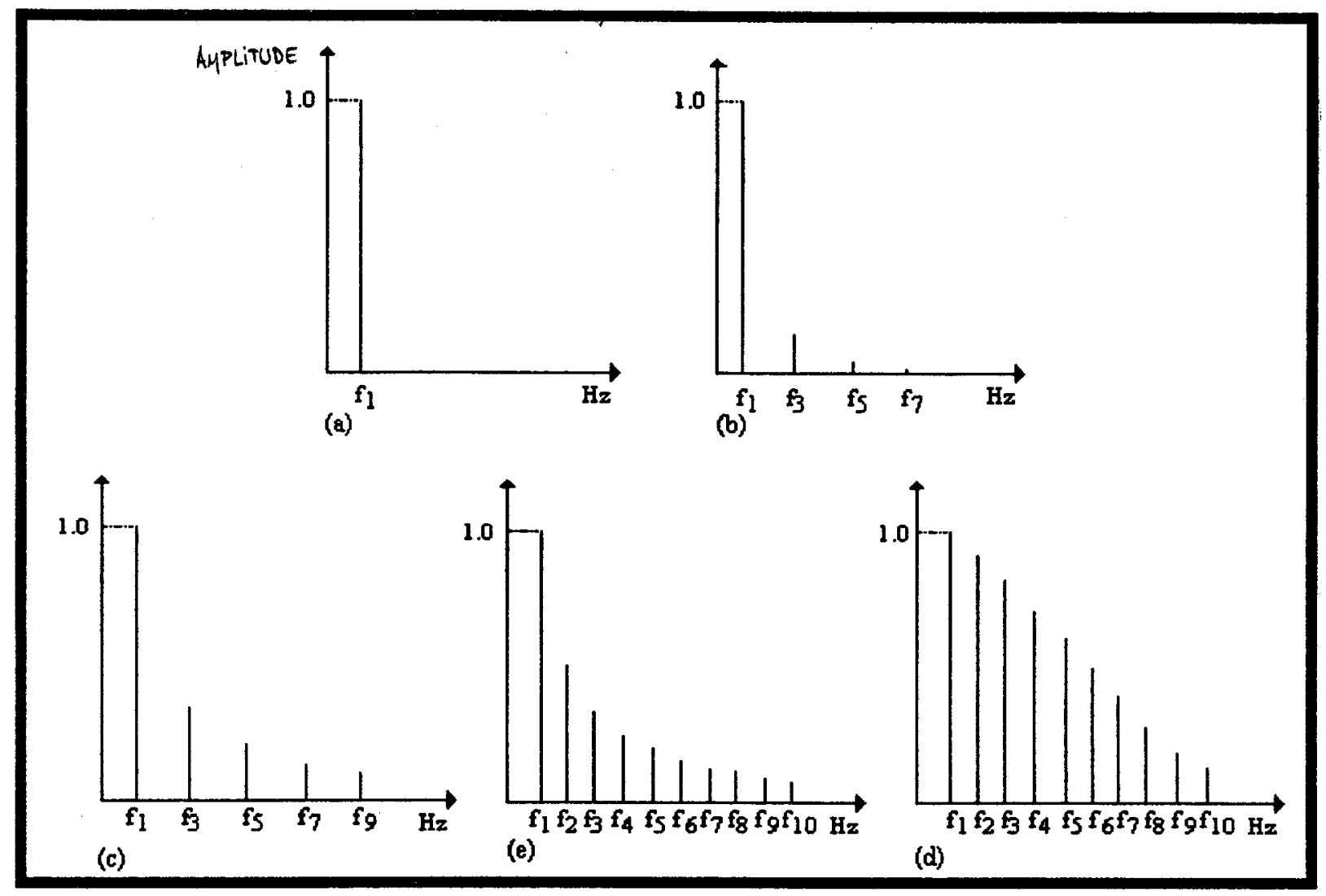

Figura 4.4: Os espectros de senoide(a), triangular(b), quadrada(c),dente de serra(d), pulso ou retangular(e) 


\subsubsection{Filtros}

A finalidade dos filtros, como o próprio nome já diz, é a de remover informações sonoras que não desejamos ouvir. Portanto, os filtros não adicionam nada ao som, ao contrário, eles apenas retiram. $\mathrm{O}$ principal controle em todos os filtros é o de atuar sobre determinada frequência, a qual é denominada frequência de corte e, dependendo do tipo de filtro utilizado, este atenuará a amplitude de todos os sobretons (abaixo, acima ou em torno da frequência de corte). Desta forma os filtros poderão influênciar no timbre de um determinado som.

Vários tipos de filtros existem para atenuar frequências indesejadas. Em geral, existem três mais comumente utilizados, que são :

- Passa Baixas

Um filtro passa-baixas é projetado de tal maneira a possibilitar que todas as frequências abaixo da frequência de corte passem através deste, sem qualquer interferência. As frequências maiores que a de corte são eliminadas. A figura 4.5 ilustra um filtro passa-baixas ideal.

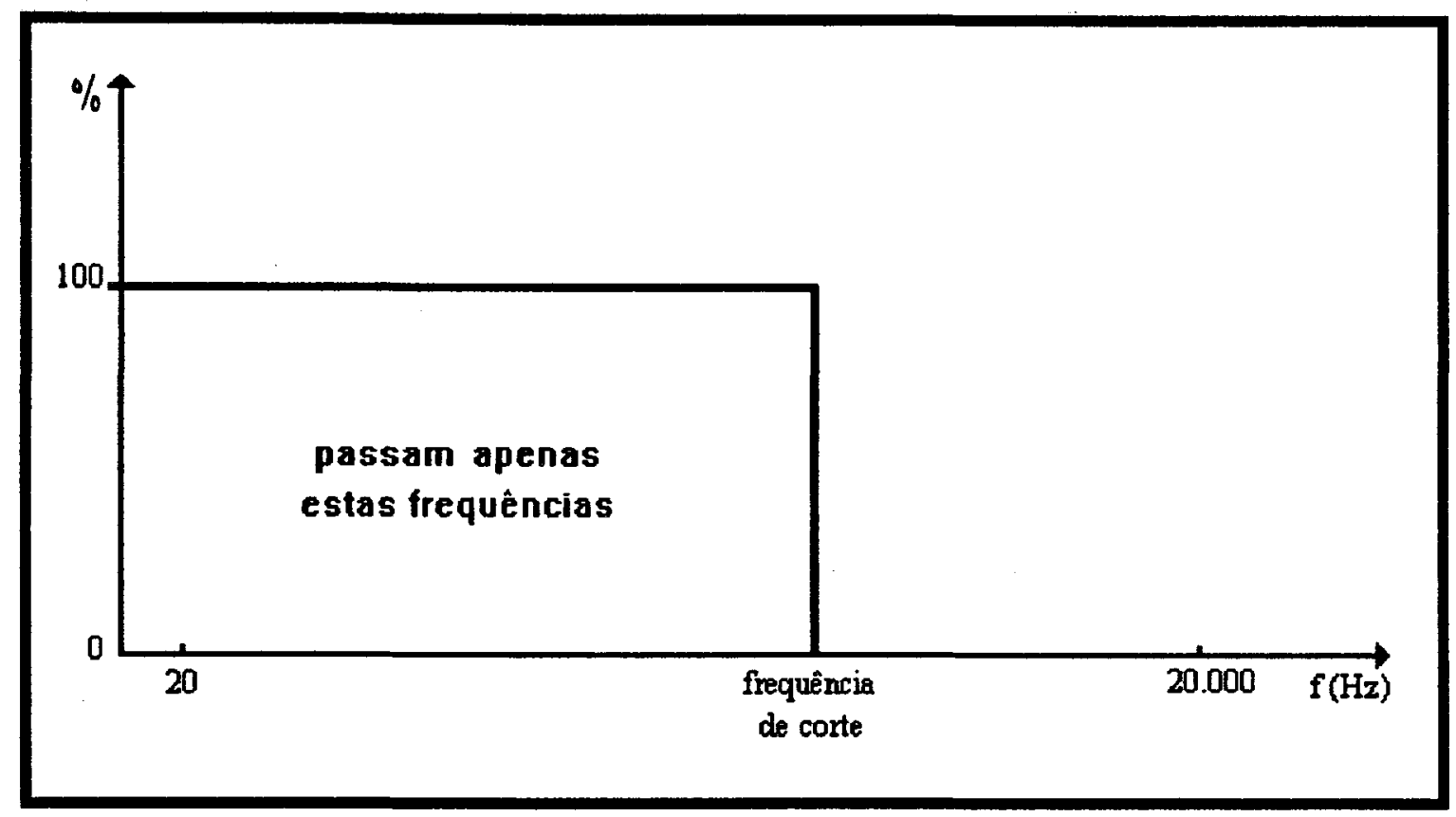

Figura 4.5: Um filtro passa-baixas para o caso ideal[RIG 85] 
Note que no filtro ideal, o filtro deixa passar $100 \%$ de todas as frequências abaixo do corte e $0 \%$ das frequências acima. Mas isto é o caso ideal, na realidade o que ocorre é ilustrado na figura 4.6.

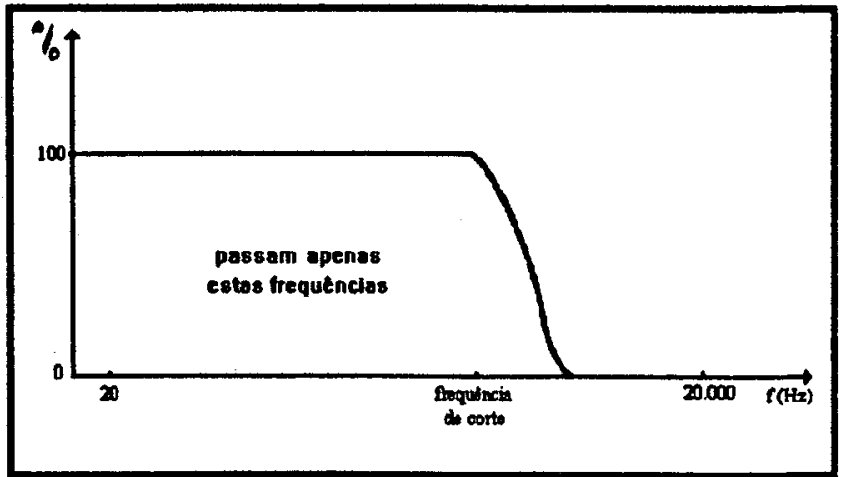

Figura 4.6: Um filtro passa-baixas para o caso real [RIG 85]

\section{- Passa Altas}

Um filtro passa-altas é projetado de tal maneira a possibilitar que todas as frequências acima da frequência de corte passem por através deste sem qualquer interferência, sendo que as frequências menores que a de corte são eliminadas. A figura 4.7 mostra um filtro passa altas real.
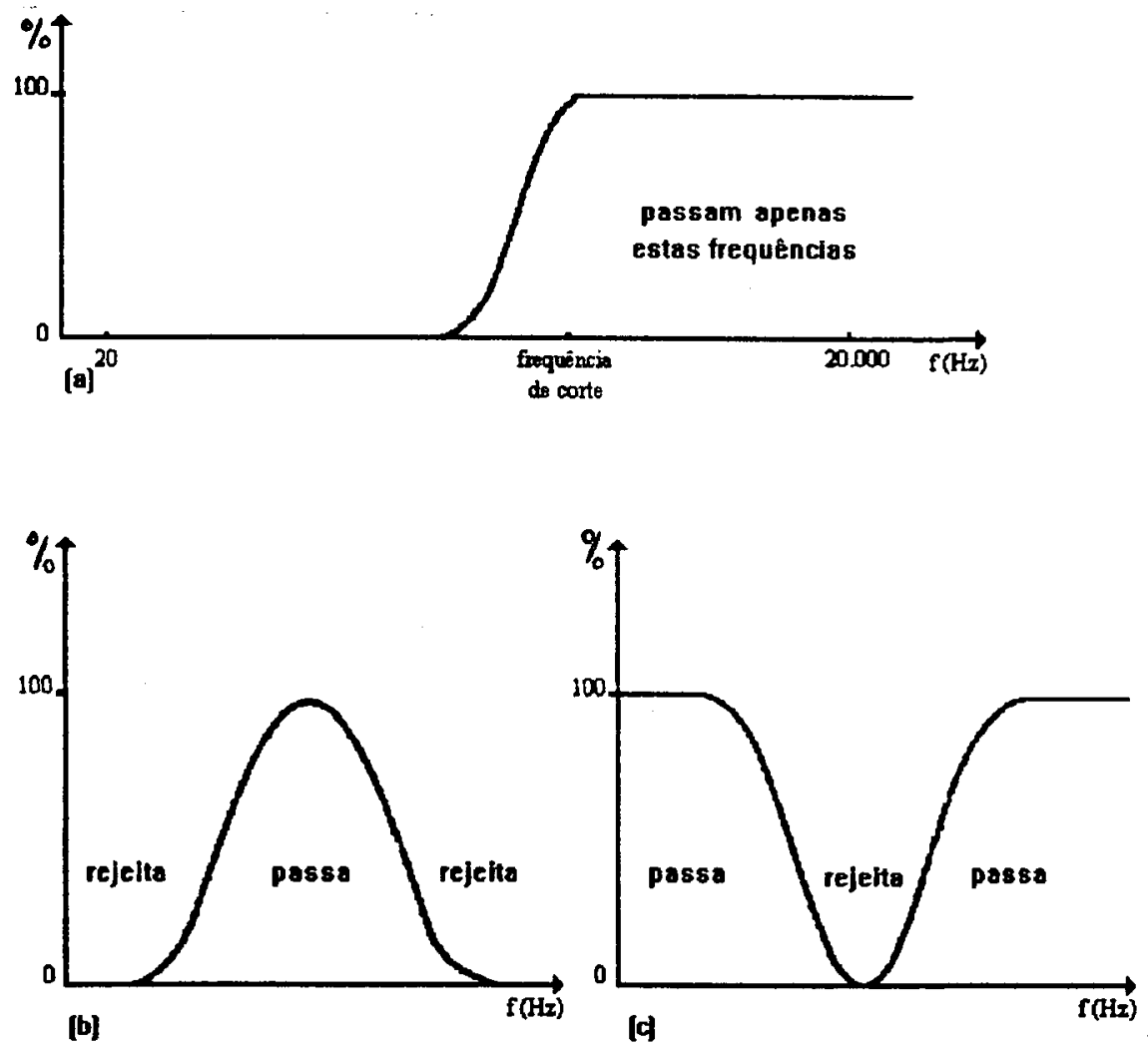

Figura 4.7: Um filtro passa-altas (a), filtro passa-banda (b), filtro rejeita-banda (c) [RIG 85] 
- Passa Banda

Um filtro passa-banda é projetado de tal maneira a possibilitar a eliminação de todas as componentes que ficarem fora de uma determinada faixa de frequências. Outro representante para esta classe de filtros é o rejeita-banda, o qual possui o efeito inverso. Estes dois tipos de filtros podem ser vistos na figura 4.7.

\subsubsection{Amplificadores}

Os amplificadores (figura 4.8) são projetados de modo a conservar as informações do sinal original, isto é, manterão a mesma relação entre os harmônicos existentes no som original. A alteração provocada será na amplitude onde ressaltará, em igual proporção, as amplitudes de todos os harmônicos pertencentes a um dado sinal.

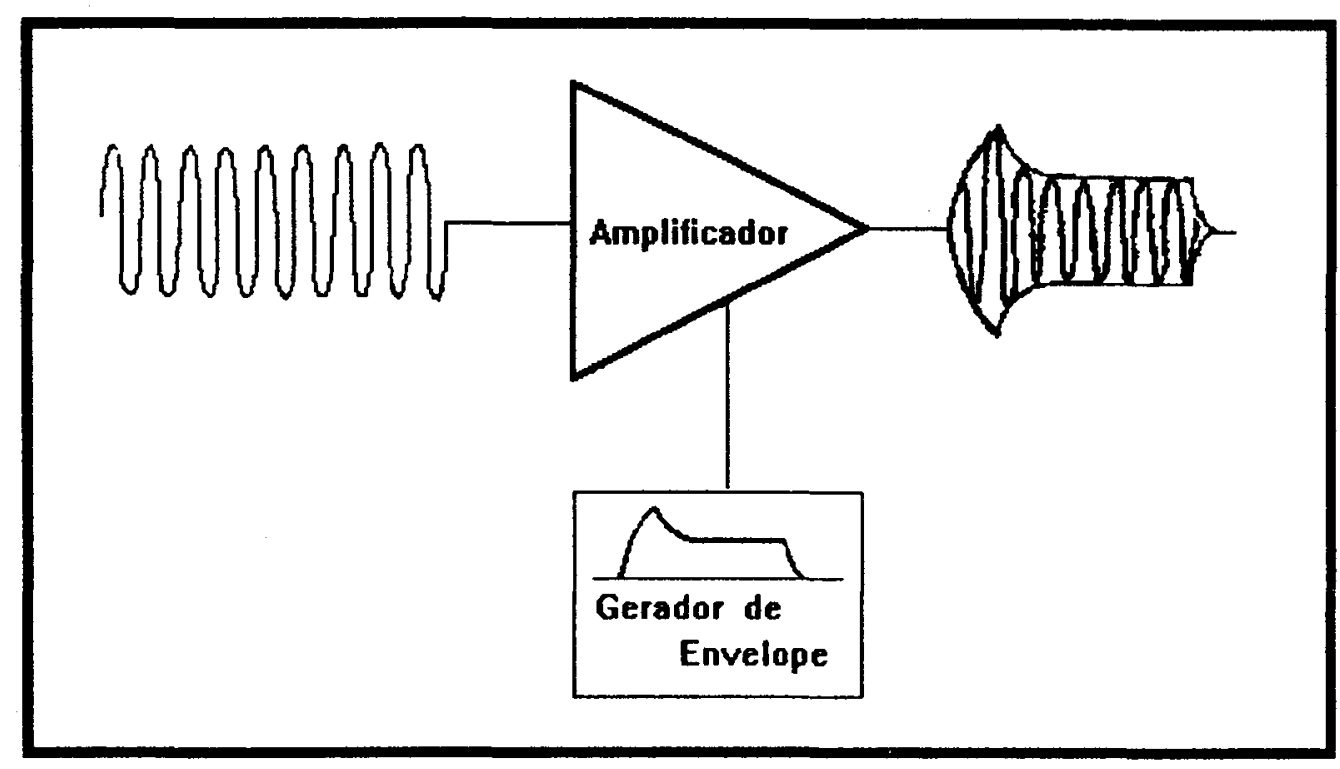

Figura 4.8: Um sinal amplificado e modelado por um envelope.[CRO 86]

\subsubsection{Geradores de Envelopes}

Os geradores de envelopes (figura 4.9) são projetados de modo a modelar as informaçôes do sinal gerado, possibilitando ao sintetizador uma melhor aproximação das 
características dos instrumentos quanto a seu timbre, de maneira a modelar tanto a amplitude como a frequência.
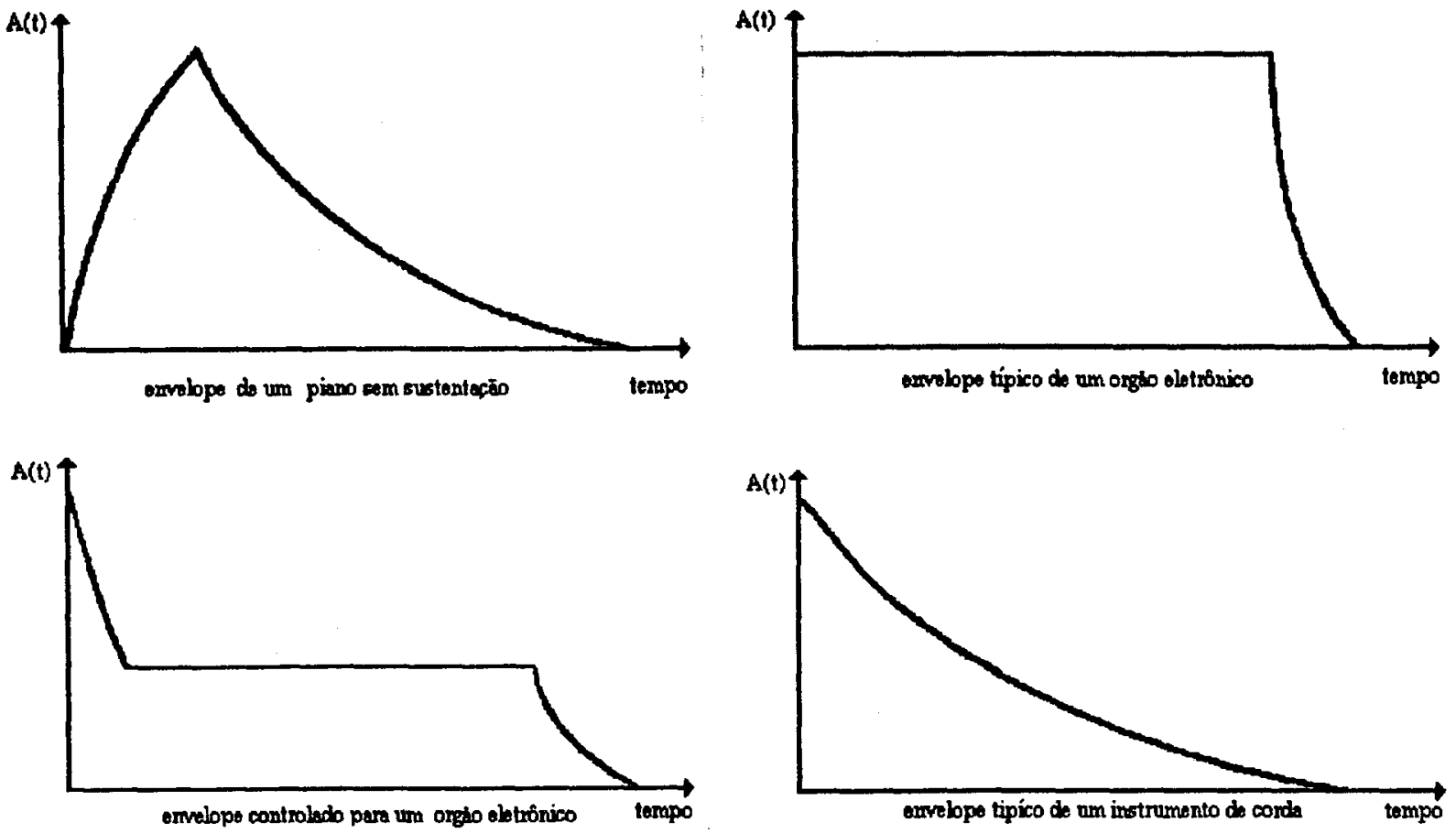

Figura 4.9: Vários geradores de envelopes usualmente utilizados em sintetizadores.

\subsection{Classes de Sínțese}

Podemos classificar as técnicas de síntese em : síntese direta, síntese baseada em análise e música concreta, dependendo da utilização e objetivo da síntese.

- Primeira Classe

Conhecida por sintese direta, esta classe possibilita ao compositor escrever um programa que produza uma amostra da forma de onda do som desejado. Uma variedade de linguagens para esta técnica foi proposta por Matheus [MAT 69], Howe [HOW 75], Vercoe [VER 71], [VER 86], Moore [MOO 90], Dannenberg [DAN 91]. Tais linguagens usualmente pretendem, a partir de uma série de módulos básicos, produzir uma forma de onda na saída. 
Conhecida por sintese baseada em análise. Nesta técnica, os tons de instrumentos originais são digitalizados e analisados. Com os resultados desta análise são obtidos parâmetros utilizados como dados para sintese [RIS 69], [MOO 77], [STA 88], [DEM 88].

\section{- Terceira Classe}

Conhecida como música concreta, esta técnica utiliza tons de instrumentos originais digitalizados. Estes serão ressintetizados com alterações em seus parâmetros para se obter novos tons, os quais podem não existir em instrumentos musicais convencionais [CRO 86], [MAS 87].

\subsection{Visão Geral sobre Síntese de Tons Musicais}

Imaginemos neste instante uma forma de onda muito simples para um tom. Por exemplo, imagine um tom produzido por um oscilador de áudio gerando uma determinada frequência. Podemos descrever este tom através de um modelo matemático, descrito pela equação 4.1, dada abaixo:

$$
F(n)= \begin{cases}A \operatorname{Sen}\left(w_{0} n T+\theta\right) & \text { para } n_{0}<n<n_{1} \\ 0 & \text { fora deste intervalo }\end{cases}
$$

onde $F(n)$ é o tom musical no tempo $n T, A$ é a amplitude, $\frac{n_{1}-n_{0}}{T}$ é o número total de amostras, $T$ é o intervalo entre duas amostras consecutivas, $w_{0}$ é a frequência fundamental e $\theta$ a fase.

Tal evento sonoro é extremamente marcante e talvez irritante para nós seres humanos, pois notamos que em tal evento não existirão mudanças, isto é, nenhuma variação no efeito sonoro ocorrerá com o passar do tempo, tornando o efeito monótono.

Quando pensamos ou ouvimos tons de instrumentos musicais reais, notamos que tais tons nunca permenecem fixos, estando sempre em constante variação no tempo. Mesmo que lentas sejam estas variações, nunca poderemos dizer que elas não ocorrem, ou mesmo ignorá-las num processo de síntese. Por exemplo, imagime um tom proveniente de um piano. A sensação inicial é que este começa forte e 'brilhante'e com o passar do tempo decai em intensidade até seu desaparecimento total. A forma de onda associada a este tom será muito mais complexa, comparada à forma de onda fixa proveniente do gerador de áudio. Tal complexidade está associada a características físicas dos instrumentos musicais. As variações percebidas em tons de instrumentos musicais reais não ocorrerão de maneira inteiramente aleatória, nem de modo inteiramente regular e sua sensação não será tão perturbadora e irritante quanto a de um tom perfeitamente regular. Associado a um tom complexo, poderiamos modelá-lo matematicamente através da equação 4.2 abaixo: 


$$
F(n)=\sum_{k=1}^{N} A_{k}(n) S e n\left(n T\left[k w_{0}+2 \pi F r_{k}(n)\right]\right)
$$

onde $F(n)$ é o sinal no tempo $\mathrm{nT}, \mathrm{N}$ é o número total de harmônicos necessários para a síntese, $A_{k}$ e $F r_{k}$ correspondem,respectivamente, às funções amplitude e frequência, n é o número da amostra , $\mathrm{T}$ é o tempo entre duas amostras consecutivas e $w_{0}$ é a frequência fundamental.

No princípio dos estudos sobre música acústica, detalhes importantes das características variantes no tempo de um tom musical eram desconhecidas [MOO 86]. Dada a ignorância sobre os parâmetros variantes no tempo, assumia- se necessariamente como parâmetros para a sintese apenas aqueles gerados pela análise de Fourier, ou seja, as funções amplitude e frequência. Consequentemente, problemas exitiam, já que a relação entre um tom forte e um fortíssimo não é apenas um aumento do volume, isto é, não conseguimos gerar um tom fortíssimo apenas girando o botão de volume do amplificador.

Por esta razão, técnicas de síntese destinadas a tons musicais devem estar munidas de uma completa análise dos parâmetros variantes no tempo, sendo tais informações extremamente relevantes para uma sintese de qualidade.

A forma exata dos parâmetros variantes no tempo pode ser gerada explicitamente pela virtuosidade do instrumentista em tempo real, ou pode ser determinada através de um conjunto de funções geradoras, que possibilitem alcançar os efeitos desejados, um dos quais indubitávelmente será a qualidade. A figura 4.10 ilustra esta noção.

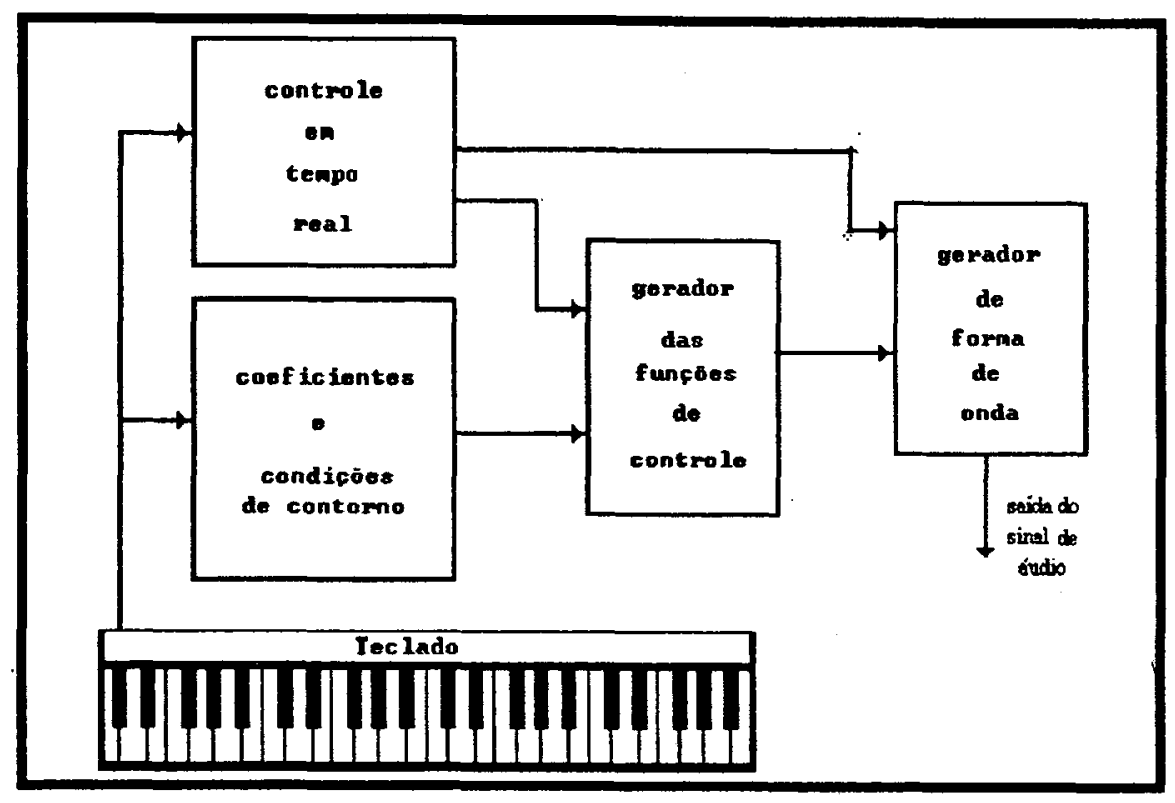

Figura 4.10: Diagrama esquemático do processo de sintese

Faremos a seguir uma descrição mais detalhada dos blocos que compõem tal diagrama. 


\section{- Controle em Tempo Real.}

Este é responsável pela geração de funções variantes no tempo, podendo gerar formas totalmente arbitrárias, pois dependerá substancialmente do instrumentista. Este controle em tempo real pode mudar os coeficientes das funções de controle, ou poderá influenciar diretamente na geração da forma de onda final.

\section{- Coeficientes e Condições de Contorno.}

Estes são responsáveis pela produção de comandos, os quais especificam a maneira de geração para as funções de controle. Em geral, estes comandos formam um conjunto de elementos invariantes no tempo, pois fornecerão os coeficientes e as condiçóes iniciais de contorno, podendo frequentemente serem armazenados em forma de uma tabela de valores.

- Gerador das Funções de Controle.

Este é responsável pela produção de um conjunto de funções variantes no tempo, cuja saída será continuamente controlada pelas propriedades físicas da forma de onda do instrumento musical. Em geral, estas funções são mais simples e variam mais lentamente que a forma de onda em questão, podendo frequentemente serem produzidas por rotinas computacionais.

- Gerador de forma de onda.

Este é responsável pela produção do sinal sonoro, podendo este ser um módulo do sintetizador ou mesmo uma rotina computacional executada num micro-computador, o qual executará fielmente aos comandos do instrumentista e aqueles provenientes das funções de controle.

A figura 4.11 mostra um exemplo específico de um sintetizador com controle hierárquico. Podemos ver que o gerador de forma de onda é realizado analogicamente por um VCO acoplado a um VCA. As funçôes de controle são aqui representadas por um oscilador de baixa frequência, LFO, e dois geradores de envelopes. A escolha do tom desejado é dada pelo bloco condições de contorno, o qual enviará informações para as funções de controle de um instrumento específico. O controle de tempo real é dado pelo teclado e sua saída é enviada para o VCO, onde a frequência fundamental será gerada. Em paralelo a esta 
informação o bloco condições de contorno identifica o instrumento em questão.

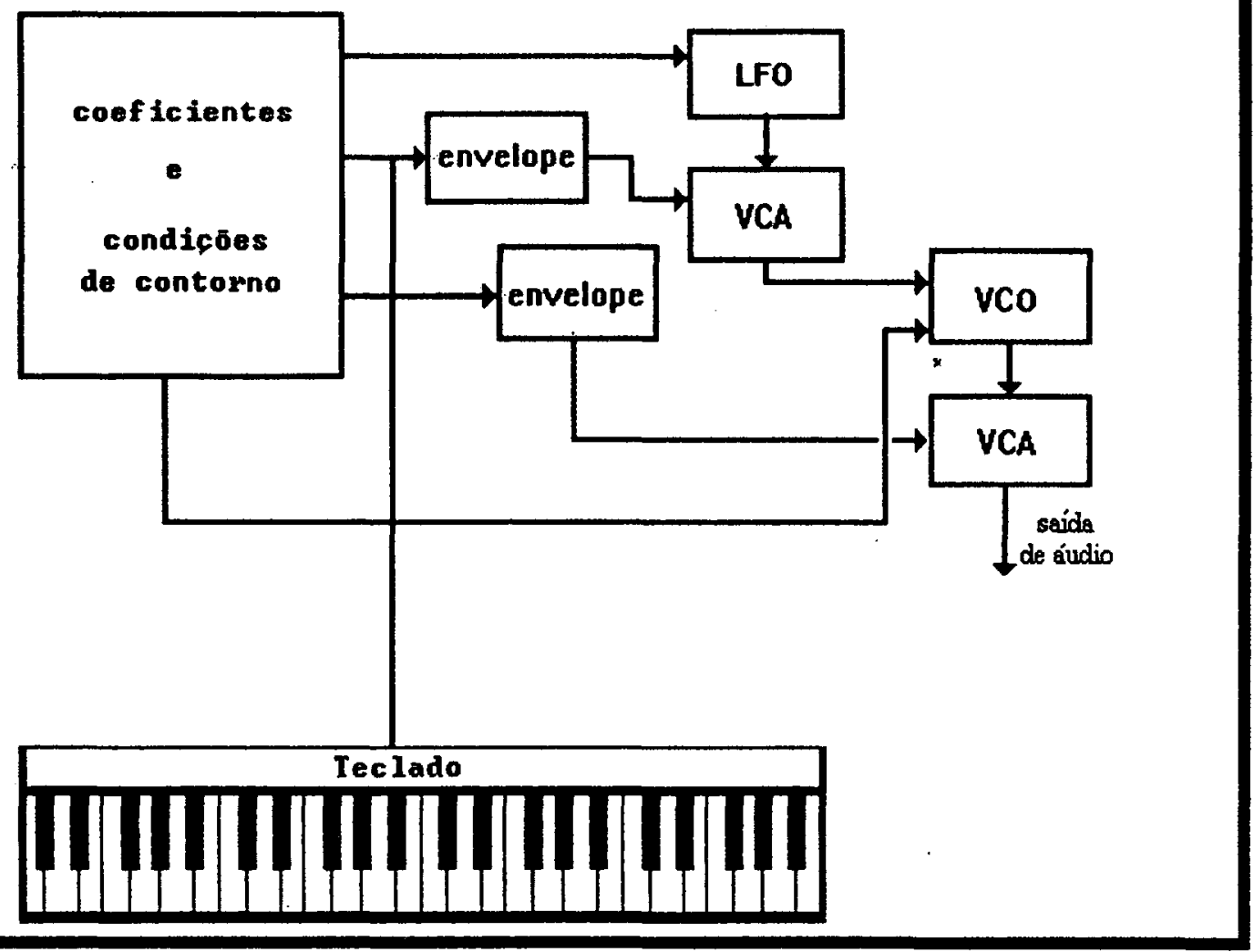

Figura 4.11 : Representação em blocos de um sintetizador analógico por controle hierárquico

\subsection{Métodos de Síntese}

Nesta seção, discutiremos características básicas de alguns métodos muito utilizados para a geração de tons musicais. Dentre os vários métodos existentes, destacamos :

- Sintese Aditiva

- Síntese Subtrativa

- Síntese por Frequência Modulada

- Síntese por Distorção de Fase 


\subsubsection{Sintese Aditiva}

A principal característica de síntese aditiva, em tons musicais, é a representação do sinal através de um conjunto de funções ortogonais. Em geral, um tom musical, $F(\bullet)$, é aproximado pela equação :

$$
F(k) \cong \sum_{i=0}^{N-1} A_{i}(k) \psi_{i}\left(\theta_{i}(k)\right)
$$

onde $\Psi$ representa o conjunto de funçôes ortogonais (funções básicas), $A_{i}(\bullet)$ representa a função amplitude (envelope) e $\theta_{i}(\bullet)$ representa a função fase. A função frequência é determinada através da derivada de $\theta_{i}(\bullet)$ no tempo (ver seção 3.6, capítulo 3 ).

Como podemos observar, na equação 4.3 os parâmetros necessários para a síntese são obtidos a partir de um tom previamente gravado. A análise deste tom fornecerá os parâmetros para o cálculo da equação 4.3. A figura 4.12 ilustra a representação de um tom musical.

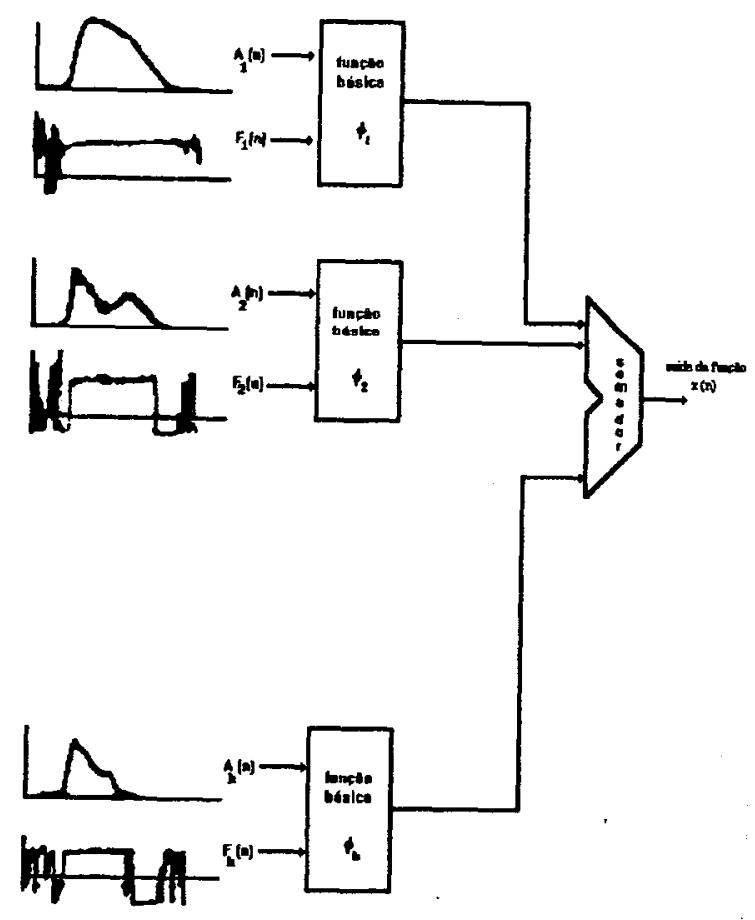

Figura 4.12 : Representação de um tom musical através de somas 
A análise não caracteriza um problema de processamento em tempo real, mas a síntese deverá ocorrer em tempo real. Em [WAW 89] aborda-se meios para contornar alguns problemas encontrados em sintese de tons musicais em tempo real.

Embora tenhamos conseguido encontrar os parâmetros necessários à síntese, não podemos dizer que o problema está solucionado. O grande problema encontrado é a enorme quantidade de dados. Por exemplo, suponhamos que nossa amostragem do sinal seja feita a uma taxa de aquisição de $40 \mathrm{Khz}$. Neste caso necessitamos armazenar 40 mil valores por segundo. Pela equação 4.3 podemos ter uma idéia do "tamanho" das funções amplitude e frequência que são de mesma ordem de $F(\bullet)$, que é a amostra do tom. Estas funções são necessárias para cada harmônico.

O esforço computacional baseado em aplicações que utilizam este método de síntese provem de duas origens :

- 1. A geração das funções amplitude e frequência para cada harmônico

- 2. A multiplicação das funçôes amplitude com as funções básicas

Teoricamente, qualquer conjunto de funções que satisfaça as condições de ortogonalidade, (capítulo 3, seção 3.6), pode ser utilizado para geração de tons musicais, baseado em síntese aditiva. A escolha deste conjunto está intimamente ligada aos objetivos propostos pela síntese. Em nosso trabalho, desejamos síntetizar tons musicais em tempo real. Para isso, a redução do número de funções básicas será uma condição necessária. A figura 4.13 ilustra um diagrama minimo para a síntese aditiva.

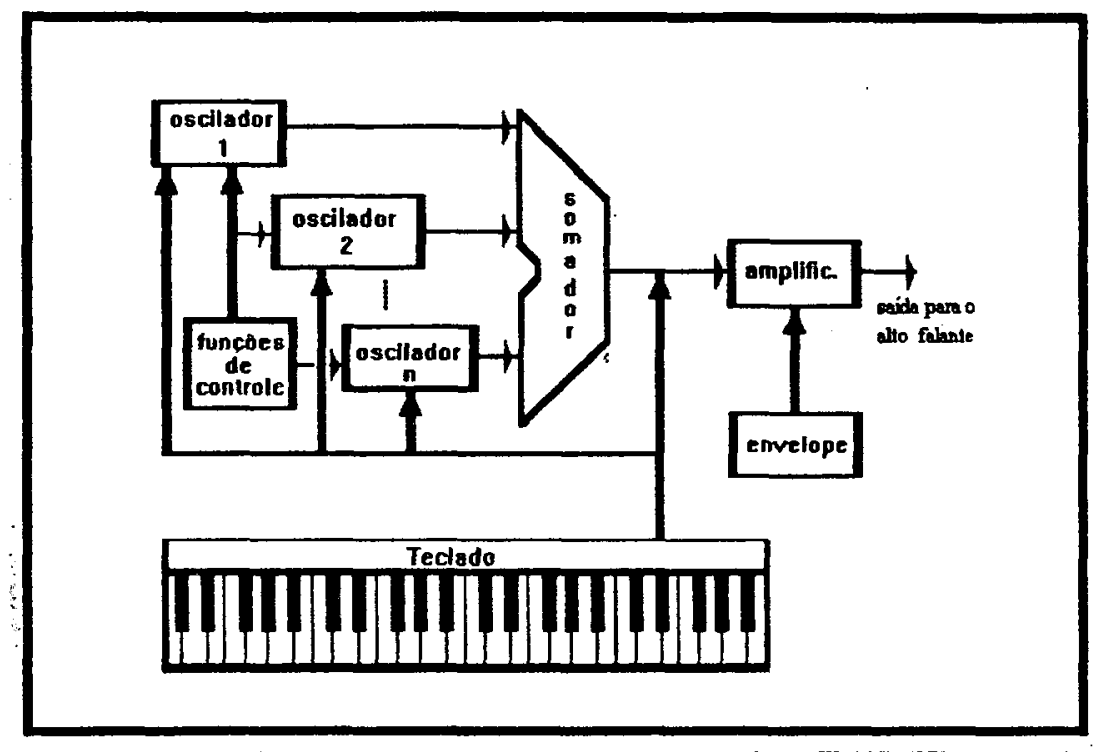

Figura 4.13: Representação em blocos para um sintetizador baseado em sintese aditiva 
Embora seja bastante natural a escolha de funçōes básicas senoidais, deve-se levar em conta o esforço computacional exigido por este conjunto. Dependendo do tom a ser gerado, serão necessárias mais de 30 senoides para minimizar as diferenças perceptiveis entre o tom sintetizado e o natural [GRE 77]. Várias pesquisas utilizando funções básicas não senoidais tem sido realizadas. As funções Walsh [AHM 75] têm apresentado muitas vantagens em relação às funções senoidais, devido à facilidade de geração destas funções básicas em computadores digitais. Infelizmente, são necessárias mais de 16 funções Walsh para minimizar as diferenças perceptuais [HUT 75].

No capítulo 5, a seguir, apresentaremos a transformada Karhunen-Lòeve com o objetivo de reduzir as funções básicas necessárias.

\subsubsection{Síntese Subtrativa}

Como o próprio nome já diz, sintese subtrativa é um sistema ao qual nós iremos remover componentes do som que não desejamos ouvir. A figura 4.14 ilustra este procedimento. Isto é obtido por meio de filtragens, as quais suprimirão componentes de um sinal de audio complexo, que contenha muitos sobretons (harmônicos).

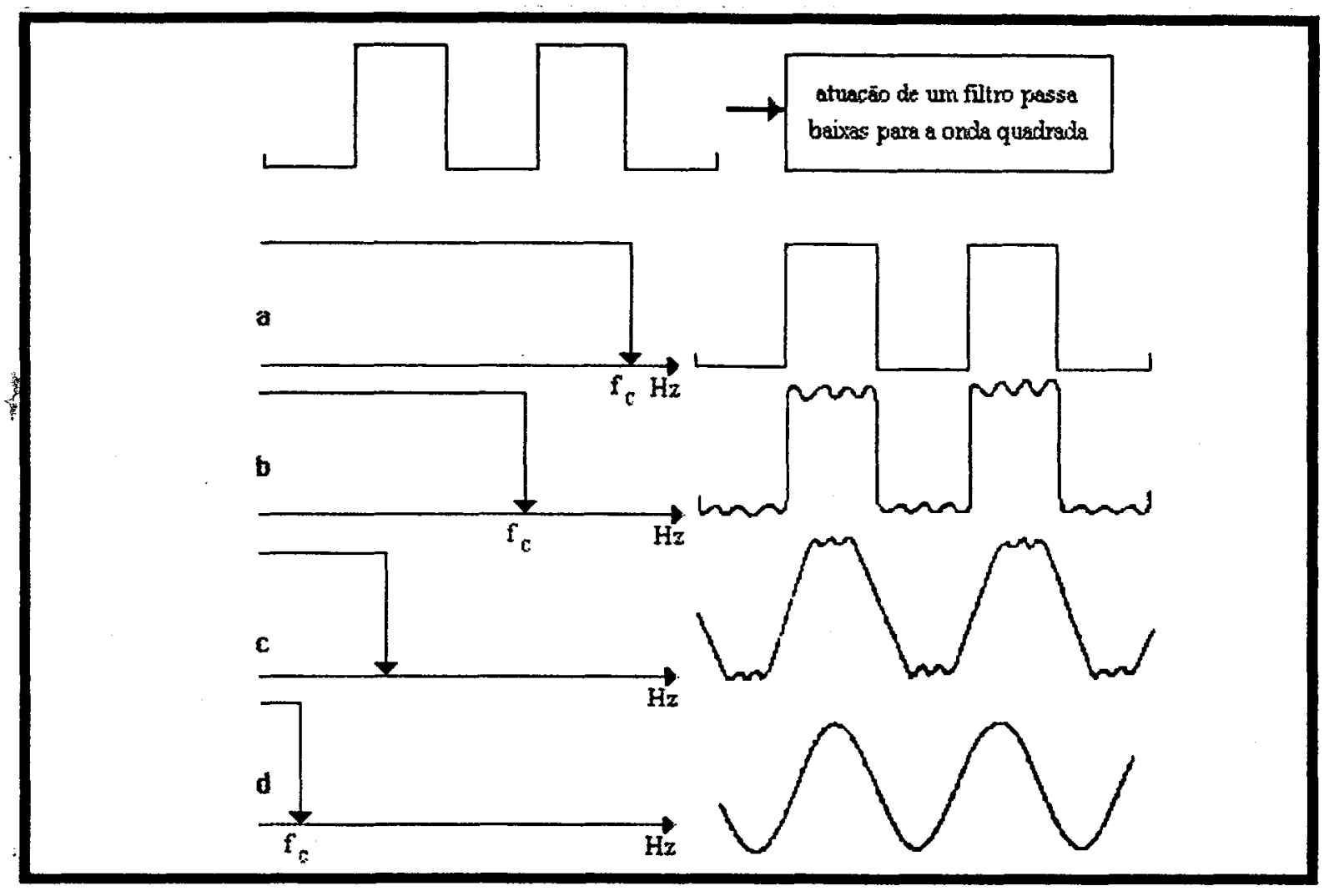

Figura 4.14 : eliminação de harmônicos em síntese subtrativa [RIG 85] 
Pela manipulação dos filtros, figura 4.15, somos capazes de remover determinados sobretons (harmônicos); aqueles que restarem comporão nosso som básico, o qual poderemos modelar numa variedade de outras maneiras com a utilização de envelopes específicos.

Muitos instrumentos musicais, e a própria voz humana, podem ser modelados como uma câmara ressonante, pela existência de excitação de uma forma de onda acústica com certas propriedades espectrais e temporais. No caso da voz humana, a câmara ressonante é formada pelo conjunto garganta, boca e cavidade nasal, e a excitação é qualquer série de pulsos da glótis (para vogais) ou rúdos (para fricativos). O modelo assume que a excitação possua um espectro relativamente rico e que $o$ ato ressonador aja como um filtro sobre a excitação, alterando este espectro, isto é atenuando ou removendo por completo certas frequências e reforçando ou deixando passar outras.

A implementação é então, simplesmente um filtro linear devidamente acoplado com uma fonte de ruído e uma fonte de pulsos, como podemos ver na figura 4.15.

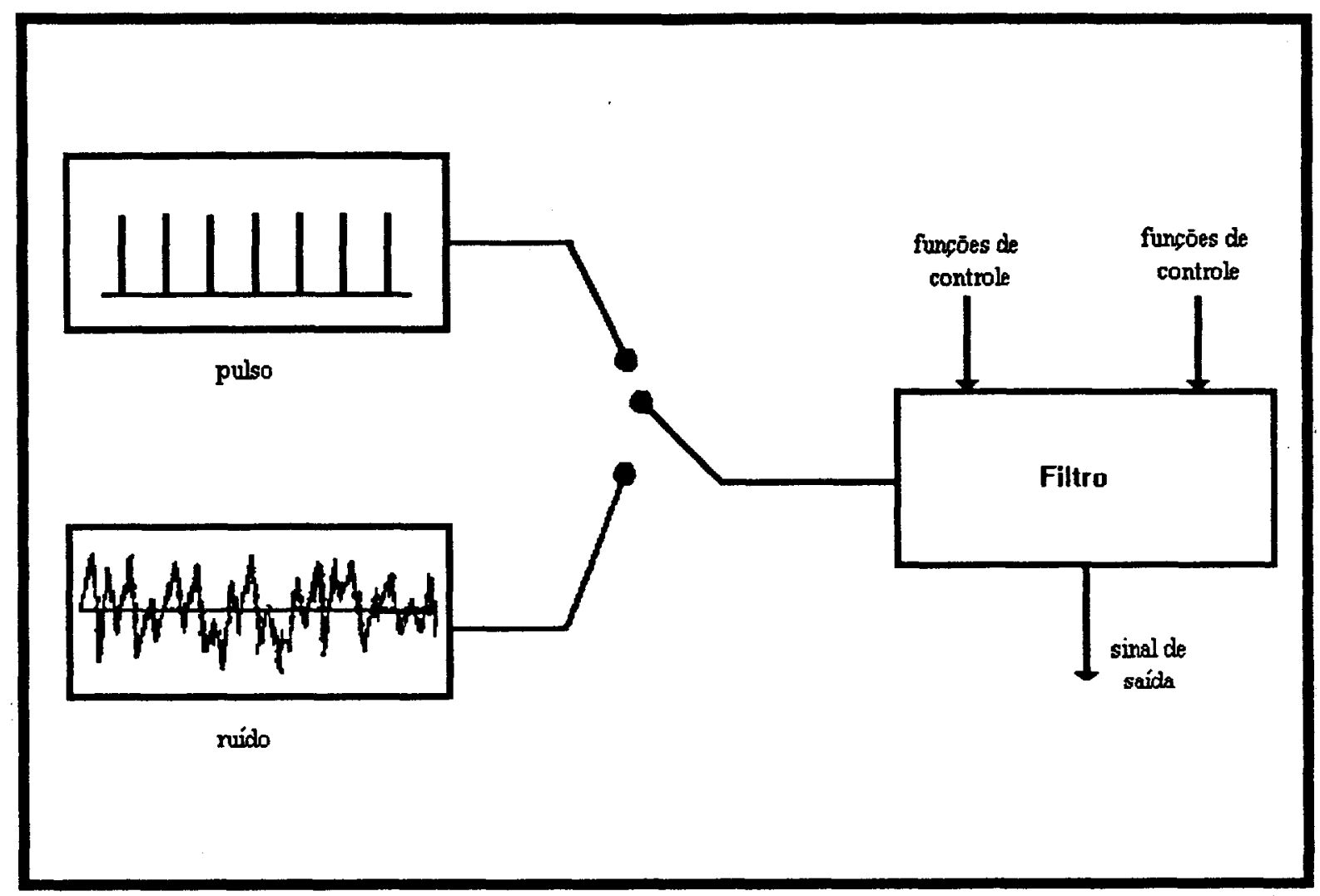

Figura 4.15: Representa um modelo para a sintese subtrativa [GOR 85]

Geralmente, utilizam-se quatro tipos de formas de onda em síntese subtrativa : a triângular, a dente de serra, a quadrada e a pulso.

As diferentes formas de ondas provocarão uma forte influência no timbre. As mais simples classes de timbres são aquelas obtidas pelas ondas senoidais. Estas não contém nenhum sobretom, possuindo apenas a frequência fundamental, produzindo um som suave, 
mas pobre em sonoridade. Esta função servirá para obtermos alguns efeitos no som gerado por outras ondas. Como exemplo : o efeito de vibrato, que causa uma variação de aproximadamente $7 \mathrm{~Hz}$ na frequência fundamental do tom musical.

A onda quadrada, a pulso, a triângular e dente de serra, são ricas em harmônicos, proprocionando a atuação dos filtros para seleção das frequências.

A figura 4.16 representa um diagrama em blocos de um sintetizador, baseado em sintese subtrativa.

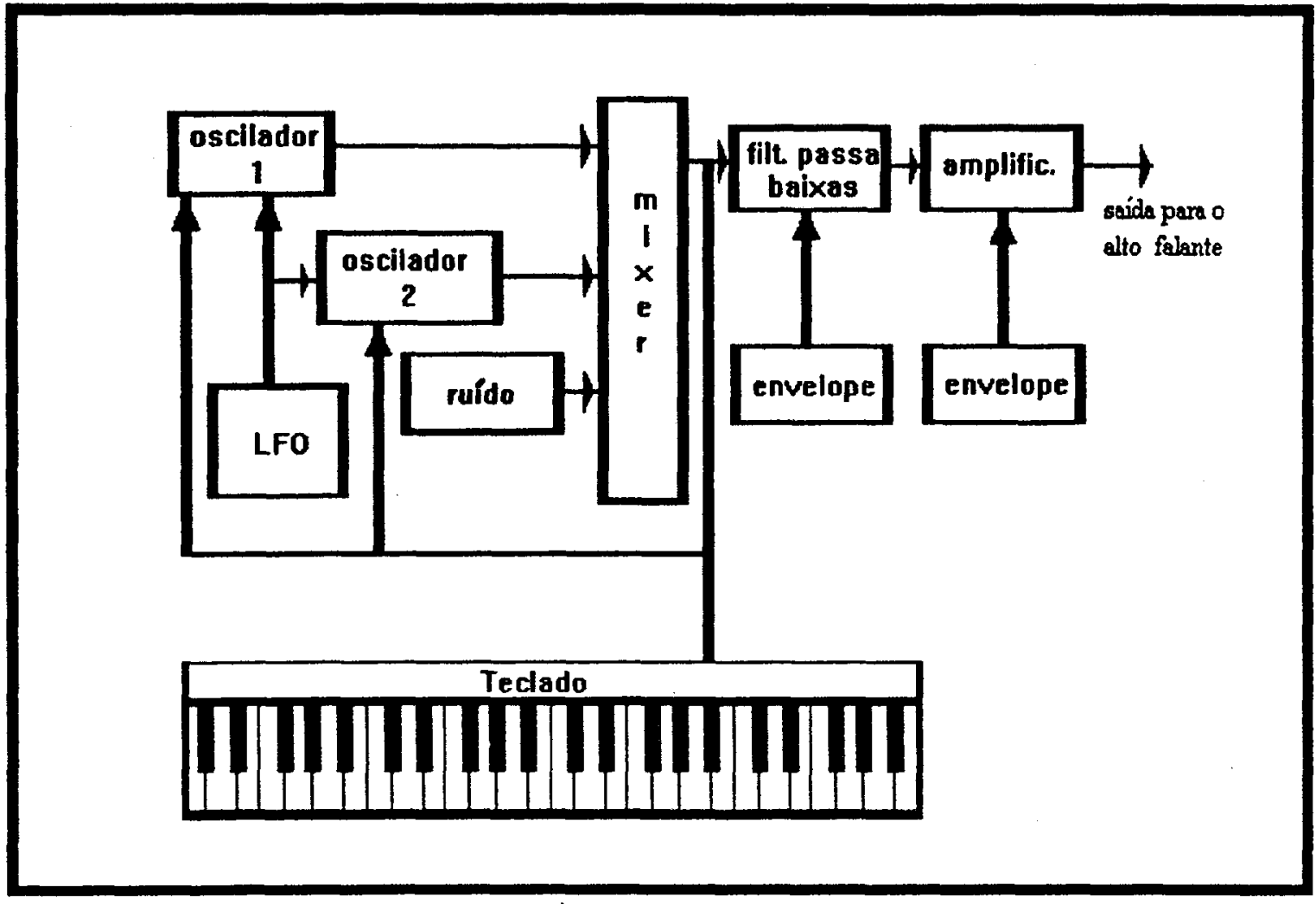

Figura 4.16: Mlustra um Diagrama mínimo para síntese subtrativa [MOR 89]

\subsubsection{Síntese por Frequência Modulada}

Muitos sistemas de comunicação empregam ondas de alta frequência como portadoras de sinais contendo a informação. O exemplo mais simples são as emissoras de rádio, mais precisamente as transmissoras por frequência modulada.

A técnica de frequência modulada (FM) [CHO 73], [MOO 76], é caracterizada pela variação da frequência de uma onda, portadora, e pela variação da amplitude de uma outra onda, moduladora. A portadora geralmente é uma frequência fixa, onde suas 
alterações em frequência ocorrem durante a modulação. A modulação é entendida como o processo de impressão de um sinal em uma onda portadora. A figura 4.17 ilustra o processo de modulação.

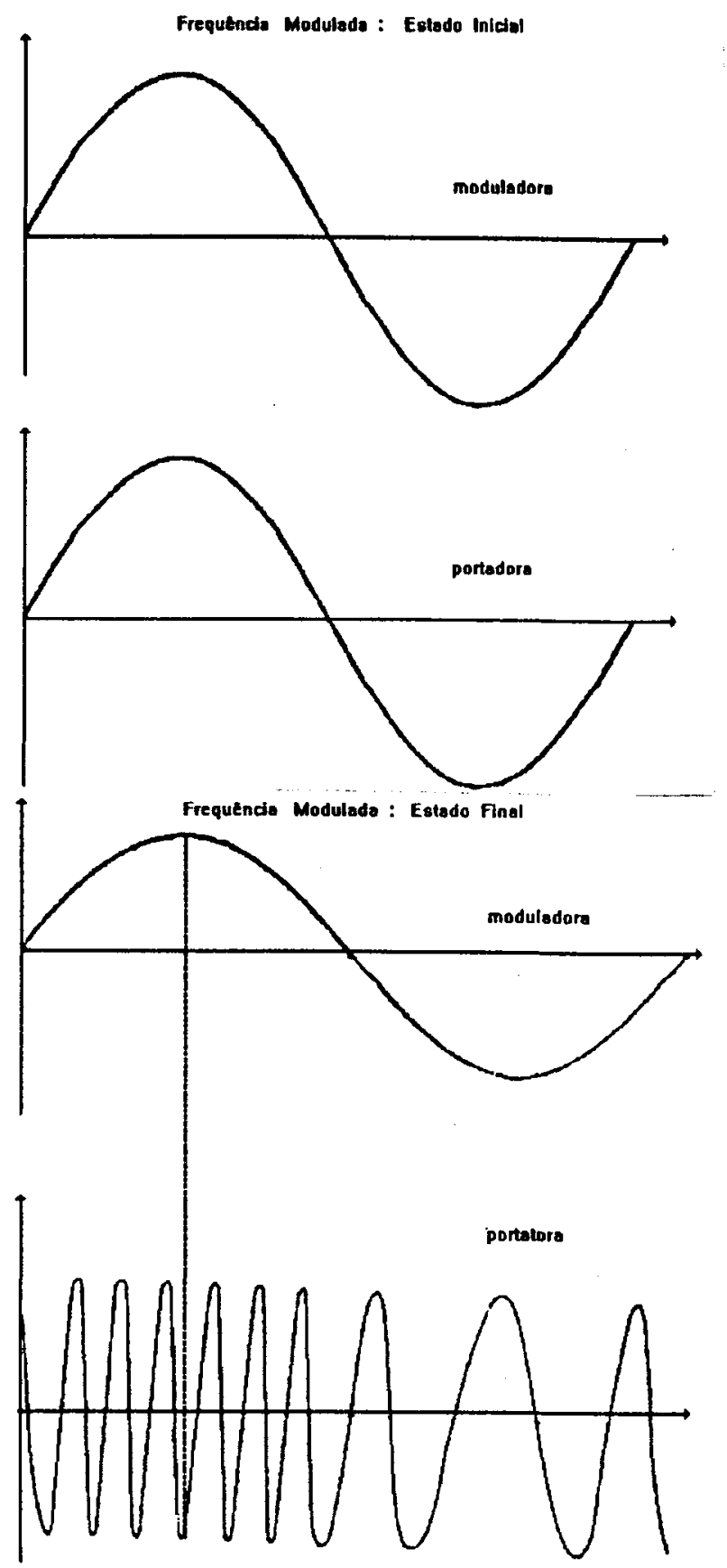

Figura 4.17: Representa o processo de frequência modulada, para duas funções senoidais

A aplicação desta técnica em sintese de tons musicais é baseada na utilização de operadores digitais. Os operadores digitais contém internamente um oscilador, um amplificador e um gerador de envelope (todos digitais), os quais sempre fornecerão, como saída, uma forma de onda. Todo operador pode ser configurado como um modulador ou 
uma portadora. A figura 4.18 ilustra um diagrama mínimo de um sintetizador baseado em síntese por frequência modulada.

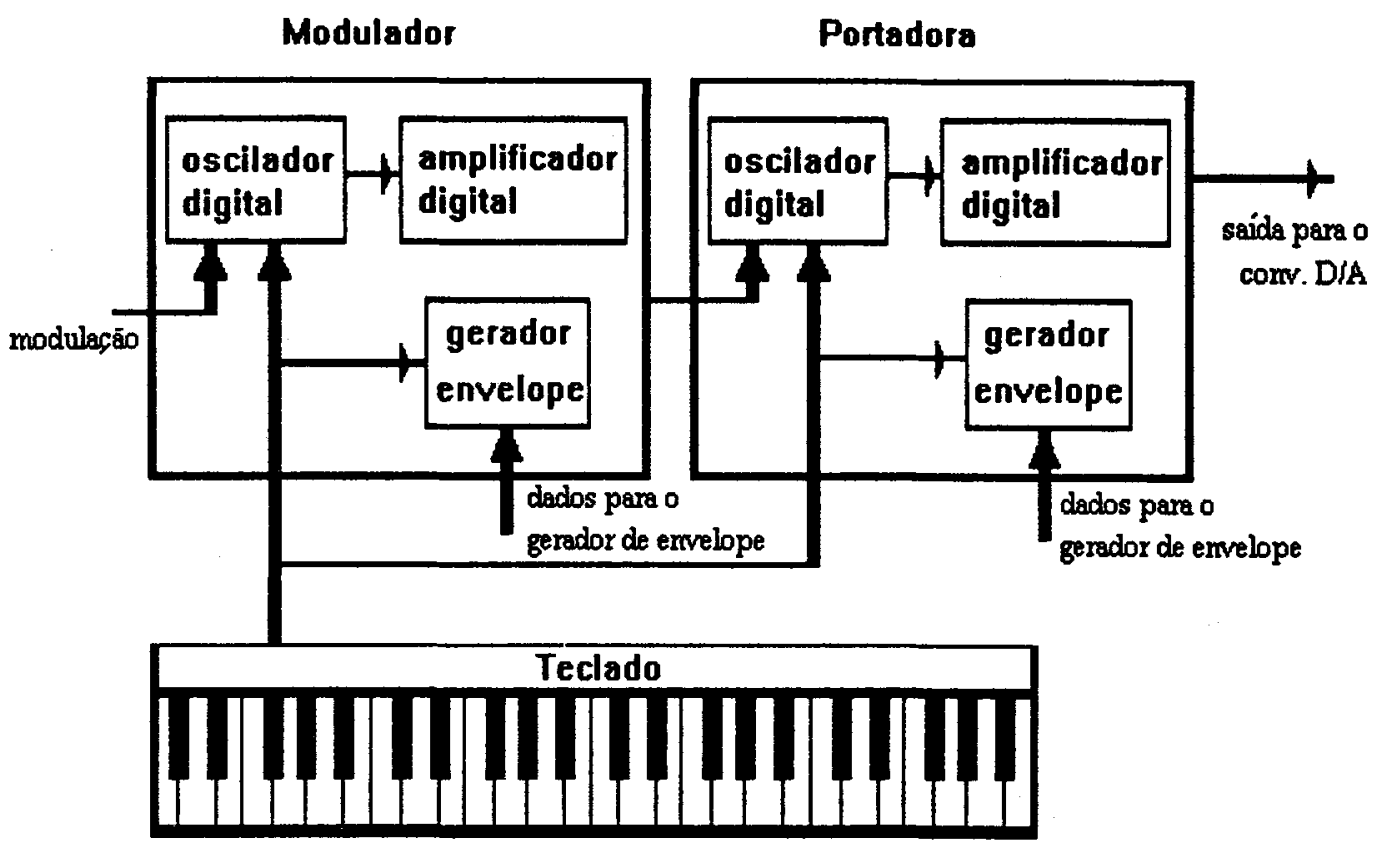

Figura 4.18: Representa um diagrama mínimo para sintese por frequência modulada. $O$ operador esquerdo nesta representação, atuará como o elemento modulador.

Consequentemente o operador direito atuará como a portadora

Em sintese por frequência modulada, as rápidas variações na frequência são utilizadas para a geração de uma grande quantidade de sobretons (harmônicos). A qualidade final (timbre) do tom, será especificada pelas frequências e amplitudes das ondas geradas pelo modulador e a portadora.

A maioria dos sintetizadores, baseados em frequência modulada oferece de 4 a 6 operadores por tom musical. Cada um destes poderá atuar como modulador ou portadora, sendo que isto dependerá da configuração ou do algoritmo a que estes operadores serão 
impostos. Os algoritmos são as possiveis formas de interligarmos os operadores, a fim de obtermos a representação de um dado instrumento. A figura 4.19 ilustra um algoritmo para os operadores em síntese por frequência modulada.

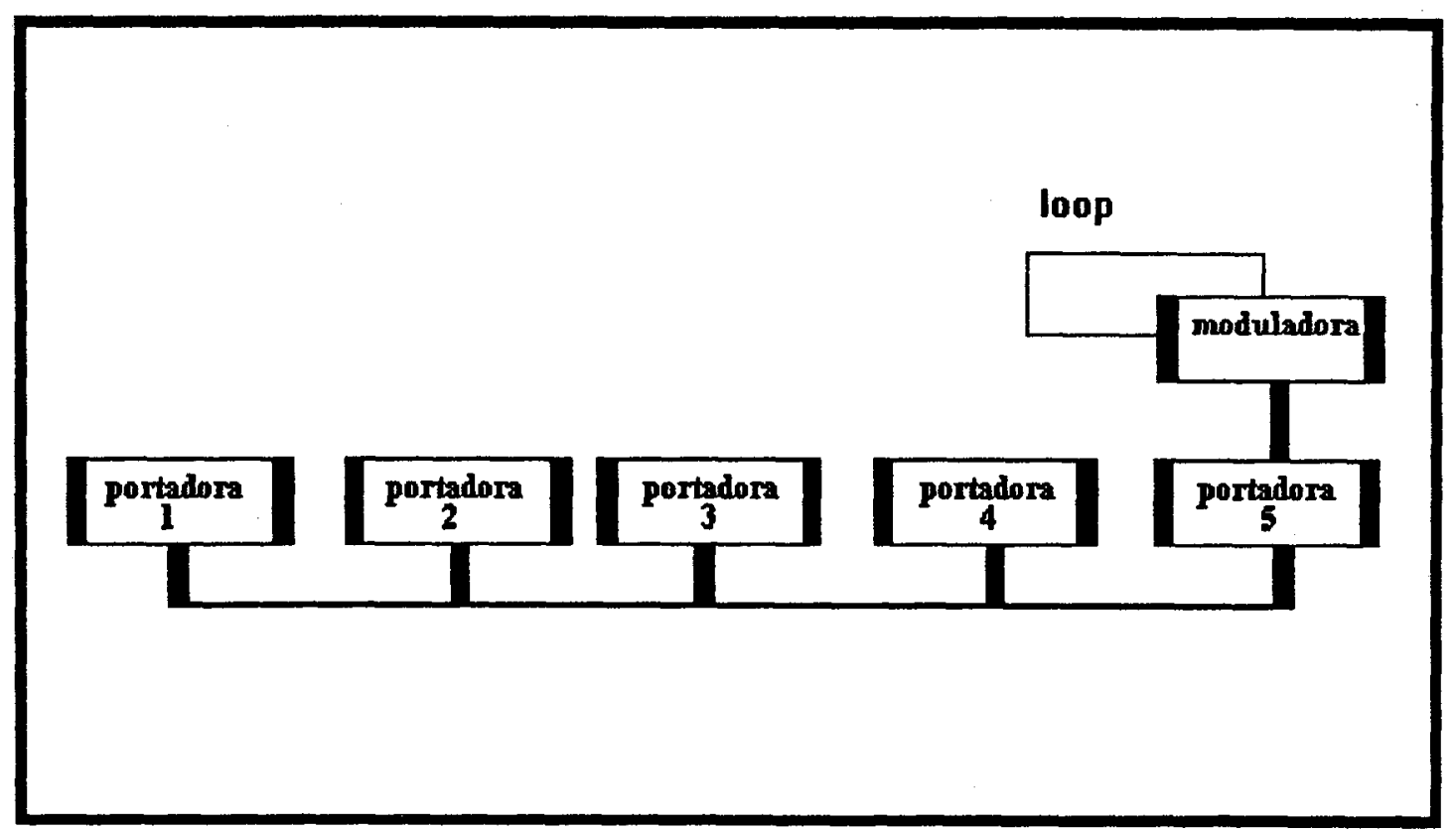

Figura 4.19 : Representação de um algoritmo para seis operadores

Como podemos observar na figura 4.19, um particular operador é designado portadora, se este for o último estágio da síntese. A forma de onda resultante de uma portadora será levada a um conversor digital-analógico, tornando audíveis os tons produzidos. Um operador é designado modulador se a sua forma de onda de saída for levada a outro operador, possibilitando a geração de uma nova forma de onda com uma maior quantidade de sobretons.

O gerador de envelope, visto na figura 4.20, modelará a forma de onda gerada pelos operadores, de maneira a possibilitar a percepção sonora correspondente ao instrumento musical desejado.

Em geral, os geradores de envelopes, utilizados em síntese por frequência modulada, são frequentemente mais complexos que os analógicos ASD (ataque, sustentação e decai- 
mento), mostrado na figura 3.1. A figura 4.20 ilustra um envelope usual em síntese por frequência modulada.

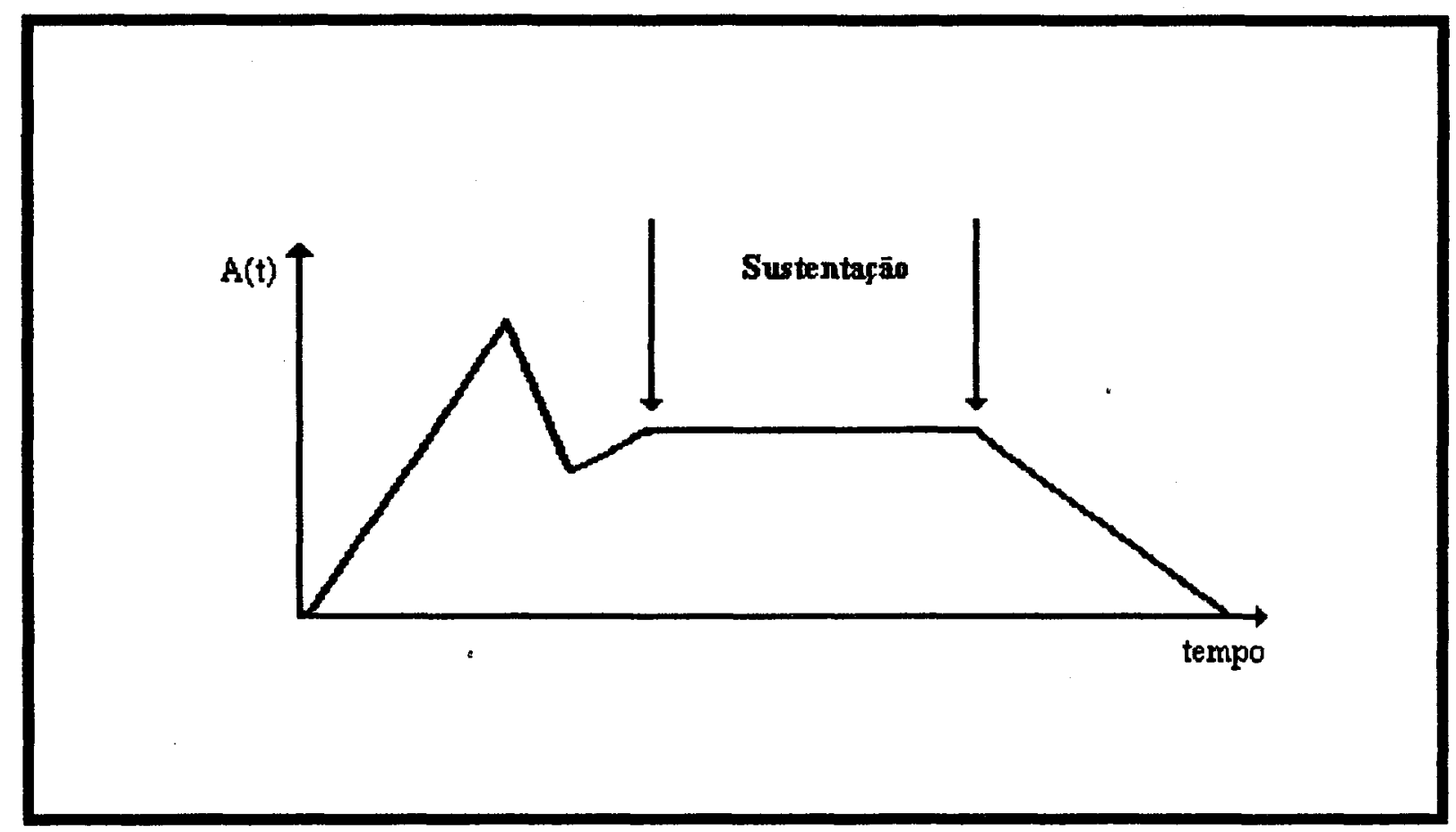

Figura 4.20: Representação de um envelope utilizado em síntese por frequência modulada

\subsubsection{Síntese por Distorção de Fase}

Esta técnica de síntese é relativamente simples. Para entendermos esta técnica necessitamos apenas de algumas ferramentas matemáticas.

Como na sintese por frequência modulada, toda aplicação por distorção de fase é feita digitalmente. Para isso, necessitamos do conceito de ângulo de fase. Por exemplo, 
consideremos uma partícula $P$ movendo-se com velocidade constante em torno de um círculo de rajo A. A figura 4.21 , ilustra este conceito.
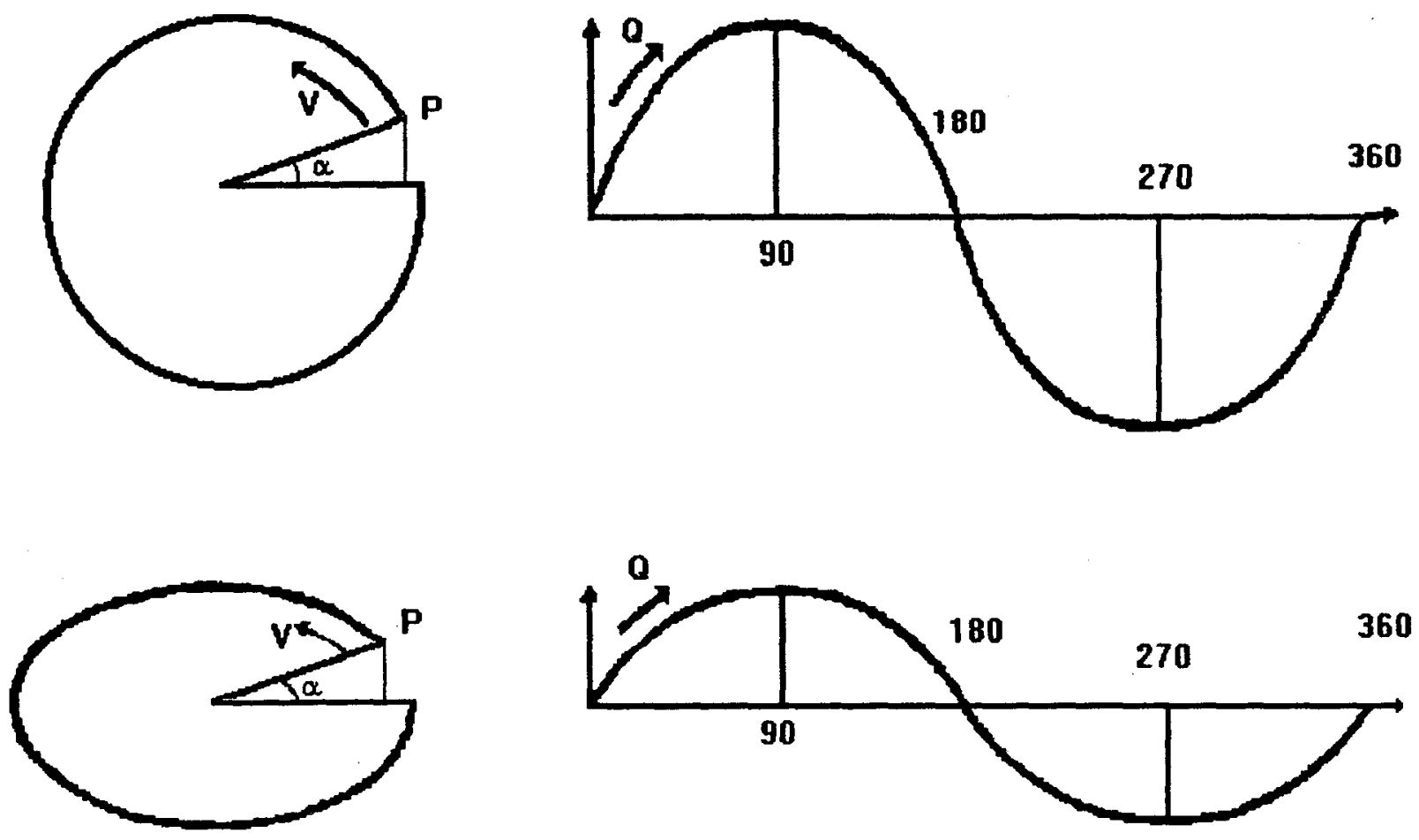

Figura 4.21: Idéia geral para distorção de fase

Onde $\mathrm{P}$ é a partícula, $\mathrm{Q}$ corresponde à posição da partícula vista pelo eixo y, $\mathrm{V}$ é a velocidade da particula $P, \alpha$ é o ângulo da particula $P$.

Se considerarmos que no instante de tempo $\mathrm{t}=0$, o angulo de fase $\alpha=0$, a trajetória da partícula $\mathrm{P}$ em torno do círculo de raio $\mathrm{A}$ será descrita pela função $\mathrm{y}=\mathrm{A}$ sen $\alpha$, onde $\alpha$ é uma função do tempo, dado que a velocidade seja constante. Poderíamos dizer que as funções $\mathrm{y}=\mathrm{A} \cos \alpha \mathrm{e} \mathrm{y}=\mathrm{A}$ sen $(\alpha+\delta)$, também descrevem o movimento da partícula $\mathrm{P}$, bastando apenas escolher uma origem apropriada para a partícula. 
A figura 4.22a ilustra a trajetória da partícula P; a figura $4.22 \mathrm{~b}$ ilustra a função do ângulo $\alpha$.
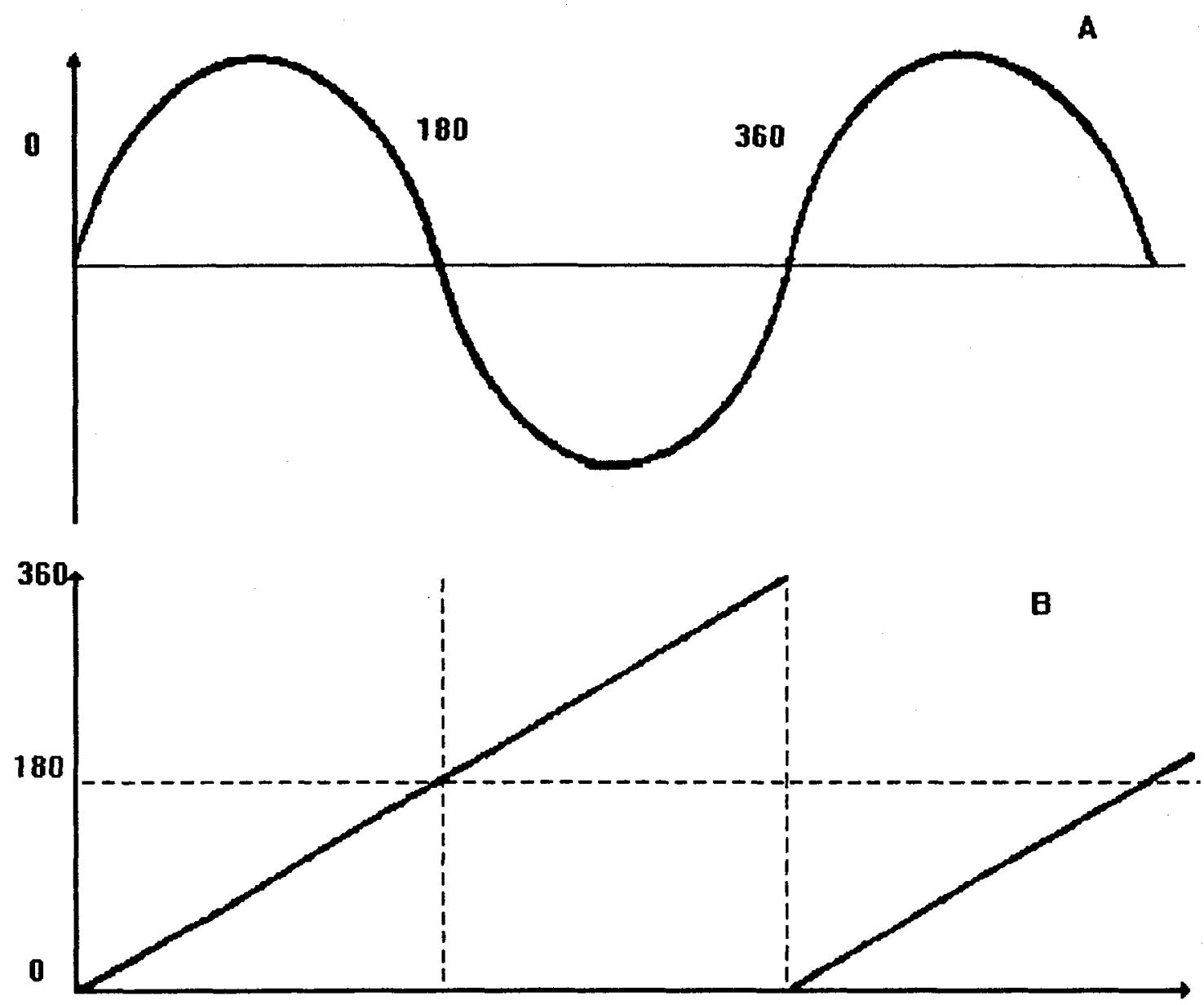

Figura 4.22 : Representação dos gráficos: (a) trajetória da partícula $P$ e (b) ângulo de fase

Vamos supor que a velocidade da particula $\mathrm{P}$ possa assumir outros valores constantes em trechos distintos de sua trajetória. A figura 4.23 ilustra a alteração gráfica sofrida 
pela senoide.
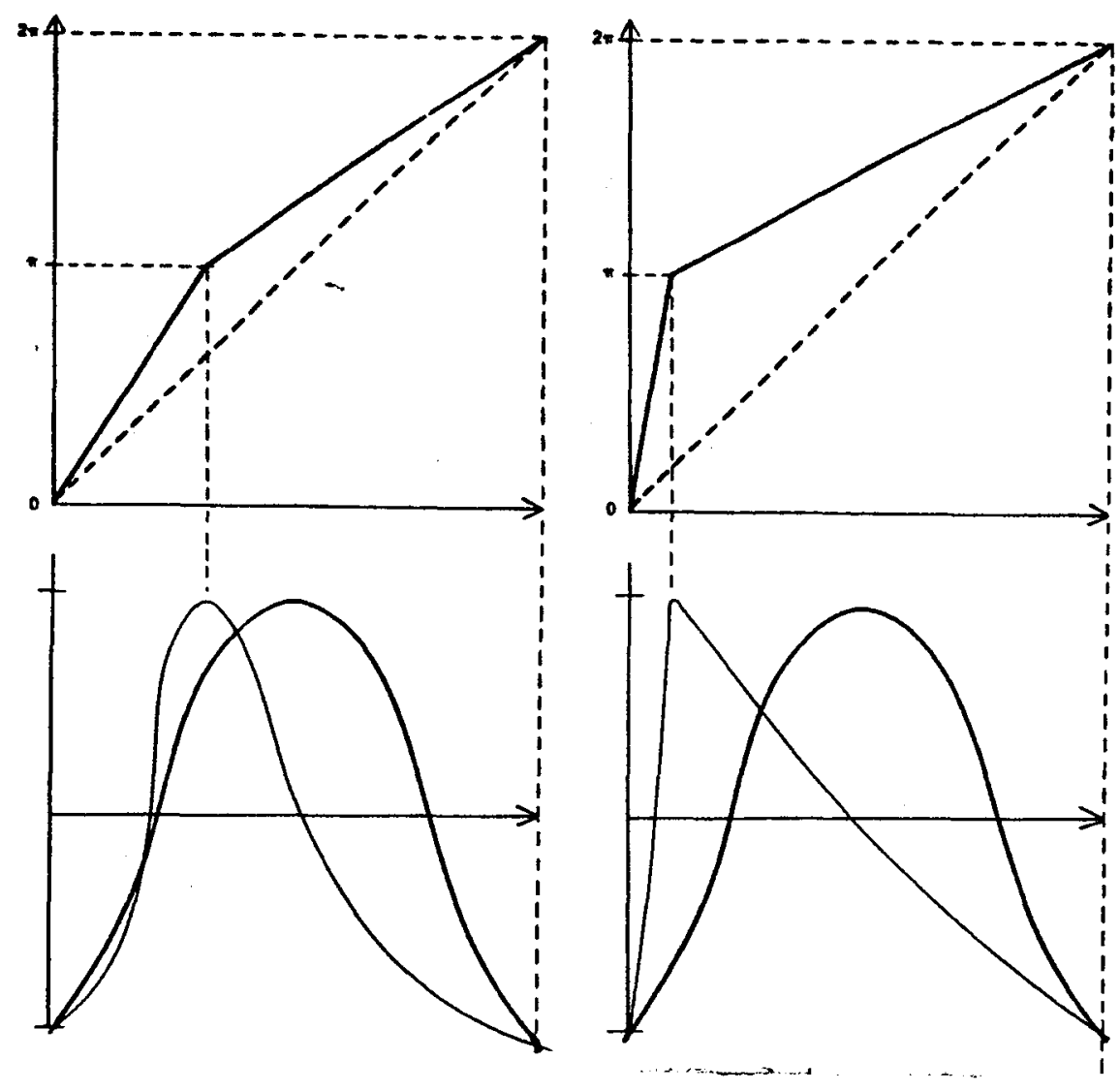

Figura 4.23: Modificação por distorção de fase

Podemos notar que, na figura 4.23, a função resultante do processo de alteração da velocidade da partícula refletirá diretamente nos valores da função do ângulo de fase. Consequentemente, a forma de onda resultante deste processo possuirá uma quantidade muito grande de sobretons (harmônicos), característica fundamental para a geração de tons musicais.

Este mesmo processo pode ser realizado digitalmente com o auxílio do computador, simplesmente armazenando-se em memória uma tabela de valores numéricos, a qual representa uma função senoidal. A geração de uma forma de onda rica em sobretons ocorrerá pela variação da velocidade de leitura desta tabela.

A este processo computacional denomina-se distorção de fase. Portanto, tal distorção é causada pela variação na velocidade de leitura dos dados armazenados na tabela em um ciclo de onda e, desta forma, gera uma forma de onda completamente nova e rica em sobretons (harmônicos). A figura 4.24 ilustra um diagrama de blocos simplificado de um 
sintetizador baseado pelo método por distorção de fase.

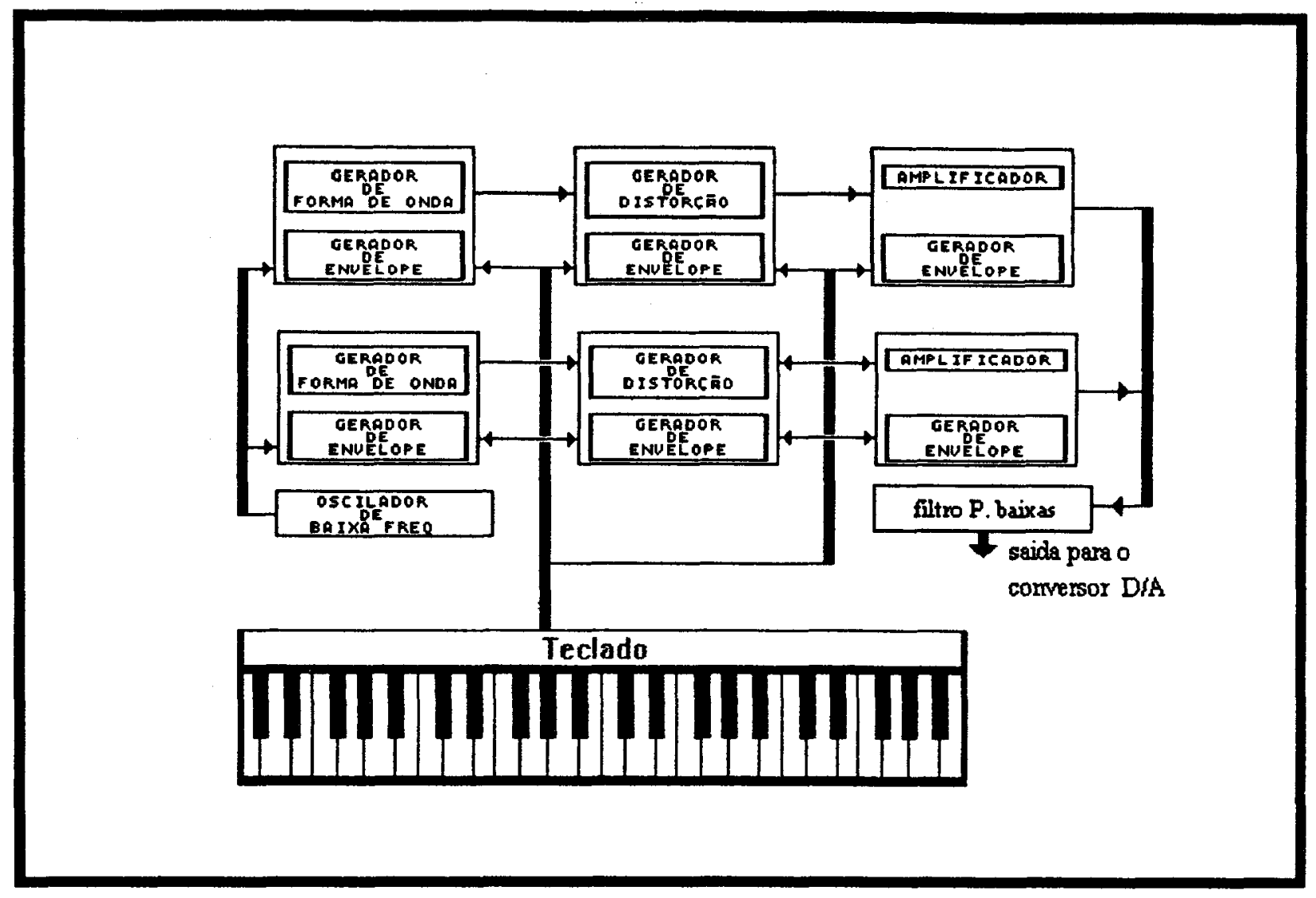

Figura 4.24: Diagrama minimo para distorção de fase [MOR 89]

A novidade nesta técnica é o controlador digital de forma de onda (DCW), o qual controla a profundidade da distorção através de um complexo gerador de envelope. A figura 4.25 ilustra um típico envelope empregado por este método, de maneira que quanto maior 
for o grau de distorção, maior será a quantidade de sobretons (harmônicos) existentes na forma de onda gerada.

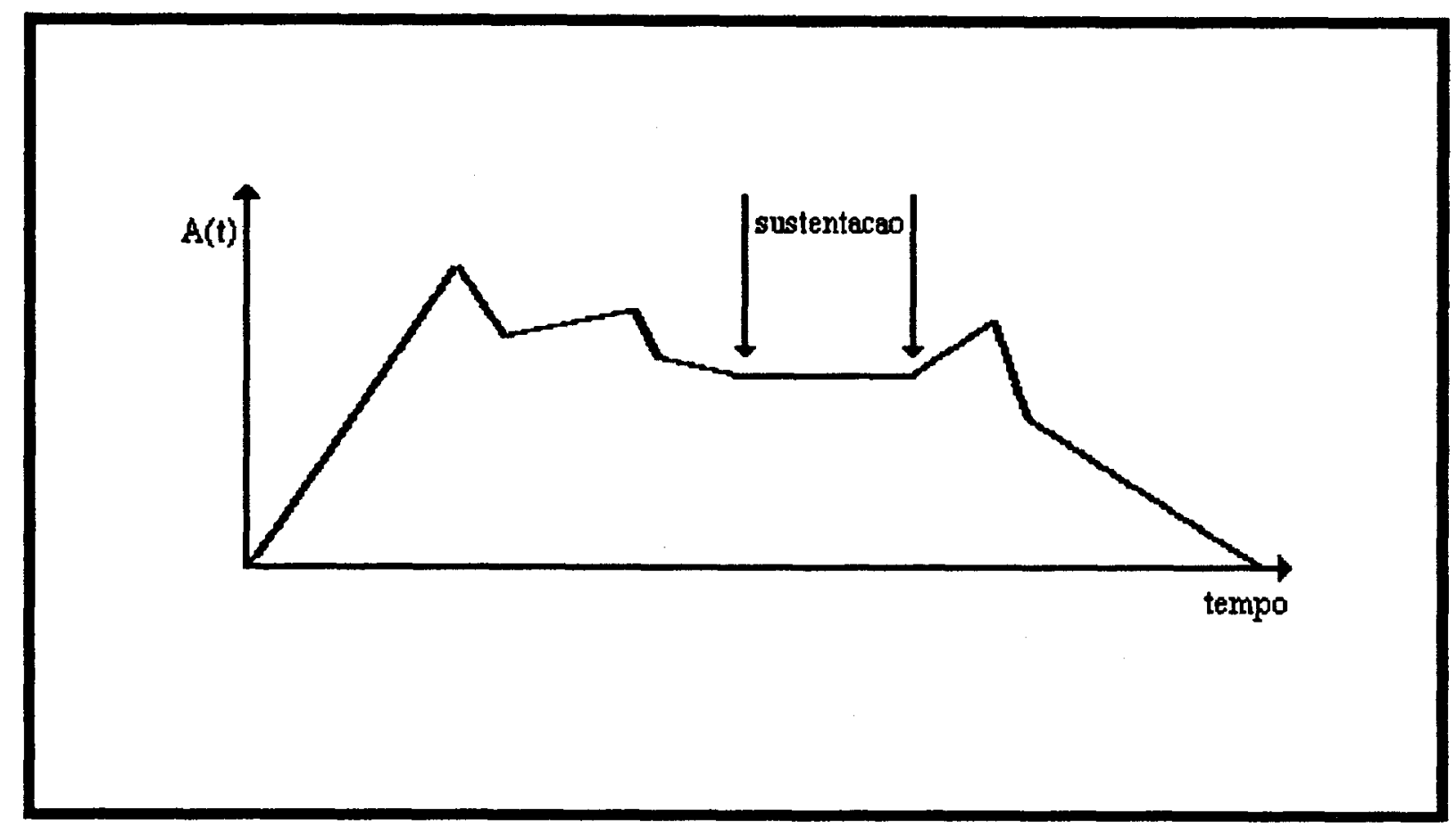

Figura 4.25: Envelope típico para distorção de fase

Como podemos observar o envelope utilizado pela sintese por distorção de fase é bastante complexo.

\subsubsection{Síntese Digital por Amostragem (Sampling)}

A técnica de síntese por sampling (amostragem) é diferente das outras estudadas, dado que esta técnica de sintese somente possibilita a reprodução de sons que estejam previamente armazenados em memória. A figura 4.26, ilustra uma visão geral para esta 
técnica.

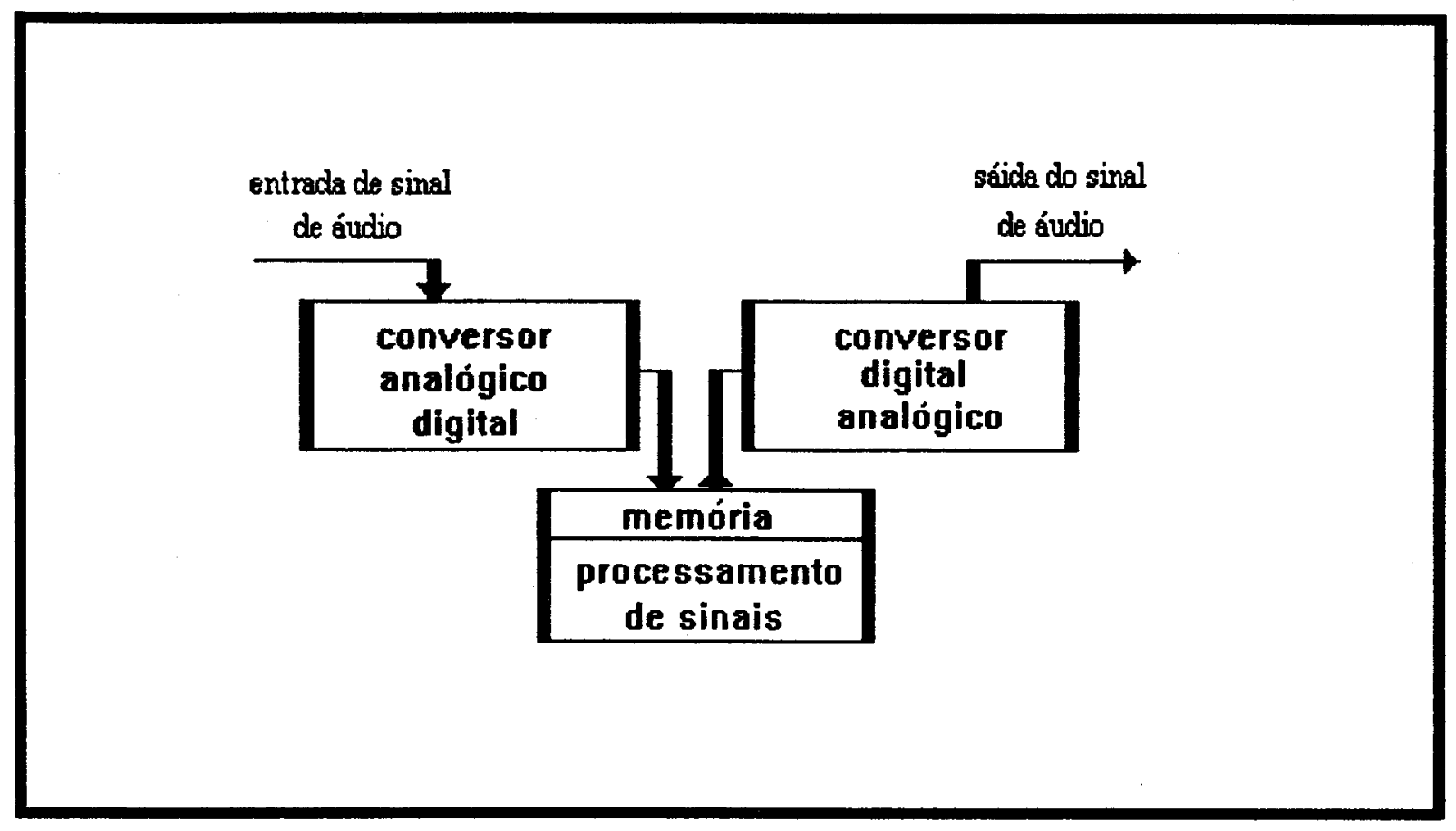

Figura 4.26: Representação macroscópica para a técnica de síntese por amostragem

Como podemos observar na figura 4.26, um sinal sonoro é captado pelo transdutor, sendo este transportado a um conversor analógico-digital, o qual será armazenado em memória. O sinal sonoro armazenado poderá ser processado de maneira a alterar suas componentes características, gerando um novo som, ou simplemente lido para uma futura 
reprodução. A figura 4.27 ilustra um diagrama mínimo de um sintetizador baseado na técnica de síntese por amostragem.

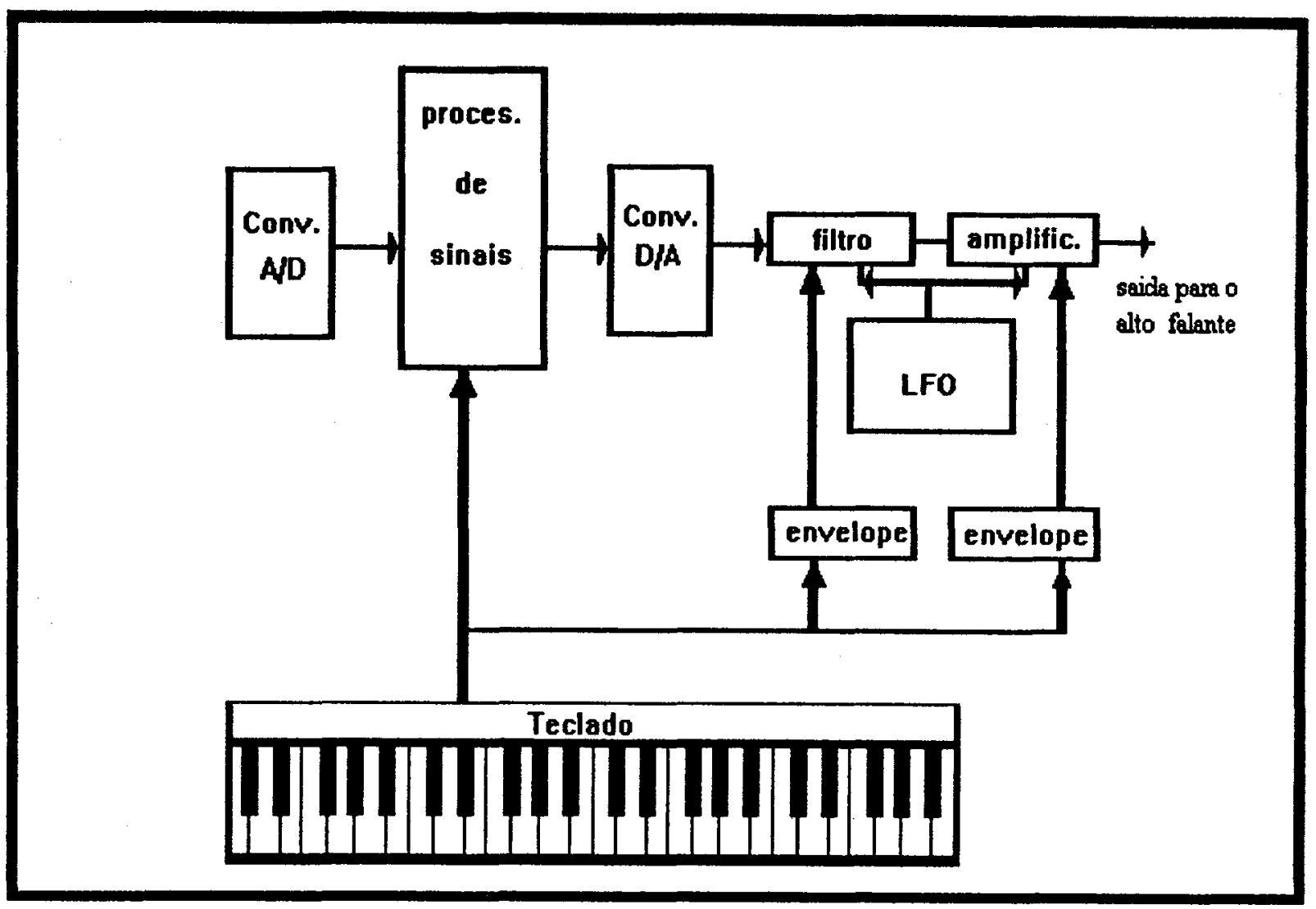

Figura 4.27: Representa um diagrama mínimo para a síntese baseada em amostragem

Embora um sistema baseado em sintese por amostragem seja bastante simples, pelo ponto de vista de implementação a nível de hardware, duas condições determinarão sua qualidade sonora dos tons musicais produzidos, as quais estão diretamente relacionadas ao conversor analógico-digital:

- A taxa de conversão das amostras

Uma característica marcante na utilização desta técnica é a grande quantidade de memória requerida para o armazenamento do sinal amostrado. Por exemplo, se a amostragem for realizada a uma taxa de $40 \mathrm{KHz}$, de maneira a se evitar os efeitos indesejáveis de aliasing audível, através deste procedimento, $40 \mathrm{~K}$ palavras de memória serão necessárias a cada segundo de amostragem.

Entretanto, para garantia da fidelidade na reprodução é necessário armazenar tons inteiros e, consequentemente, a quantidade de memória exigida será muito grande.

Vários métodos existem para economizar memória, dos quais destacamos dois de grande importância para esta técnica de síntese : 
- 1. Sabemos que o som se comporta de maneira mais ou menos estável durante o período de sustentaçâo de um tom tocado, assim sendo, poderíamos utilizar neste caso um loop para este intervalo.

- 2. Métodos de compressão de dados podem ser utilizados para reduzir a quantidade de memória requerida. A redução de dados é um tópico muito estudado em processamento de voz [OPP 75]. Mas nossa meta em música por computador é bem diferente em essência, em termos de comparação; na transmissão de voz a meta é adequar fidelidade com as limitações impostas pelos meios de transmissão, aos quais estes sinais trafegarão, por exemplo linha telefônica.

Em música por computador, os sons musicais produzidos deverão apresentar como critério primordial a alta fidelidade. Exitem muitas maneiras de reduzirmos os dados sem degradarmos a fidelidade. Por exemplo, utilizando a codificação Huffman ou modulação em delta [MOO 77]. O inconveniente na aplicação destas técnicas é a dificuldade do controle dos parâmetros, amplitude e frequência, que compõem o som, tornando difícil a geração de novos sons.

- A capacidade binária do conversor analógico-digital

Quanto maior for a capacidade de manipulação binária por parte do conversor analógico-digital, menor será o erro de quantização do som original para o amostrado.

Por exemplo, se utilizarmos um sistema conversor de 8 bits, poderemos apenas representar 256 valores diferentes. Por outro lado, um sistema conversor de 16 bits poderá representar 65.536 valores diferentes. 


\section{Capítulo 5}

\section{A Transformada Karhunen-Loève}

\subsection{Introdução}

Uma importante aplicação de transformadas ortogonais, em processamento de sinais digitais, é a compressão de dados [AND 70],[AHMa75],[AHM 75], [WOM 77], [STA 88], [CHE 91], isto é, a representação de um sinal de maneira mais eficiente. As transformadas ortogonais podem ser divididas em duas classes, segundo as funções básicas utilizadas. Desta forma, temos a classe baseada em funções não senoidais e a de funções senoidais, tendo esta última como única representante a transformada de Fourier.

No final dos anos 80 surgiu uma nova ferramenta matemática conhecida por transformada wavelets (pequenas ondas) [DAU 90], a qual vem chamando a atenção de muitos pesquisadores. Desde então, uma grande quantidade de trabalhos, aplicando as wavelets, têm surgido [GRO 87],[DAU 88], [KRO 88], [KRO 87], [MAL 89]. Os artigos [KRO 88], [KRO 87] tratam de aplicação em análise e síntese de tons musicais e processamento de voz.

Semelhante à transformada rápida de Fourier (FFT), a transformada discreta wavelets (DWT) é rápida, linear, possui a inversa e também opera com um vetor de comprimento igual a uma potência de 2 , transformando este em outro de mesmo comprimento. Ambas, a FFT e a DWT, podem ser vistas como uma rotação no espaço de funções. Entretanto, a FFT utiliza em seu dominio a familia de funções senoidais (senos e cossenos), enquanto a DWT utiliza outras um tanto mais complicadas, que recebem o nome de funções mãe e wavelets, as quais por não serem específicas asseguram uma infinidade de possíveis bases para o espaço de funções.

Em wavelets não existe um único conjunto de coeficientes para representar um determinado sinal, enquanto a transformada de Fourier está limitada a encontrar coeficientes únicos para a representação deste. Uma vantagem imediata das wavelets é a possibilidade 
de procurar uma representação esparsa, a qual simplificará o cálculo de convoluções [DAU 88].

No capítulo 4, apresentamos vários métodos para síntese de tons musicais. A síntese aditiva, baseada na representação de Fourier truncada, é um dos métodos mais conhecidos em geração de tons, devido à sua fidelidade. Entretanto, a representação de Fourier não é utilizada em aplicações de tempo real, devido à grande demanda de potência aritmética exigida do processador. Este método tem sua performance ainda mais degradada, principalmente se for esperado que um mesmo sintetizador gere tons de diversos instrumentos.

Neste capítulo, mostraremos uma transformada ortogonal composta de funções básicas não senoidais, a qual possibilita a representação de sinais de maneira eficiente sendo ótima com relação ao critério do mínimo erro quadrado [PAR 67], a fim de possibilitar a aplicação de síntese de tons musicais em tempo real [STA 88]. Esta é denominada transformada Karhunen-Loève.

\subsection{Representação de Sinais Utilizando Transformada Karhunen-Loève}

Seja $\{\mathrm{X}\}$ um conjunto de vetores, obtidos por amostragem, de uma classe de sinais aleatórios. Seja $\mathrm{T}$ uma matriz ortogonal, cuja transposta é dada por :

$$
T^{t}=\left(\begin{array}{llll}
\psi_{1} & \psi_{2} & \ldots & \psi_{N}
\end{array}\right)
$$

onde os $\psi_{i}, i=1,2,3, \ldots, N$, são vetores de dimensão N. Admitiremos doravante, a seguinte definição para os vetores utilizados : Se $X$ é um vetor, então sua representação será através de um vetor coluna, seu transposto denotaremos por $X^{t}$.

Assumiremos por conveniência que os vetores $\psi_{i}$ sejam de valores reais e ortonormais, isto é:

$$
\psi_{i}^{t} \psi_{j}= \begin{cases}1 & \text { se } i=j \\ 0 & \text { se } i \neq j\end{cases}
$$

Das relações (5.1) e (5.2), temos :

$$
T^{t} T=I
$$

onde $I$ é a matriz identidade.

Desta maneira, podemos escrever qualquer elemento do $\{X\}$, como combinação linear das colunas de $T^{t}$ : 


$$
X=y_{1} \psi_{1}+y_{2} \psi_{2}+\ldots+y_{N} \psi_{N}=\sum_{i=1}^{N} y_{i} \psi_{i}
$$

Nosso desejo é fixar um subconjunto $\left\{y_{1}, y_{2}, \ldots, y_{M}\right\}$ de maneira a estimarmos $X$. Este procedimento será realizado substituindo as $N-M$ componentes restantes, por constantes $b_{i} s$, obtendo :

$$
\hat{X}=\sum_{i=1}^{M} y_{i} \psi_{i}+\sum_{i=M+1}^{N} b_{i} \psi_{i}
$$

onde $\hat{X}$ denota uma aproximação de $X$. O erro introduzido, é dado por:

$$
\Delta X=X-\hat{X}=X-\sum_{i=1}^{M} y_{i} \psi_{i}-\sum_{i=M+1}^{N} b_{i} \psi_{i}
$$

Das equações (5.4) e (5.6), segue que :

$$
\Delta X=\sum_{i=M+1}^{N}\left(y_{i}-b_{i}\right) \psi_{i}
$$

Por definição, o mínimo erro quadrado, $\varepsilon(M)$, é dado por :

$$
\varepsilon(M)=|\Delta X|^{2}
$$

Vale a pena ressaltar, que $\hat{X}$ é um vetor de mesma dimensão que a matriz $\mathrm{T}$.

Substituindo a equação (5.7) em (5.8), temos :

$$
\varepsilon(M)=\sum_{i=M+1}^{N} \sum_{j=M+1}^{N}\left(y_{i}-b_{i}\right)\left(y_{j}-b_{j}\right) \psi_{i}^{t} \psi_{j}
$$

Este resultado pode ser simplificado utilizando-se a relação (5.2) e, a nova relação, será dada por :

$$
\varepsilon(M)=\sum_{i=M+1}^{N}\left(y_{i}-b_{i}\right)^{2}
$$

Da equação (5.9), segue que, devemos escolher os $\psi_{i}$ s e os $b_{i}$ s de maneira a obtermos o valor minimo para $\varepsilon(M)$. A seguir mostraremos a escolha dos $\psi_{i}$ s e $b_{i}$ s para o conjunto $\{\mathrm{X}\}$, realizada em dois passos : 


\section{- Passo 1.}

Da equação (5.9), temos :

$$
y_{i}=\psi_{i}^{t} X
$$

Utilizando-se o fato de que a média aritmética é um estimador de mínimos quadrados [HOF 42], temos que :

$$
b_{i}=\psi_{i}^{t} \bar{X}
$$

Assim :

$$
\varepsilon(M)=\sum_{i=M+1}^{N} \psi_{i}^{t}(X-\bar{X})(X-\bar{X})^{t} \psi_{i}
$$

onde $\mathrm{X}$ é um elemento do $\{\mathrm{X}\}$.

Uma extensão do cálculo do mínimo erro quadrado para $\circ\{\mathrm{X}\}$, pode ser dado por:

$$
\varepsilon(M)=\sum_{i=M+1}^{N} \psi_{i}^{t} R_{X} \psi_{i}
$$

onde $R_{X}$ é a matriz de covariância do $\{X\}$, definida por $E\left[(X-\bar{X})(X-\bar{X})^{\mathfrak{t}}\right]$.

\section{- Passo 2}

Para obtermos os $\psi_{i}$ s ótimos, devemos não somente minimizar $\varepsilon(M)$ com relação aos $\psi_{i}$ s, mas também devemos satisfazer a restrição $\psi_{i}^{t} \psi_{i}=1$. Para isso, utilizamos o método dos multiplicadores de Lagrange [MUN 78], onde obtemos:

$$
\hat{\varepsilon}(M)=\varepsilon(M)-\sum_{i=M+1}^{N} \beta_{i}\left(\psi_{i}^{t} \psi_{i}-1\right)=\sum_{i=M+1}^{N}\left(\psi_{i}^{t} R_{X} \psi_{i}\right)-\beta_{i}\left(\psi_{i}^{t} \psi_{i}-1\right)
$$

onde $\beta_{i}$ denota o multiplicador de Lagrange. Da equação (5.14) obtemos os seguintes resultados parciais:

$$
\nabla_{\psi_{i}}\left(\psi_{i}^{t} R_{X} \psi_{i}\right)=2 R_{X} \psi_{i}
$$

e

$$
\nabla_{\psi_{i}}\left(\psi_{i}^{t} \psi_{i}-1\right)=2 \psi_{i}
$$

Assim da equação (5.14), temos :

$$
\nabla_{\psi_{i}}\left(\hat{\varepsilon}_{M}\right)=2 R_{X} \psi_{i}-2 \beta_{i} \psi_{i}=0
$$




$$
R_{X} \psi_{i}=\beta_{i} \psi_{i}
$$

Por definição, a equação (5.15) implica que os valores $\beta_{i}$ serão os auto-valores, $\lambda_{i}$ da matriz de covariância de $X$, e os $\psi_{i}$ correspondem aos auto-vetores. Substituindo a equação (5.15) em (5.13), obteremos que o mínimo erro quadrado é dado por:

$$
\varepsilon_{\min }(M)=\sum_{i=M+1}^{N} \psi_{i}^{t} \lambda_{i} \psi_{i}
$$

Pela relação $(5.2)$, temos :

$$
\varepsilon_{\min }(M)=\sum_{i=M+1}^{N} \lambda_{i}
$$

Isto significa que, se utilizarmos apenas $M$ auto-vetores para a representação de sinais, o erro de truncamento será mínimo sendo dado pela equação (5.16). A equação (5.4), escrita em termos dos auto-vetores da matriz de covariância, é denominada expansão Karhunen- Loève. A correspondente transformação ortogonal, na equação (5.3), é chamada transformada Karhunen-Loève (K-L).

\subsection{Aplicação de Transformada Karhunen-Loève em Tons Musicais}

Como vimos anteriormente, a síntese aditiva é representada analíticamente por :

$$
F(k) \cong \sum_{i=1}^{N} y_{i}(k) \psi_{i}\left(\theta_{i}(k)\right)
$$

Onde $F(\bullet)$ corresponde a um tom completo, $y_{i}(\bullet)$ é o envelope associado a i-ésima função básica, $\psi_{i}(\bullet)$ e $\theta_{i}(\bullet)$ são a funcão básica e fase respectivamente. A frequência é determinada pela derivada da função fase. As funções amplitude e frequência, correspondem aos parâmetros variantes no tempo, sendo que no algoritmo de determinação destes, utilizaremos a técnica de funções lineares por partes (piecewise linear) [MOO 77], como forma de redução ao número de computação necessária para a síntese. As funções $\psi_{i}$ s serão extraidas utilizando-se o método Karhunen-Loève, as quais por definiçâo de síntese aditiva, devem ser períodicas.

O esforço computacional exigido pela síntese aditiva provem de duas origens : 
- 1. A geração das funções amplitude e frequência para cada harmônico.

- 2. A multiplicação da função amplitude pela função básica.

Uma redução na quantidade de funções básicas e a representação aproximada das funções amplitude e frequência através de funções lineares por partes, auxiliará ambos os problemas.

No entanto, da maneira que expomos a transformada Karhunen-Loève (K-L), pode nos sugerir uma aplicação direta do tom musical completo. Porém, se observarmos atentamente a equação (5.15), notaremos que a dimensão da matriz de covariância está associada a duração do tom musical e este, por sua vez, à taxa de amostragem, a qual o tom foi submetido. Em geral, tons musicais são amostrados à $40 \mathrm{KHz}$. Portanto, uma aplicação direta da transformada K-L seria impossivel, devido à dimensão da matriz de covariância. Contudo, esta preocupação está descartada, pois, por definição, a síntese aditiva requer apenas que o conjunto de funções básicas seja períodico, e não de mesmo comprimento do tom original.

Neste instante, faremos algumas adaptaçòes à transformada K- L para tons musicais, mais específicamente na computação da matriz de covariância, para uma grande quantidade de tons musicais.

Para cada tom musical amostrado, selecionamos um conjunto de funções-amostras para o cálculo da matriz de covariância. Isto é, seja $\left\{x_{\xi}\right\}$ um conjunto de funções-amostras de $F_{\xi}(\bullet)$, um membro deste conjunto é dado por $x_{\xi}^{t}=\left(x_{1}, x_{2}, \ldots, x_{k p}\right)$, em [AHMa 75] assume que tais amostras possuem média zero, facilitando o cálculo da matriz de covariância. Desta forma, podemos expressar a matriz de covariância, através da seguinte equação :

$$
R_{x}=\frac{1}{M} \sum_{\xi} x_{\xi} x_{\xi}^{t}
$$

Como sabemos, as funções básicas K-L são determinadas através da solução dos autovetores, pela equação :

$$
R_{x} \psi_{i}=\lambda_{i} \psi_{i}
$$

Um resultado interessante, obtido através do método $K-L$, é que o espectro de frequências de um auto-vetor pode ser escrito como combinação linear das transformadas de Fourier das funções-amostras, o qual é dado utilizando a equação (5.18):

$$
\begin{gathered}
F\left\{\lambda_{i} \psi_{i}\right\}=F\left\{\sum_{\xi} x_{\xi} x_{\xi}^{t} \psi_{i}\right\} \\
F\left\{\lambda_{i} \psi_{i}\right\}=\sum_{k} \sum_{\xi} x_{\xi}(k) x_{\xi}^{t} \psi_{i} e^{-j w k T_{a}}
\end{gathered}
$$




$$
\begin{gathered}
F\left\{\lambda_{i} \psi_{i}\right\}=\sum_{\xi} x_{\xi}^{t} \psi_{i}\left\{\sum_{k} x_{\xi}(k) e^{-j w k T_{a}}\right\} \\
F\left\{\lambda_{i} \psi_{i}\right\}=\sum_{\xi} x_{\xi}^{t} \psi_{i} F\left\{x_{\xi}\right\}
\end{gathered}
$$

Baseado neste resultado, impomos as seguintes restrições :

- 1. As funções-amostras devem ter um período fundamental, por exemplo $k_{p}$ amostras. Isto determinará o período fundamental dos auto-vetores.

- 2. As funções-amostras devem ser periodicas e terem banda limitada. Assim, os auto-vetores terão estas propriedades.

Com estas restrições em mente, agruparemos estas amostras em classes, para a computação das funções básicas. Após esta computação, determinaremos as funções amplitude e frequência, pela técnica de funções lineares por partes (piecewise linear). 


\section{Capítulo 6}

\section{Algoritmos para Utilização da Transformada K-L em Síntese Aditiva}

\subsection{Introdução}

Neste capítulo, discutiremos os algoritmos necessários para aplicação da transformada Karhunen-Loève em síntese de tons musicais. Na prática, nosso objetivo será alcançado dividindo- se o problema de síntese em 5 partes, as quais são:

- 1. Normalização e Filtragem das Funções- amostras.

- 2. Alinhamento de Fase.

- 3. Classificação das Funções-amostras.

- 4. Determinação das Funções Básicas Karhunen-Loève.

- 5. Determinação das Funções amplitude e frequência

Os quatro primeiros algoritmos estão associados à determinação das funções básicas 
K-L. A figura (6.1) ilustra a os procedimentos necessários em forma de fluxograma.

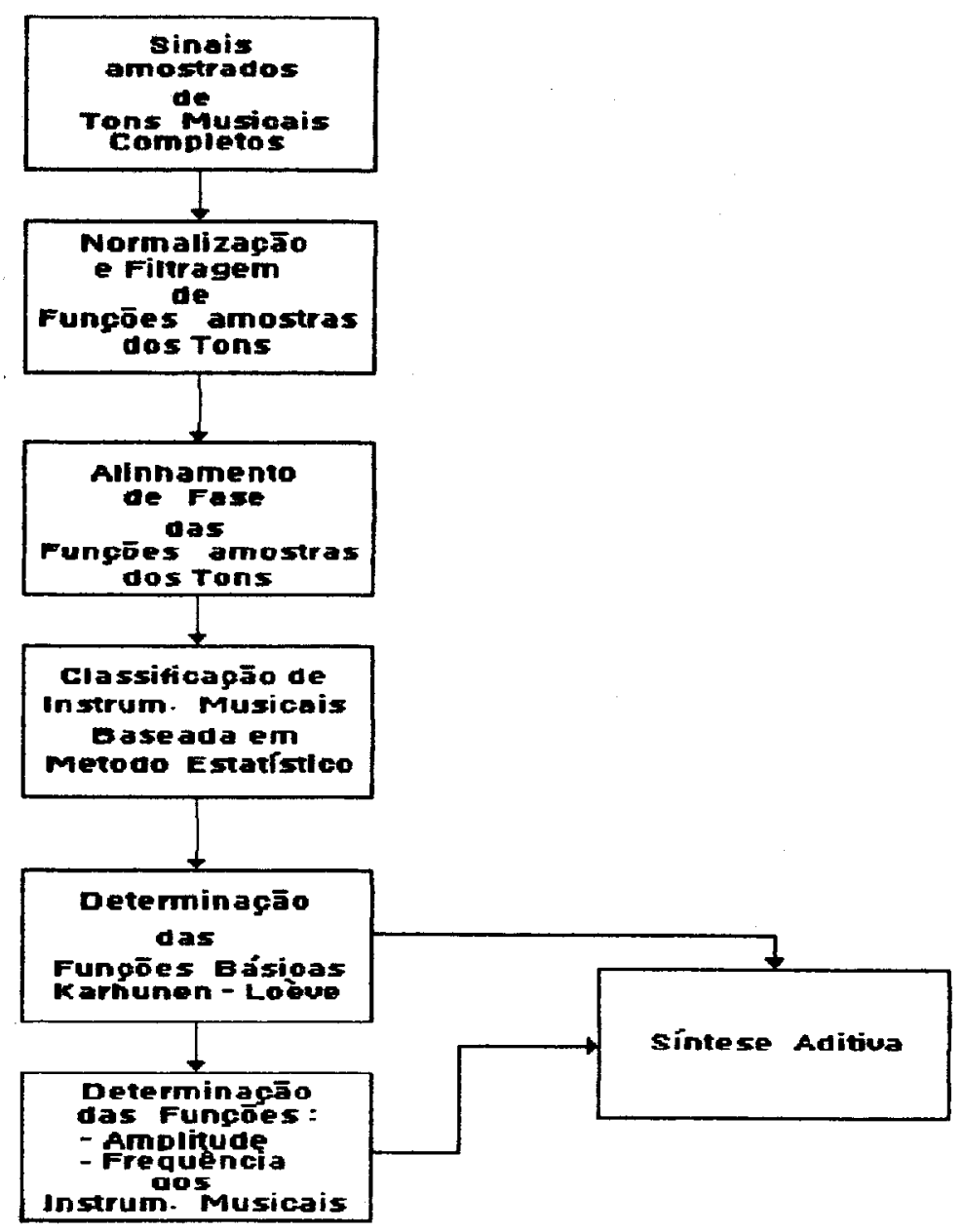

Figura 6.1: Diagrama de fluxo para a aplicação da transformada $K-L$ em sintese de tons musicais

\subsection{Normalização e Filtragem das Funções-amostras}

Tons musicais, coletados de diferentes instrumentos, são frequentemente tocados em diferentes notas e oitavas, de maneira que a frequência fundamental será diferente para todos os instrumentos amostrados. Outra questão relevante é que estes tons são, geralmente, não periódicos (ou quasi-períodicos)[STR 66]. Isto é, o valor de $F_{\xi}\left(k+k_{p}\right)$, onde $k_{p}$ é o periodo, poderá ser apreciavelmente diferente de $F_{\xi}(k)$, devido à variação natural da amplitude e da frequência do tom original, proveniente do instrumento, pois estes dois parâmetros variam lentamente com o tempo de duração do tom musical. 
Dado que, em nossa aplicação utilizaremos várias amostras de sinais pertencentes a instrumentos diferentes, isto implicará em um número diferente de amostras por período para cada instrumento, tornando proibitiva qualquer análise em conjunto destes sinais. Desta forma, devemos realizar uma normalização em período, a qual irá satisfazer a restrição 1, imposta no capítulo 5 (seção 5.3).

Devemos salientar que tal restrição refere-se à mudança da taxa de amostragem de um sinal, que é uma prática muito comum em aplicações de processamento de sinais digitais. A mudança de taxa de um sinal pode ser alcançada por um entre dois possiveis métodos, os quais são:

\section{- Método 1}

Converte-se o sinal digital, para analógico, por meio de um conversor D/A, e novamente amostra-se o sinal analógico na taxa desejada. Tal método não é adequado aos nossos propósitos, pois a perda de informação seria muito grande, prejudicando a qualidade da síntese. Este método é bastante interessante para sistemas de telecomunicações, que recebem e transmitem sinais de diferentes taxas.

\section{- Método 2}

Mudança de taxa de amostragem totalmente realizada no domínio digital. Este método se adapta melhor à característica de nosso problema, onde, a única restrição prática para a sua utilização, é que, à razâo da nova taxa com a antiga deve ser um número racional [PRO 88]. Esta restrição limita muitas aplicações práticas para sinais aleatórios. Em nossa aplicação este fato não causará nenhuma limitação, pois podemos escolher os sinais antes da aplicação do método.

Existem duas situações importantes a se considerar na conversão da taxa de amostragem de um sinal, que são:

\section{- Redução da taxa do sinal original}

Este processo é conhecido na literatura como decimação [OPP 75]; sua característica é a redução do número de amostras por período. Problemas existirão na aplicação de tal método, proveniente do teorema de Nyquist. A fim de prevenirmos os efeitos de aliasing, faz-se necessária uma redução do comprimento da banda do sinal, o qual é obtido por filtragem.

- Incremento da taxa do sinal original

Este processo é conhecido na literatura como interpolação, sendo sua característica própria, o incremento do número de amostras por período [OPP 75].

Como vimos anteriormente, o número de amostras por período determinará a dimensão da matriz de covariância. Devemos balancear nosso desejo de uma matriz de covariância 
pequena, mas que preserve as informações do sinal original, garantindo a qualidade da síntese.

Adotaremos um período padrão de $312.5 \mathrm{~Hz}$. Desta maneira, nossas funções-amostras possuirão 128 pontos por período, devido à taxa de amostragem ser de $40 \mathrm{KHz}$.

Um algoritmo bastante conhecido para mudança de taxa de amostragem digital foi proposto por Schafer e Rabiner. Tal algoritmo é conhecido por "Interpolação Digital Padrão", descrito em [SCH 73]. Portanto, a normalização em periodo estará resolvida com a utilização deste método.

Após a normalização em período, alcançaremos a limitação em banda e periodicidade (segunda restrição) filtrando tom musical de maneira circular, como mostra a equação abaixo:

$$
\tilde{F}_{\xi}=L\left\{F_{\xi}\left(k \bmod k_{p}\right)\right\}
$$

Onde L denota um filtro passa baixas, $\tilde{F}_{\xi}$ denota o tom musical limitado em banda, periódico e com $k_{p}$ amostras por período.

O filtro passa baixas é projetado de maneira a prevenir os efeitos de aliasing audíveis, os quais são resultantes da criação de uma sequência periódica de um segmento de tom, que não é perfeitamente periódico. Este filtro suprimirá todas as frequências acima de $20 \mathrm{KHz}$ em no mínimo $50 \mathrm{db}$, uma vez que a nossa taxa de amostragem é de $40 \mathrm{~K} \mathrm{~Hz}$. Este resultado foi proposto por Goeddel e Bass, em trabalho realizado para sintese subtrativa [GOE 81]. O cálculo para frequência de corte, de maneira a se prevenir os efeitos de aliasing nos tons sintetizados, é dado por:

$$
f_{p}=\frac{1}{k_{p} T_{a}}
$$

onde $f_{p}$ denota a frequência padrão e $T_{a}$ a taxa de amostragem. Para que nosso filtro tenha uma resposta abaixo de $50 \mathrm{db}$, a frequência de corte $f_{c}$, é dada pela equação abaixo:

$$
f_{c}=\frac{f_{p}}{f_{a}}-\frac{1}{2 T_{a}}
$$

onde $f_{a}$ denota a maior frequência que poderemos reconstruir. $\mathrm{O}$ valor para $f_{a}$ pode ser verificado na figura (1.2), capitulo 1. Desta maneira, limitamos a menor frequência de um tom, em $32.7 \mathrm{~Hz}$ e a maior em $1046.5 \mathrm{~Hz}$, a qual corresponte a $f_{a}$ na equação (6.3), para um alcance total de 5 oitavas do sintetizador. Adotaremos o termo normalização de função, quando quizermos nos referir a uma função períodica, com banda limitada e com período de $k_{p}$ amostras.

Poderíamos, a partir deste instante, determinar as funções básicas Karhunen-Loève, utilizando amostras de $\left\{\tilde{F}_{\xi}\right\}$ como dados para a construção da matriz de covariância. 
Entretanto, para garantirmos uma redução na quantidade de funções básicas necessárias, para uma síntese de alta qualidade, devemos utilizar uma ferramenta para auxiliar a concentração de energia nas principais funções básicas. Este procedimento é conhecido por alinhamento de fase.

\subsection{Alinhamento de Fase}

Uma dificuldade na aplicação de transformadas Karhunen- Loève, em análise de sinais, é que as funções básicas derivadas deste processo possuem uma forte dependência das fases relativas às funçôes-amostras [CHR 79]. Neste artigo, Christensen e Hirschman demonstram que um alinhamento de fase nas funções-amostras auxilia na concentração de energia nos primeiros auto-vetores, consequentemente nas funções básicas, possiblitando uma redução significativa do conjunto de geradores para a sintese.

Em resumo, o alinhamento de fase ressalta características das funções-amostras que ocorram em um mesmo tempo. Por exemplo, se cada função amostra possuir um ponto de máximo, o qual contenha uma grande fração de energia do sinal, estas funções serão alinhadas de maneira a que estes máximos ocorram no mesmo tempo para todas as funçõesamostras.

O melhor alinhamento será obtido pela maximização da correlação obtida das funçõesamostras com o primeiro auto-vetor, pois é este que conterá a maior fração de energia. $\mathrm{O}$ procedimento para o alinhamento de fase das funções-amostras é realizado de modo iterativo, como mostra o algoritmo abaixo:

\section{- Passo 1}

Escolhemos um valor inicial de fase para todas as funções amostras, o qual denotamos por $L_{\xi}^{(k)}$, onde $k$ é o contador de iterações. Inicialmente adotamos $k=0$. Desta forma, selecionaremos o conjunto de funçõesamostras $\left\{x_{\xi}^{(0)}\right\}$, da seguinte forma:

$$
x_{\xi}^{(0)}=\tilde{F}_{\xi}\left(i+L_{\xi}^{(0)}\right) \quad i=1,2, \ldots, k_{p}
$$

Note que $\tilde{F}_{\xi}$ é uma função normalizada, isto é, periódica, limitada em banda e com $k_{p}$ amostras por período.

\section{- Passo 2}

Obtemos o primeiro auto-vetor, $\psi_{1}^{(k)}$, da matriz de covariância, $R_{x}^{(k)}$, através do método das potências [ISA 66], [LAZ 80]. 


\section{- Passo 3}

Neste passo, encontraremos as fases relativas para cada $x_{\xi}^{(k)}$, para a máxima correlação com o primeiro auto-vetor $\psi_{1}^{(k)}$. Em outras palavras, tentaremos valores para $L_{\xi}^{(k)}$ até encontrar aquele que maximize:

$$
\operatorname{MAX}\left(L_{\xi}^{(k)}\right)=\sum_{i=1}^{k_{p}} x_{\xi}\left(i+L_{\xi}^{(k)}\right)^{(k)} \psi_{1}^{(k)}(i)
$$

Note que as fases relativas das funções-amostras, estarão em frequente mudança até que a energia associada com o primeiro auto-vetor, obtido pela transformada K-L, seja maximizada.

\section{- Passo 4}

Se a taxa de variação da correlação aumentar acima de um determinado limiar, para alguma função-amostra, incrementamos o valor de $k$ e retornamos ao passo 2. Caso contrário, o conjunto de funções $\left\{x_{\xi}^{(k)}\right\}$ encontra-se alinhado.

A figura 6.2 ilustra o resultado da aplicação deste algoritmo, para um conjunto de funções senoidais.
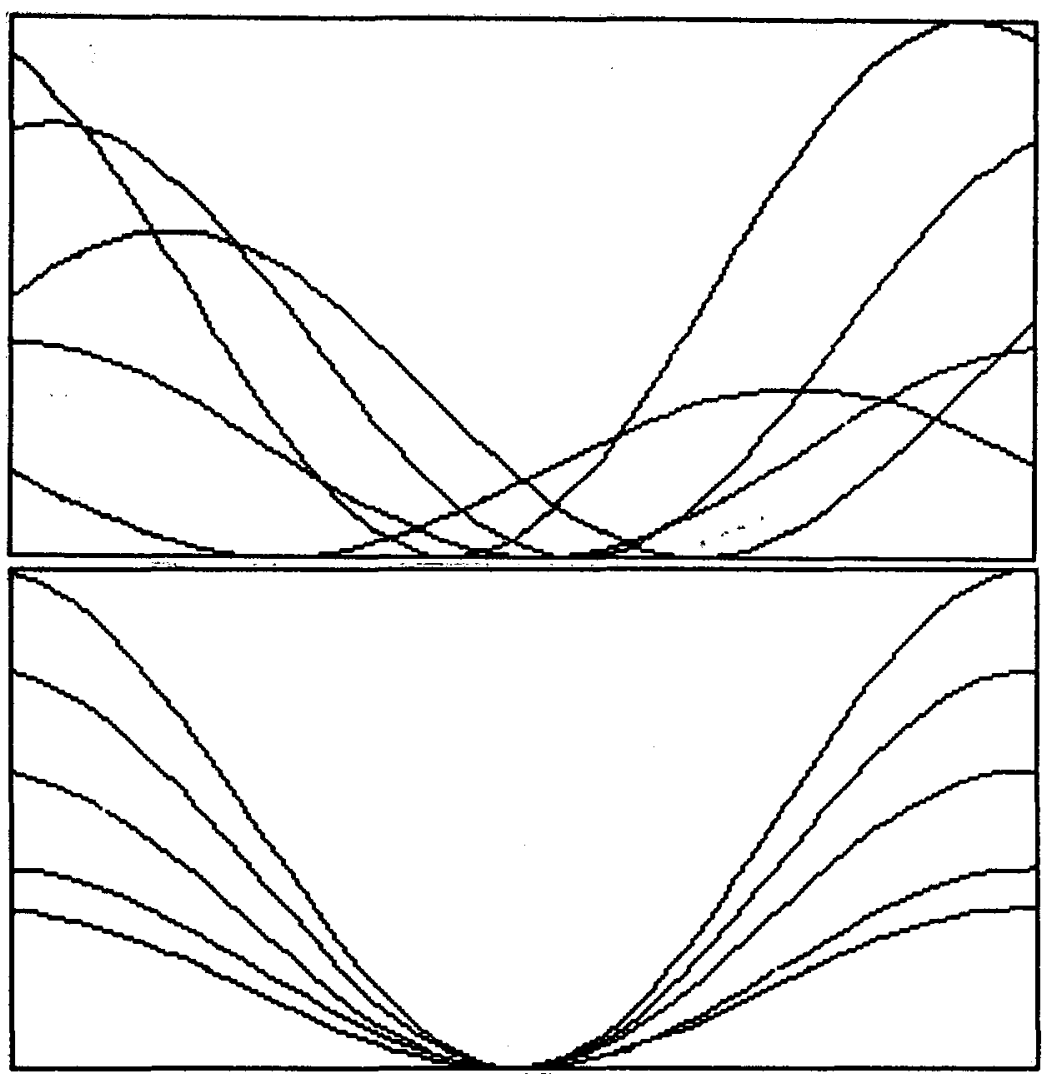

Figura 6.2: Representa a aplicação do algoritmo para alinhamento de fase. Onde a figura (a) corresponde às funções-amostras antes e (b) depois do alinhamento. 
O algoritmo de alinhamento não se limita a aplicações em transformada KarhunenLoève; também pode ser utilizado em expansões sub-ótimas, tais como ( Cosseno, Wash, etc.), as quais tem sido muito utilizadas para uma grande variedade de aplicações de compressão de dados [AHM 75]. Embora, este pré processamento não garanta uma alta taxa de compressão para expansôes sub-ótimas [CHR 79].

\subsection{Classificação das Funções-amostras}

Em [STA 88], Stapleton e Bass, mostraram que aplicando-se o método de classificação preliminar para as funções amostras, encontraremos mais uma maneira para auxiliar a concentração de energia das funções básicas. Tal classificação de sinais possibilitará melhorias no processo de síntese, pois com um conjunto pequeno de funções básicas a velocidade deste processamento será major, sem contudo comprometer a qualidade sonora.

Stapleton e Bass afirmam neste artigo que, quanto maior a correlação entre as funções amostras, os auto-valores associados à matriz de covariância decrescem em módulo rápidamente. Desta forma, a maior parte da energia da classe fica retida nos primeiros auto-vetores. $\mathrm{O}$ algoritmo para a classificação das funções-amostras é dado abaixo:

\section{- Passo 1}

De cada tom, selecionamos uma função-amostra normalizada em período e energia, para identificar a primeira classe de tons.

- Passo 2

Alinhamos em fase as funções-amostras pelo algoritmo proposto na seção (6.3).

- Passo 3

Calculamos a matriz de correlação entre cada par de funções-amostras, dada pela equação:

$$
\begin{gathered}
Q(i, j)=\sum_{k=1}^{k_{p}} x_{i}^{t}(k) x_{j}(k) \\
i=1,2,3, \ldots, N \quad j=1,2,3, \ldots, N
\end{gathered}
$$

Onde $N$ denota o número total de funções-amostras, $Q(i, j)$ a matriz de correlação. 
- Passo 4

Para cada função amostra $x_{i}$, encontraremos um conjunto $S_{i}$, associado às funções amostras, especificado pela relação abaixo:

$$
S_{i}=\left\{x_{j} \mid Q(i, j)>\delta\right\}
$$

Todo elemento do conjunto $S_{i}$ possui uma correlação com a funçãoamostra $x_{i}$, a qual excede un limiar $\delta$ previamente estabelecido.

- Passo 5

Os elementos pertencentes a uma classe, serão identificados através da interseç̧ão dos conjuntos $S_{i}$, dado pela seguinte relação:

$$
S=\bigcap_{i} S_{i}
$$

Este passo requer alguns cuidados para o tratamento da intersecção. Por exemplo, se uma função amostra foi rejeitada devido ao fracasso de sua correlação com o limiar, com somente uma ou duas outras funçõesamostras, podemos inclui-la na classe.

Assim, temos dois parâmetros para determinar o tamanho e a característica da classe:

- O limiar no passo 4

- O número de exceções

O limiar deve ser sempre escolhido, de maneira que existam pelo menos dois elementos por classe. Em geral, sempre existirá um número significativamente grande de tons, os quais não se qualificam para a primeira classe. Desta forma, classes adicionais serão formadas, a partir das funções-amostras rejeitadas. Para isso, retornamos ao passo 2 com estas funções.

\subsection{Determinação das Funções Básicas Karhunen- Loève}

Após a classificação, estamos preparados para a computação das funções básicas K-L, para um conjunto de tons musicais. $\mathrm{O}$ algoritmo para a determinação das funções básicas K-L é dado a seguir: 
- Passo 1

Dentro de cada classe encontrada, selecionaremos algumas amostras igualmente espaçadas de cada instrumento, no regime de sustentação do tom musical.

- Passo 2

Para todas as amostras selecionadas no passo 1 , normalizaremos e alinharemos em fase. Desta maneira, as tornaremos periódicas com $k_{p}$ amostras por período, limitadas em banda e alinhadas em fase.

- Passo 3

Para cada classe, calcularemos a matriz de covariância e determinaremos os auto-vetores. Os auto-vetores podem ser determinados pelo método das potências [ISA 66], [LAZ 80].

Os auto-vetores obtidos através deste algoritmo possuem propriedades verificadas na equação (5.19), isto é, eles são periódicos, limitados em banda e possuem $k_{p}$ amostras por período. Temos agora um conjunto de funções básicas para cada uma das classes encontradas. Para realizarmos a sintese aditiva devemos encontrar as funções amplitude e frequência, as quais dependem das funções básicas.

\subsection{Determinação das funções Amplitude e Fre- quência}

Uma maneira eficiente para a geração das funções amplitude e frequência é dada através de funções lineares por partes (piecewise linear) [MOO 77], [GRE 77], [STA 88], [SER 90], para este tipo de função, necessitamos apenas armazenar o valor inicial da função, um conjunto de rampas e os pontos onde estas rampas deverão ser ligadas ("breakpoints"), possibilitando assim, uma reconstrução aproximada para a função original.

As funçôes lineares por partes para a amplitude e frequência possuem a seguinte forma, respectivamente:

$$
\begin{gathered}
y\left(k_{j}\right) T_{a}=y\left(k_{j-1}\right) T_{a}+\Delta y\left(k_{j}\right) T_{a}^{2} \\
w\left(k_{j}\right) T_{a}=w\left(k_{j-1}\right) T_{a}+\Delta w\left(k_{j}\right) T_{a}^{2}
\end{gathered}
$$


Onde $\Delta y\left(k_{j}\right)$ e $\Delta w\left(k_{j}\right)$ são as rampas entre os "breakpoints", o $k_{j}$ e $k_{j-1}$, e $T_{a}$ representa a taxa de amostragem. A função fase por sua vez, têm a seguinte representação:

$$
\theta\left(k_{j}\right) T_{a}=\theta\left(k_{j-1}\right) T_{a}+w\left(k_{j-1}\right) T_{a}+\frac{\Delta w\left(k_{j}\right) T_{a}^{2}}{2}
$$

A sintese aditiva baseada na transformada Karhunen-Loève deve ser restrita a uma sintese harmônica, isto é, todas as funções básicas iniciarão com a mesma fase e seguirão a mesma função fase, a qual estará associada a primeira função básica, estatisticamente a mais importante [STA 88]. Desta maneira, reescrevemos a equação (5.17) em termos das amplitudes necessárias para a multiplicação com as respectivas funções básicas, as quais estarão compartilhando a mesma função fase, esta nova equação é dada por:

$$
y_{i}\left(k_{j}\right)=\sum_{s=k_{j}}^{k_{j}+K} F_{\xi}(s) \psi_{i}(\theta(s)) \quad i=1,2, \ldots, M
$$

Onde $\mathrm{M}$ é o número de funções básicas. Para a equação acima, algumas considerações devem ser feitas : A cada "breakpoint" encontrado, alinhamos em fase a primeira função básica com o tom. Este procedimento determina o ponto inicial da função fase $\theta\left(k_{j}\right)$, que será compartinhado com todas as funções básicas. $O$ valor da função amplitude no "breakpoint" $k_{j}$, será determinado pela correlação de um periodo local (K amostras) do tom com cada função básica.

O algoritmo para a seleção dos "breakpoints", alinhamento das funções básicas com o tom e o cálculo da correlação é dado abaixo:

\section{- Passo 1}

Devemos estimar o período fundamental, $(K)$, do tom musical, o qual pode ser encontrado por um entre vários métodos existentes [NOL 67], [SON 68], [GOL 69]. Definimos então, a frequência nominal, que é dada por:

$$
\hat{w}=\frac{2 \pi}{K T_{a}}
$$

\section{- Passo 2}

Inicialmente trabalharemos na região de sustentação do tom, deixando para o final do algoritmo a região do ataque. Denominamos a posição inicial do regime de sustentação de $k_{0}$ e determinaremos o ponto inicial da fase para $k_{0}$, a qual chamamos de $\theta\left(k_{0}\right)$ e esta maximiza a seguinte equação: 


$$
\left|\sum_{k=k_{0}}^{k_{0}+k} F(k) \psi_{1}\left(\theta\left(k_{0}\right)+\hat{w} *\left(k-k_{0}\right) T_{a}\right)\right|
$$

Note que esta equação apenas encontrará a fase para a primeira função básica, a qual será compartilhada com as demais funções básicas. A figura (6.3) ilustra o ponto $k_{0}$.

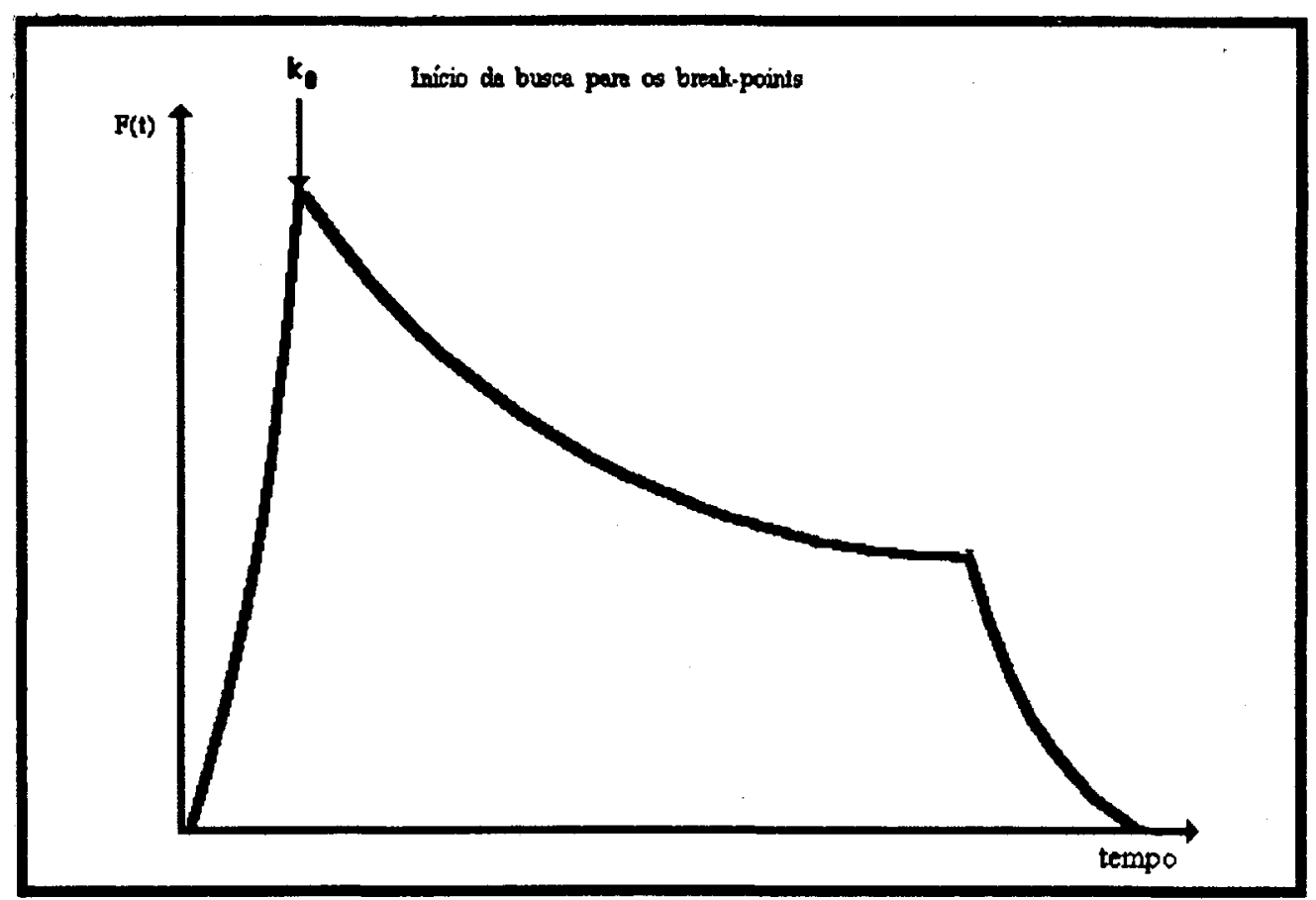

Figura 6.3 : Representa o valor inicial $k_{0}$, o qual encontra-se no início do regime de sustentação. $O$ alinhamento de fase, possibilitará encontrar a fase correta para a melhor correlaçẫo com o tom musical

\section{- Passo 3}

Neste passo, encontraremos os "breakpoints" para o restante do tom musical. Utilizaremos um parâmetro $P$, o qual informará o número aproximado de períodos que devemos saltar entre os "breakpoints". Este parâmetro será incrementado em regiões onde o tom musical permanece estável e decrementado em regiões flutuantes. Inicialmente, saltaremos aproximadamente um período para obter o próximo "breakpoint", o qual é dado pela seguinte equação : 


$$
k_{1}=k_{0}+P K \quad P=1
$$

A generalização da equação acima para as próximas chamadas do passo 3, é dada por:

$$
k_{j}=k_{j-1}+P K
$$

\section{- Passo 4}

Neste passo, encontraremos o ponto inicial da função fase que será compartilhado com todas as funções básicas. Uma estimativa inicial para a fase é dada através da equação (6.7), assumindo constante as frequências entre os "breakpoints" $k_{j-1}$ e $k_{j}$, a qual é dada pela seguinte equação :

$$
\hat{\theta}\left(k_{j}\right)=\theta\left(k_{j-1}\right)+\hat{w} K P T_{a}
$$

Utilizaremos um parâmetro $I$, o qual informará o intervalo de ajuste de fase para determinação da fase correta (uma boa estimativa inicial é $I=\frac{\pi}{4}$ [STA 88]). Desta forma, tentaremos valores de fase $\theta\left(k_{j}\right)^{*}$ acima e abaixo de $\hat{\theta}\left(k_{j}\right)$, a fim de encontrarmos o maior valor absoluto, através da relação:

$$
y_{1}\left(k_{j}\right)=\sum_{k=k_{j}}^{k_{j}+K} F(k) \psi_{1}\left(\theta\left(k_{j}\right)^{*}+\hat{w} *\left(k-k_{j}\right) T_{a}\right)
$$

Se um máximo não for encontrado, tentaremos valores fora do corrente intervalo de ajuste da fase até encontrarmos o máximo absoluto. Uma vez encontrado o máximo, realizaremos uma interpolação quadrática para obtermos a melhor fase $\theta\left(k_{j}\right)$.

\section{- Passo 5}

Utilizando a fase $\theta\left(k_{j}\right)$, obtida no passo 4 , determinamos os coeficientes de amplitude para as outras funções básicas, os quais são dados por :

$$
y_{i}\left(k_{j}\right)=\sum_{k=k_{j}}^{k_{j}+K} F(k) \psi_{i}\left(\theta\left(k_{j}\right)^{*}+\hat{w} *\left(k-k_{j}\right) T_{a}\right) \quad i=2,3, \ldots, M
$$

Devemos salvar os valores de $\theta\left(k_{0}\right)$, e os valores $y_{i}\left(k_{0}\right)$, para calcularmos as rampas para a amplitude e a realização do processo de síntese.

\section{- Passo 6}

Neste passo, encontraremos as rampas para as funções amplitude e frequência. A rampa para amplitude é obtida reorganizando a equação (6.5) e é aproximada por: 


$$
\Delta y\left(k_{j}\right) T_{a}=\frac{y\left(k_{j}\right)-y\left(k_{j-1}\right)}{K P}
$$

Reorganizando a equação (6.6), para calularmos a rampa da frequência:

$$
\Delta w\left(k_{j}\right) T_{a}^{2}=\frac{-2\left(\theta\left(k_{j}\right)-\theta\left(k_{j-1}\right)-w\left(k_{j-1}\right) T_{a} K P\right)}{K P^{2}}
$$

O cálculo da frequência será dado pela equação abaixo:

$$
w\left(k_{j}\right) T_{a}=w\left(k_{j-1}\right) T_{a}+\Delta w\left(k_{j-1}\right) T_{a}^{2} K P
$$

assumiremos que $w\left(k_{0}\right)=\hat{w}$, como valor inicial para a frequência.

\section{- Passo 7}

Definiremos agora, uma estratégia para ajustar o comprimento dos passos $P$ e o intervalo para o ajuste da fase $I$. Se o valor estimado para a fase tiver sido bem próxima da correta, devemos incrementar o tamanho do passo $P$, desde que não exceda um limite superior. Caso contrário, decrementamos o tamanho do passo, desde que isto não fique abaixo de um limite inferior.

Um típico limite superior varia entre 3 a 4 períodos, um típico limite inferior é $\frac{1}{2}$ período.

Se o limite superior tiver sido alcançado e a fase correta tiver sido encontrada, nós decrementamos o intervalo de ajuste da fase $I$ para o próximo passo. Se o limite inferior tiver sido alcançado e a fase estimada estiver muito longe da correta, nós incrementamos o intervalo de ajuste da fase $I$ para o passo seguinte.

\section{- Passo 8}

Retornaremos ao passo 3 até o fim do tom ser encontrado. Retornamos então a posição $k_{0}$ e inicializamos a fase para $\psi\left(k_{0}\right)$ para a determinação da região de ataque. Iniciaremos o processo com passo $P=-1$ e retornamos ao passo 3, utilizando incremento negativo até o início do tom ser alcançado.

Obtidas as funções básicas e as funções amplitude e frequência de cada instrumento 
musical, podemos sintetiza-los como mostra a figura (6.4) abaixo:

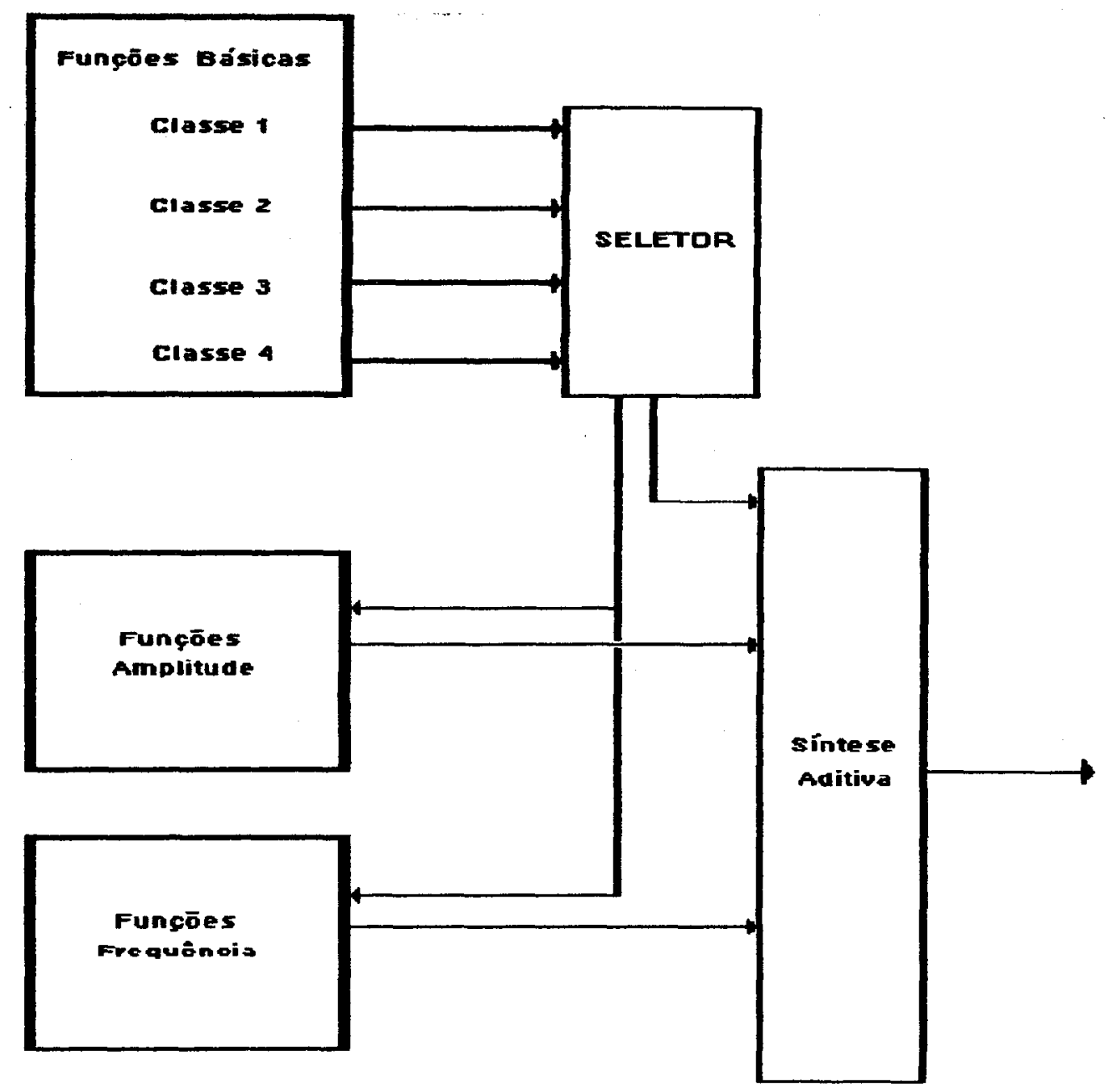

Figura 6.4 : Ilustra o processo de sintese aditiva baseado em transformada Karhunen-Loève para 4 classes de instrumentos musicais. Utilizamos um seletor para enviar apenas as funções básicas necessárias para cada instrumento e suas respectivas funções amplitude e frequência 


\section{Capítulo 7}

\section{Conclusões e Trabalhos Futuros}

Todos os sinais sonoros existentes na natureza são complexos, analógicos e contínuos no tempo. Através de uma cuidadosa mostragem, podemos obter uma sequência de valores discretos no tempo para a representação fiel destes sinais. Desta forma, os computadores podem ser utilizados para processar ou reproduzir este tipo de informação.

A análise matemática de sinais discretos no domínio da frequência, têm por objetivo extrair características físicas importantes, colocando em evidência certas propriedades do sinal que seriam difíceis de encontrar em sua forma original, isto é, no domínio do tempo.

A transformação de sinais entre os domínios do tempo e frequência, geralmente, não se configura como um problema de grandes proporções e várias ferramentas estão disponíveis, como é o caso da transformada de Fourier. Entretanto, os sinais sonoros compõem uma classe de sinais com algumas particularidades. Eles apresentam um quadro de componentes composto pelo volume, frequência e timbre que variam com o tempo de duração do sinal. A reconstrução destes sinais a partir de suas características espectrais estáticas - e tal é o caso da representação de sinais por transformada de Fourier, não propicia as informações vitais para sua reconstrução. Desta forma, as componentes que variam no tempo devem ser tratadas dinâmicamente, o que resulta em uma grande demanda de potência aritmética do processador e/ou na quantidade de memória requerida.

Neste trabalho, apresentamos algumas técnicas mais usualmente utilizadas em síntese de tons musicais, entre as quais destacamos a síntese aditiva, a síntese subtrativa, a síntese por distorção de fase, a síntese por frequência modulada e a síntese por amostragem ( $\mathrm{sam}$ pling). Para cada uma delas mostramos as características fundamentais para a geração de tons musicais.

Sons de alta qualidade tem sido gerados por técnicas de síntese aditiva. Uma das vantagens desta técnica é a flexibilidade fornecida no controle das funções básicas que são somadas para a reconstrução do tom. Entretanto, a carga computacional exigida na implementação desta técnica, quando baseada na representação truncada de Fourier, 
limita seu uso em aplicações de tempo real, devido a grande quantidade de funções básicas necessárias. Este quadro se complica ainda mais, quando se deseja que um mesmo sintetizador reproduza tons de vários instrumentos.

Dentro deste contexto, estudamos maneiras alternativas de representação de sinais utilizando transformadas ortogonais baseadas em funções não senoidais, dentre as quais destacamos a transformada Karhunen-Loève. Esta transformada possibilita a representação de sinais sonoros a partir de um número reduzido de funções básicas.

A redução das funções básicas é conseguida através de uma análise conjunta de amostras de todos os instrumentos desejados, envolvendo os seguintes passos :

\section{- Normalização}

Estabelece uma quantidade fixa de amostras por periodo.

\section{- Filtragem}

Limita em banda e torna as funções-amostras periódicas.

\section{- Alinhamento de fase}

Auxilia a concentração de energia nas primeiras funções básicas que serão extraídas.

- Classificação das funções-amostras

Possibilita que as funções-amostras fortemente correlacionadas, sejam agrupadas.

- Determinação das funções básicas

Dentro de cada classe, calcula-se os auto-vetores correspondentes às funções básicas.

- Determinação das funções amplitude e frequência

Assumindo que o envelope possa ser aproximado pela união de partes lineares, determinamos os "breakpoints" nos quais as informações de amplitude e fase serão modificadas, possibilitando a variação dinâmica das componentes do tom, durante sua existência.

A utilização desta técnica tem mostrado sua eficiência. Na análise realizada por Stapleton [STA 88], mostra-se a classificação e a síntese para vários instrumentos. A tabela (7.1) ilustra o resultado da classificaçâo para 12 instrumentos musicais. 


\begin{tabular}{|c|c|c|c|}
\hline Classe & Instrumento & Funções básicas & Total de funcôes \\
\hline 1 & $\begin{array}{c}\text { Diapasão } \\
\text { Flauta } \\
\text { Guitarra } \\
\text { Marimba } \\
\text { Violino } \\
\text { Contrabaixo }\end{array}$ & $\begin{array}{c}1,2 \\
1,2,3,4 \\
1,2,3 \\
1,2,3,5 \\
1,2,3,4 \\
1,2,3,5\end{array}$ & 5 \\
\hline 2 & $\begin{array}{c}\text { Trompete } \\
\text { Trompa Francesa } \\
\text { Trombone }\end{array}$ & $\begin{array}{c}1,2,3 \\
1,2 \\
1,2\end{array}$ & 3 \\
\hline 3 & $\begin{array}{c}\text { Clarinete } \\
\text { Sax Tenor } \\
\text { Sax Alto }\end{array}$ & $\begin{array}{c}1,2,3 \\
1,2 \\
1,2\end{array}$ & 3 \\
\hline
\end{tabular}

Tabela 7.1: Ilustra um exemplo de classificação de instrumentos musicais obtida através do algoritmo de classificação das funções-amostras [STA 88]

Como podemos observar, a tabela (7.1), apresenta os instrumentos divididos em classes, as funções básicas utilizadas por cada instrumento e a quantidade total de funções básicas por classe. Um exemplo da eficiência da técnica é observado quando da sintese do clarinete : uma representação razoável utilizando Fourier exigiria em torno de 19 funções básicas [MOO 77], enquanto que por Karhunen-Loève, seriam necessárias apenas 3, como visto acima.

Este método de representaçào de sinais pode ser utilizado com sucesso em outras aplicações onde as informações componentes dos sinais variam rapidamente. Prevê-se, por exemplo, sua utilização na simulação de sons ambientais, um dos requisitos normalmente encontrados em aplicações de multimídia, realidade virtual, simuladores de vôo, etc. 


\section{Bibliografia}

[AHM 75] N. Ahmed, K.R. Rao, Ortogonal Transforms for Digital Signal Processing, Springer-Verlang, New York, 1.975.

[AHMa 75] N. Ahmed, P.J. Milne, S.G. Harris, Eletrocardiographic Data Compression Via Orthogonal Transforms, IEEE Transactions on Biomedical Engineering, vol.bme22 ,Nro 6, November 1.975, p 484-487.

[AND 70] H. C. Andrews, J. Kane, Kronecker Matrices, Computer Implementation, and Generalized Spectra, Journal of the Association for Computing Machinery, Vol 17, Nro 2, April 1.970, p 260-268.

[BEA 69] J.W. Beauchamp, Music by Computers: A Computer System for Time-Variant Harmonic Analysis and Synthesis of Musical Tones, John Wiley \& Sons, Inc., 1.969, p 19-61.

[BLA 87] R.E. Blahut, Fast Algorithms for Digital Signal Processing, Addison-Wesley Publishing Company, Reading, MA, 1.987.

[BOA 66] M.L. Boas, Mathematical Methods in The Physical Sciences, John Wiley \& Sons, Inc., New York, 1.966.

[BOY 79] W.E. Boyce, R.C. Diprima, Equações Diferenciais Elementares e Problema de Valores de Contorno, Editora Guanabara Dois S.A., Rio de Janeiro, 1.979.

[BRI 67] E.O. Brigham, R.E. Morrow, The Fast Fourier Transform, IEEE Spectrum, December 1.967, p 63-70.

[CAM 71] S.J. Campanella, G.S. Robinson, A Comparison of Orthogonal Transformations for Digital Speech Processing, IEEE Transactions on Communication Technology, Vol.Com-19, Nro 6, December 1.971, p 1045-1049.

[CHE 91] C.S. Chen, K.S. Huo, Karhunen-Loève Method for Data Compression and Speech Synthesis, IEE Proceedings-I, Vol. 138, Nro. 5, October 1.991, p 377-380.

[CHO 73] J.M Chowning, The synthesis of Complex Audio Spectra by means of Frequency Modulation, J. Audio Eng.Soc, Vol. 21, Nro. 7, September 1.973, p 526-534. 
[CHR 79] R.A. Christen, A.D. Hirschman, Automatic Phase Alignment for the Karhunen - Loève Expansion,IEEE Transactions on Biomedical Engineering, vol.bme-26,Nro 2, February 1.979, p 94-99.

[COO 65] J.W. Cooley, J.W. Tukey, An Algorithm for the Machine Calculation of Complex Fourier Series, Mathematics of Computation, Vol 19, Nro 90, Publication National Academy of Sciences - National Reserch Center by The Americam Mathema tical Society, April 1.965, p 297-301.

[CRO 86] D. Crombie, The New Complete Synthesizer, Omnibus Press, London, 1.986.

[DAN 91] R.B. Dannenberg, C.L. Fraley, P. Velikonja, Fugue: A functional Language for Sound Synthesis, IEEE Computer, July 1.991, p 36-41.

[DAU 88] I. Daubechies, Orthonormal Basis of Compactly Supported Wavelets, Comm. Pure Applied Math., 1.988, Vol. 41, p 909-996.

[DAU 90] 1. Daubechies, The Wavelets Transform, Time-Frequency Localization and Signal analysis, IEEE Transactions on Information Theory, September 1.990, Vol. 36, Nro. 5, p 961-1005.

[DEM 88] A. Dembo, D. Malah, Statistical Design of Analysis/Synthesis Systems with Quantization, IEEE Transactions on Acoustics,Speech and Signal Processing, Vol. 36, Nro 3, March 1.988, p 328-341.

[DeF 88] D.J. DeFatta, J.G. Lucas, W.S. Hodgkiss, Digital Signal Processing: A System Design Approach, John Wiley \& Sons, New York, 1.988

[DOL 89] M. Dolson, Fourier-Transform-Based Timbral Manipulations, Current Directions in Computer Music Research, The MIT Press, Massachusetts, 1.989.,p 105-112

[FER 86] A.B.H. Ferreira, Novo Dicionário da Língua Portuguesa, Editora Nova Fronteira S.A., Rio de Janeiro, 1.986.

[FIG 87] D.G. Figueiredo, Análise de Fourier e Equaçôes Diferenciais Parciais, Projeto Euclides-IMPA, Rio de Janeiro, 1.987.

[GOE 81] T.W. Goeddel, S.C. Bass, The Efficient Digital Implementation of Subtractive Music Synthesis, IEEE Micro, Vol. 1, 1.981, p 24-36

[GOL 69] B. Gold, L. Rabiner, Parallel Processing Techniques for Estimating Pitch Periods of Speech in the time Domain, Journal Acoust. Soc. Amer., Vol. 46, Nro. 2, Aug. $1.969, \mathrm{p} 442-448$.

[GOR 85] J.W. Gordon, System Architectures for Computer Music, Computing Surveys, Vol 17, Nro 2, June 1.985, p 191-233.

[GRE 77] J.M. GREY, J.A. Moorer, Perceptual evaluations of Synthesized Musical Instrument Tones, J. Acoust. Soc. Am., Vol. 62, Nro 2, August 1.977, p 454-462. 
[GRO 87] A. Grossmann, M. Holschneider, R. Kronland- Martinet, J. Morlet, Inverse Problems- An interdisciplinar Study : Detection of Abrupt Changes in Sounds Signals with the help of Wavelet Transform, Advances in Eletronics and Electron Physics, Supp. 19, New York: Academic, 1.987

[HAR 78] F.J. Harris, On the use Windows for Harmonic Analysis with the Discrete Fourier Transform, Proceedings of the IEEE, Vol. 66, Nro 1, January 1.978, p 51-83.

[HEL 73] H.D. Helms, Literature in Digital Signal Processing: terminology and permuted title index, IEEE Press, 1.973.

[HOF 42] R. Hoffmann, Análise de regressão : Uma introdução a econometria, EDUSP - SP.

[HOW 75] H.S. Howe, Eletronics Music Synthesis, W.W. Norton \& Co.,Inc., 1.975.

[HUT 75] B.A. Hutchins, Applications of a real-time Hadamard Transform Network to sound synthesis, Journal of Audio Engineering Society,Vol 23, Nro 7, September 1975, p 558-562.

[ISA 66] E. Isaacson, H.B. Keller, Analysis of Numerical Methods, Jonh Wiley \& Sons, New York, 1.966 .

[JOS 69] J.J. Josephs, La Fisica del Sonido Musical, Van Nostrand Company,Inc., Mexico 1.969 .

[KAH 70] D.K. Kahaner, Matrix Description of the Fast Fourier Transform, IEEE transactions on Audio and EletroAcoustics, Vol AU-18, Nro 4, December 1.970, p 442-450.

[KAR 90] O. Károlyi, Introduçâo à Música, Editora Martins Fontes, São Paulo, 1.990.

[KOE 65] L. Koenigsberger, Helmann von Helmholtz, Dover Publications,Inc., New York, 1.965 .

[KRE 69] E. Kreyszig, Matemática Superior, Editora Litec Ltda, Rio de Janeiro, 1.969.

[KRO 87] R. Kroland-Martinet, J. Morlet, A. Grossmann, Analysis of Sound Patterns Through Wavelet Transform, Int. J. pattern Recognition and Artificial Intelligence, 1.987, Vol. 1, p 273-302.

[KRO 88] R. Kroland-Martinet, The Use of Wavelet Transform for Analysis, Synthesis and Processing of Speech and Music Sounds, Computer Music Journal, MIT Press, December 88, Vol. 12(4).

[LAZ 80] C. Lazarini, N.M.B. Franco, Tópicos de Cálculo Numérico, Volume II, ICMSC, 1.980 .

[MAH 90] R.C. Maher, Evaluation of a Method for Separating Digitized Duet Signals, J. Audio Eng. Soc., Vol. 38, Nro. 12, December 1.990, p 956-979. 
[MAL 89] S.G. Mallat, A Theory for Multiresolution Signal Decomposition: The Wavelet Representation, IEEE Transactions on Pattern Analysis and Machine Intelligence, July 1.989, Vol. 11, Nro. 7, p 674-693.

[MAS 87] H. Massey, A. Noyes, D. Shklair, A Synthesist's Guide to Acoustic Instuments, Amsco Publications, New York, 1.987.

[MAT 69] M. Mathews, The Technology of Computer Music, MIT Press, Boston, 1.969.

[MOO 76] J.A. Moorer, The Synthesis of Complex Audio Spectra by Means of Discrete Summation Formulas, J.Audio Eng. Soc., Vol 24, Nro 9, Nov 1.976, p 717-727.

[MOO 77] J.A. Moorer, Signal Processing Aspects of Computer Music : A Survey, Proceedings of IEEE, Vol 65,Nro 8, August 1.977, p 1108-1137.

[MOO 86] R.A. Moog, Digital Music Synthesis, Byte, June 1.986, p 155-168.

[MOO 90] F.R. Moore, Elements of Computer Music, Prentice-Hall, Englewood Cliffs, New Jersey, 1.990.

[MOR 89] E.S. Moreira, The Design of an Arithmetic Unit for Digital Signal Processing Systems, PhD Thesis, University of Manchester, November 1.989.

[MUN 78] M.A. Munem, D.J. Foulis, Cálculo, Volume 2, Editora Guanabara Dois, Rio de Janeiro, 1.978

[NAG 65] B.S. Nagy, Introduction to Real Functions and Ortogonal Expansions, Oxford University Press, New York, 1.965

[NOL 67] A.M. Noll, Cepstrum Pitch Determination, The Journal of the Acoustical Soc. of America, Vol. 41, Nro. 2, 1.967, p 293-309.

[OPP 75] A.V. Oppenheim, R.W. Schafer, Digital Signal Processing, Prentice-Hall international, Inc., London, 1.975.

[OTN 72] R.K. Otnes, L. Enochson, Digital Time Series Analysis, John Wiley \& Sons, New York, 1.972.

[PAL 32] R.E.A.C. Paley, A Remarkable Series of Ortogonal Functions, Proc. London Math. Soc. (2) 34, 1.932, p 241-279.

[PAP 66] A. Papoulis, Error Analysis in Sampling Theory, Proceedings of the IEEE, Vol. 54 , Nro. 7, July 1.966, p 947-955.

[PAR 67] E. Parzen, Time Series Analysis Papers, Holden-Day, Inc., San Francisco, 1.967.

[POR 80] M.R. Portnoff, Time-Frequency Representation of Digital Signals and Systems Based on Short-Time Fourier Analysis, IEEE Transactions on Acoustics,Speech and Signal Processing, Vol. 28, Nro. 1, February 1.980, p 55-78. 
[PRO 88] J.G. Proakis, D.G. Manolakis, Introduction to Digital Signal Processing, Macmillan Publishing Company, New York, 1.988.

[RIG 85] J. Rigden, Physics and then Sound of Music, Jonh Wiley \& Sons,Inc.,New York, 1.985 .

[RIS 69] J.C. Risset, M. Matheus, Analysis of Musical-Instrument Tones, Physics Today, Vol 22, Nro 2, February 1.969, p 23-30.

[SCH 73] R.W. Schafer, L.R. Rabiner, A Digital Signal Processing Approach to linear interpolation, Proceedings of the IEEE, Vol. 61, Nro 6, June 1.973, p 692-702.

[SER 90] M.H. Serra, D. Rubine, R. Dannenberg, Analysis and Synthesis of Tones by Spectral Interpolation, J. Audio Eng. Soc., Vol. 38, Nro. 3, March 1.990, p 111-128.

[SON 68] M.M. Sondhi, New Methods of Pitch Extraction, IEEE Transactions on Audio and Electroacoustics, Vol. AU-16, Nro. 2, June 1.968, p 262-266.

[STA 88] J.C. Stapleton, S.C. Bass, Synthesis of Musical Tones Based on the KarhunenLoéve Transform, IEEE Transactions on Acoustics, Speech and Signal Processing, Vol. 36, Nro. 3, March 1.988, p 305-319.

[STR 66] G. Strang, Music by Computer : The Problem of Imperfection in Computer Music, John Wiley \& Sons, Inc., New York, 1.966, p 133-139.

[THE 69] P. Theilheimer, A Matrix Version of the Fast Fourier Transform, IEEE transactions on Audio and EletroAcoustics, Vol AU-17, Nro 2, June 1.969, p 158-161.

[TOF 80] A. Toffler, A Terceira Onda, Editora Record, 1.980.

[VER 71] B. Vercoe, The Music 360 Language for Digital Sound Synthesis, Proc. American Society of University Composers, Vol 6, 1.971

[VER 86] B. Vercoe, Csound: A Manual for the Audio Processing System and Supporting Programs, MIT Media Lab, MIT, Cambridge, Mass., 1.986.

[WAL 23] J.L. Walsh, A Closed Set of Normal Orthogonal Functions, American J. Math. $45,1.923, \mathrm{p} 5-24$

[WAW 89] J. Wawrzynek, VLSI Models for Sound Synthesis, Current Directions in Computer Music Research, The MIT Press, Massachusetts, 1.989, p 113-148

[WIN 78] S. Winograd, On Computing the Discrete Fourier Transform, Math. Comp. 32, 1.978 .

[WOM 77] M.E. Womble, J.S. Halliday, S.K. Mitter, M.C. Lancaster, J.H. Triebwasser, Data Compression for Storing and Transmitting, Proceedings of the IEEE, Vol 65, Nro 5, May 1.977, p 702-706. 